

\section{VISNYK \\ No. 250 2020}

\section{OF THE NATIONAL BANK OF UKRAINE}

https://journal.bank.gov.ua

\section{Editorial Board}

\section{Dmytro Sologub}

(Editor-in-Chief)

Deputy Governor, National Bank of Ukraine,

Kyiv, Ukraine

\section{Tom Coupe}

PhD, Associate Professor, University of Canterbury, Christchurch, New Zealand

\section{Yuriy Goroghdnichenko}

PhD, Professor, University of California,

Berkeley, USA

\section{Mihnea Constantinescu}

$\mathrm{PhD}$, Head of Research, Monetary Policy and Economic Analysis Department, National Bank of Ukraine, Kyiv, Ukraine

\section{Oleg Korenok}

PhD, Associate Professor, Virginia

Commonwealth University, Richmond, USA

\section{Viktor Koziuk}

ScD, Professor, Ternopil National Economic University, Doctor of Economics, Member of the National Bank of Ukraine Council, Ternopil, Ukraine

\section{Oleksiy Kryvtsov}

$\mathrm{PhD}$, Senior Research Director, International Economic Analysis Department, Bank of Canada, Ottawa, Canada

\section{Volodymyr Lepushynskyi}

PhD, Director of Monetary Policy and Economic Analysis Department, National Bank of Ukraine, Kyiv, Ukraine
Tymofiy Mylovanov

PhD, President of the Kyiv School of Economics, Kyiv, Ukraine

\section{Sergiy Nikolaychuk}

PhD, Director of Research Department of Investment Capital Ukraine (ICU), Kyiv, Ukraine

\section{Oleksandr Petryk}

$\mathrm{ScD}$, Member of the National Bank of Ukraine Council, Kyiv, Ukraine

\section{Marko Skreb}

Central Banking Lead, Financial Sector Reform Activity (FINRA) project, Sarajevo, Bosnia and Herzegovina

\section{Inna Spivak}

$\mathrm{ScD}$, Head of International Economy Analysis Unit, Monetary Policy and Economic Analysis Department, National Bank of Ukraine, Kyiv, Ukraine

\section{Oleksandr Talavera}

PhD, Professor, University of Birmingham, Birmingham, United Kingdom

Andriy Tsapin

$\mathrm{PhD}$, Deputy Head of Research Unit, Monetary Policy and Economic Analysis Department, National Bank of Ukraine, Kyiv, Ukraine

Vitaliy Vavryshchuk

Director of Financial Stability Department, National Bank of Ukraine, Kyiv, Ukraine

Vadym Volosovych

$\mathrm{PhD}$, Associate Professor, Erasmus University Rotterdam, Rotterdam, Netherlands

Founder and publisher: National Bank of Ukraine

Editorial Board ensures compliance with ethical standards of publishing

For reprinting materials published herein the reference to the journal

"Visnyk of the National Bank of Ukraine" is compulsory

The Editorial Board can publish materials being under discussion, not sharing the author's opinion

(C) National Bank of Ukraine 1995-2020

(C) Authors. Under CC BY-NC 4.0 License

Address: 9, Instytutska Street, Kyiv, 01601, Ukraine

E-mail: journal@bank.gov.ua
Design and layout: Zlatograf LTD.

Address: 12, Prorizna Street, office 10,

Kyiv, 01001, Ukraine.

Phone: +380 (44) 360-94-60. 


\section{PREFACE BY THE EDITOR-IN-CHIEF}

\section{Dear readers,}

The current issue of the Visnyk of the National Bank of Ukraine investigates questions relevant for macroprudential regulation, financial stability, and monetary policy. Useful insights from presented studies can help readers understand the influence of interest rates on exchange rates, deepen your knowledge of the role of the global financial cycle in capital flows, and predict possible bank defaults.

The first article How Does the Interest Rate Influence the Exchange Rate? by Adam Hashchyshyn, Kateryna Marushchak, Oleksandr Sukhomlyn, and Andrii Tarasenko, employs meta-analysis techniques to infer the interest-rate exchange-rate relationship. This relationship is found to be positive and significant in the short run, but dissipates in the long run. According to the authors' results, a shortterm appreciation/depreciation of the hryvnia may be observed in response to an increase/decrease in the key policy rate in Ukraine.

In the second article, The Missing "Cycle" Part and Other Thoughts on the Global Financial Cycle, Olga Bondarenko examines co-movements in cross-border capital flows that give rise to a phenomenon dubbed the global financial cycle. The author estimates a global common factor in capital flows, explores its cyclical properties, and states its limited importance for capital flows. This result implies that domestic policies play the primary role in maintaining macroeconomic stability.

In the third article, Predicting Bank Defaults in Ukraine: A Macro-Micro Perspective, Anatolii Hlazunov and Olesia Verchenko propose a modeling approach that successfully generates an outof-sample signal of a systemic crisis four periods ahead of the 2014-2015 turmoil. The authors argue that the probability of default exceeding $11 \%$ could signal a vulnerability in a bank and in a financial system in general.

The Visnyk of the National Bank of Ukraine invites scholars and policymakers to join the discussion initiated by our authors. We expect your submissions and would like to draw your attention to the upcoming online conferences co-organized by the National Bank of Ukraine: (1) the 5th conference for students and young researchers Banking and Monetary Policy: Prospects for Development (21 May 2021, with Kyiv School of Economics), and (2) the 6th annual research conference The Policy Toolkit for a World in Flux (10-11 June 2021, with Narodowy Bank Polski). We encourage you to submit your papers and participate in the conferences, as these events provide opportunities for fruitful discussion and potential cooperation.

Best regards, Dmytro Sologub 


\title{
HOW DOES THE INTEREST RATE INFLUENCE THE EXCHANGE RATE?
}

\section{ADAM HASHCHYSHYN ${ }^{\mathrm{a}}$, KATERYNA MARUSHCHAK ${ }^{\mathrm{a}}$, OLEKSANDR SUKHOMLYN ${ }^{b}$, ANDRII TARASENKO ${ }^{c}$}

\author{
${ }^{a}$ Kyiv School of Economics \\ E-mail: ahashchyshyn@kse.org.ua \\ kmarushchak@kse.org.ua \\ ${ }^{b}$ National Bank of Ukraine \\ E-mail: osukhomlyn@kse.org.ua \\ 'University of Mannheim \\ E-mail: atarasenko@kse.org.ua
}

Abstract Understanding the effect of increasing the key policy rate on the exchange rate of the national currency remains one of the most critical issues for central banks. The goal of this study is to infer about the signs and the magnitude of this impact using existing studies conducted for 30 countries and aggregating estimates applying the meta-analysis procedure. Results indicate that the short-term impact of interest rate changes on the exchange rate is positive and statistically significant, although the economic significance is weak, while the longterm relationship is found to be insignificant. The analyzed studies do not reveal any evidence of publication bias, which contributes to the validity of empirical findings. The received results conclude that there might be a short-term appreciation of the hryvnia in response to an increase in the key policy rate in Ukraine.

\section{JEL Codes E43, E52, E58, Y90}

Keywords exchange rate, interest rate, key policy rate, meta-analysis, monetary policy, transmission mechanism.

\section{INTRODUCTION}

In an era of floating exchange rate regimes and independent central banks concentrating on price stability, exchange rates have lost their priority in economic policy decisions. Meanwhile, the debate on the importance of considering exchange rate movements in an open economy continues to evolve. On the one hand, the impact of monetary policy on the value of the national currency is inexorable as exchange rates remain both a substantial component in the transmission mechanism and the factor that reflects crosscountry differences in interest rates through the uncovered interest rate parity (Taylor, 2001). On the other hand, authors such as Obstfeld and Rogoff (1995) warn that substantial deviations from PPP in the short- and the long-run, caused by policies targeted at exchange rate stabilization, are undesirable for the economy. Therefore, understanding the extent of the impact of monetary policy tools, especially the key policy rate, on subsequent exchange rate fluctuations has crucial importance for central banks striving to make prudent and justifiable decisions.

Although the incidence of currency appreciation resulting from the increase in domestic interest rates has a strong theoretical background, making decisions based solely on theoretical grounds is not viable. The main reason for that is a large number of country-specific factors, which might have an impact on the interest rate-exchange rate relationship, making this relationship both economically and statistically insignificant.

The ability to conduct an empirical research of the relationship in Ukraine is restricted due to an insufficient amount of data: before 2014, the NBU had been keeping the exchange rate stable using foreign exchange interventions under a fixed exchange rate regime. Therefore, an inference about of such relationship could be made by analyzing the experience of other countries and conducting a metaanalysis of existing studies, and answering the question, "What are the short- and long-term impacts of increasing interest rates on the domestic exchange rate?"

In this study, an inference about empirical papers examining the interest rate-exchange rate relationship are investigated, and their findings are aggregated using metaanalysis techniques. The research also checks the validity of the effects described in publications and examines whether they are truthful or if there is a publication bias, leaving numerous findings not published due to the mismatch of these findings with theory and due to the statistical insignificance of results. Section 2 describes existing theoretical and empirical evidence on the relationship between interest rates and exchange rates. Sections 3 and 4 describe the particular features of the data and methodology used. Section 5 describes the findings based on the examined literature. 
The study reveals the presence of the genuinely positive and statistically significant short-term effect of increases in interest rates on the exchange rate. The findings could be helpful for the National Bank of Ukraine and provide evidence of what to expect from an increase in the key policy rate in terms of the dynamics of the hryvnia exchange rate.

\section{LITERATURE REVIEW}

Standard theoretical models in international macroeconomics (e.g., Mundell-Fleming model, Dornbusch model) assume the link between interest rates and exchange rate movements through interest rate parity. For the sake of simplicity, it relaxes the presence of possible arbitrage opportunities arguing that ex-ante there are no excess returns from holding deposits or financial assets in one country relative to another (Engel, 2015). For example, whenever interest rates rise in one country, additional gains from investing in its financial assets will soon cease through the appreciation of its currency. Dornbusch (1976) provides a more detailed explanation of this channel as an exchange rate component in the process of adjustment to economic expansion. In the short run, the currency depreciates in response to lower demand and changes in terms of trade. In its turn, it is accompanied by strengthening inflation (even though rising prices might also be accompanied by currency appreciation).

Although the mentioned links seem direct in theory, several decades of empirical studies have revealed that this link frequently does not work (Blinder, 2006). Obtained estimates vary in their signs and the magnitude of their coefficients. Often estimates are statistically insignificant. For example, Gould \& Kamin (2000) analyzed this link in Korea, Mexico, Philippines, Indonesia, Malaysia, and Thailand during the Asian financial crisis. They stated that Granger causality tests do not show a statistically significant causal relationship in any of the cases. The authors concluded that although monetary policy could have important impacts on exchange rate movements, a substantial amount of time is required for these effects to be observed in the real data. Eichenbaum and Evans (1995) argue that even though contractionary monetary policy shocks lead to currency appreciation, the persistent changes in the real exchange rate throw into question the short-term nature of adjustment, as predicted by interest rate parity.

Even though it might seem that developed financial markets help make exchange rate adjustment faster, the results are generally mixed even for developed economies. For example, studying the link between interest rates and exchange rates in the U.S., Germany, Japan, and the U.K., Meese and Rogoff (1985) found little evidence of the stable systematic link between these two variables. Similarly, Coe and Golub (1986) have studied the relationship between interest rates and exchange rates for 18 OECD economies and revealed that only in four of them (Austria, Germany, Belgium and France) did an increase in long-term interest rates differential have a statistically significant effect on the appreciation of the domestic currency.

Often the results of many studies on the topic are intensely debated concerning the estimation methods used. Edison and Pauls (1993), as well as Baxter (1994), failed to find a statistically significant causal effect of interest rates on exchange rates using the Engle-Granger cointegration methods. However, MacDonald and Nagayasu (1999), argued that the long-run relationship starts being observed as long as another estimation technique is used. Using the sample of 14 industrialized countries and methods of Johansen, they showed that interest rates have a statistically significant long-run effect on the exchange rate. Similar findings were reported by Edison \& Melick (1999) and MacDonald (1999).

Ultimately, reading a multitude of studies does not endow policymakers with a clear picture of the exchange rate consequences of the interest rate changes. First of all, with the majority of results estimated for developed countries, it is not clear what outcomes to expect in developing economies. Secondly, without considering possible problems with estimation, the dependence of results on the methodology used exacerbates the incomparability of results. Therefore, the proper aggregation of estimates with meta-analysis procedure might help in getting at least the approximate direction of effect (if any) for Ukraine.

\section{DATA DESCRIPTION AND METHODOLOGY}

During the process of investigation, more than 50 studies have been collected and analyzed on the topic of the impact of such a monetary policy instrument as the key policy rate on a country's exchange rate. However, more than $80 \%$ of the papers turn out to be inapplicable for the meta-analysis procedure due to several reasons, including the lack of descriptive statistics, the dependent and independent variables mismatch, etc. Moreover, for the validity and data comparability of the results, only studies with a uniform variables type were chosen. Hence, the final sample of studies includes eight papers that describe the investigated relation in the following form:

$$
d\left(e_{i t}\right)=\beta_{0}+\beta_{1} \cdot d\left(r_{i t}\right)+\beta_{2} \cdot X_{i t}+\varepsilon,
$$

whereas

$e$ - exchange rate,

$r$ - interest rate,

$d(. .$.$) - difference operator,$

$X-$ a vector of control variables,

$i$ and $t$ - country and time indicators, respectively, and $\varepsilon-$ error term.

Even though the dependent and independent variables in the models forming the final sample for the meta-analysis are the same, the estimation methods vary substantially across the papers. More than $30 \%$ of models are estimated using Dynamic Ordinary Least Squares (DOLS), while the half of studies are evenly divided between those applying Fixed Effects (FE) and those using the Vector Error Correction Model (VEC). The rest of the authors aiming at determining the effect of the interest rate on the exchange rate apply the Vector Autoregressive Model (VAR) and Generalized Autoregressive Conditional Heteroscedasticity Model (GARCH).

The coefficients and estimates collected from the studies form a sample of 41 observations of the impact of interest rates on the exchange rate, both in the short run and in the long run. The former is represented as an instantaneous change of the exchange rate in response to interest rate movements, while the latter is determined as the lagged effect of interest rate alterations. Moreover, in the long run, coefficients are found to be insignificant, and are present both positive and negative in equal proportion, while the short term estimates are rather significant and positive. From 31 observations of the short-run effect, 16 coefficients are 
positive and statistically significant at the $5 \%$ level confidence interval, 9 are positive insignificant, 3 are negative significant and 3 are negative insignificant; the long-run effects consist of 4 positive and 6 negative insignificant coefficients.

The data collected represents the effect size of interest rates on the exchange rate for 30 countries. According to the UN's country classification, 14 of them are developed, 15 are developing, and one is a transition economy. Furthermore, the papers cover different periods from 1999 to 2014, and several studies include estimates for the same countries. Despite the initial methodological heterogeneity of studies, the meta-analysis procedure is geared towards normalizing results and defining the unbiased estimator for the effect of the interest rate on the exchange rate.

The first step is the estimation of the association between the interest rate and exchange rate net of the impact of the set of controlling variables that is the partial correlation coefficient (PCC):

$$
P C C_{i j}=\frac{t_{i j}}{\sqrt{t_{i j}^{2}+d f_{i j}}},
$$

whereas $t-t$-statistics from $i$-th regression of $j$-th study, $d f-$ number of degrees of freedom.

The second step is the normalization of the PCC obtained using the Fisher z-transformation of the PCCs (Havranek, et al., 2005):

$$
Z_{P C C_{i j}}=0.5 \cdot \ln \left(\frac{1+P C C_{i j}}{1-P C C_{i j}}\right)
$$

whereas PCCij - partial correlation coefficient from $i$-th regression of $j$-th study.
However, the estimates obtained could be biased through the heterogeneity of studies analyzed, which vary by time period of the effect of the interest rate on the exchange rate; and by country, for which the effect is estimated. Hence, we segregated the data into the following groups: by the period of the effect, and by country. The latter includes subgroups of the income level and the level of monetary freedom.

When talking about income levels, we used the World Bank's classifications to divide countries into two groups. The first one includes countries that the World Bank designates as low and lower middle developed economies. The second group includes economies designated as upper middle and high income. Countries were assigned categories based on their status during the period of study. Should a country change categories during the period of research, status was assigned regarding the income level that dominated in this particular country for the majority of years investigated. For example, Romania analyzed by Sarmidi, Salleh (2011) was marked as a low and lower-middle income economy during the research period of 15 years (1995-2009), nine of which it was classified by the World Bank as a lower-middle economy.

To account for heterogeneity in monetary policies, we made use of a third criterion, which is the level of monetary freedom as modeled by the Index of Monetary Freedom developed by the Heritage Foundation that combines a measure of price stability with an assessment of price controls. Heritage Foundation calculates the Index of Monetary Freedom by subtracting from the base of 100 points the square root of weighted average inflation for the last three years and the penalty (a maximum 20 points) for price control conducted by the government. We have chosen 70 points as a threshold: countries that get less than 70 points are suggested to have a low level of monetary freedom, and countries ranked with more than 70 points are treated as states with high monetary freedom. The 70 points level was determined as a threshold since obtaining at least 70 points allows for combining moderate price control for a penalty of

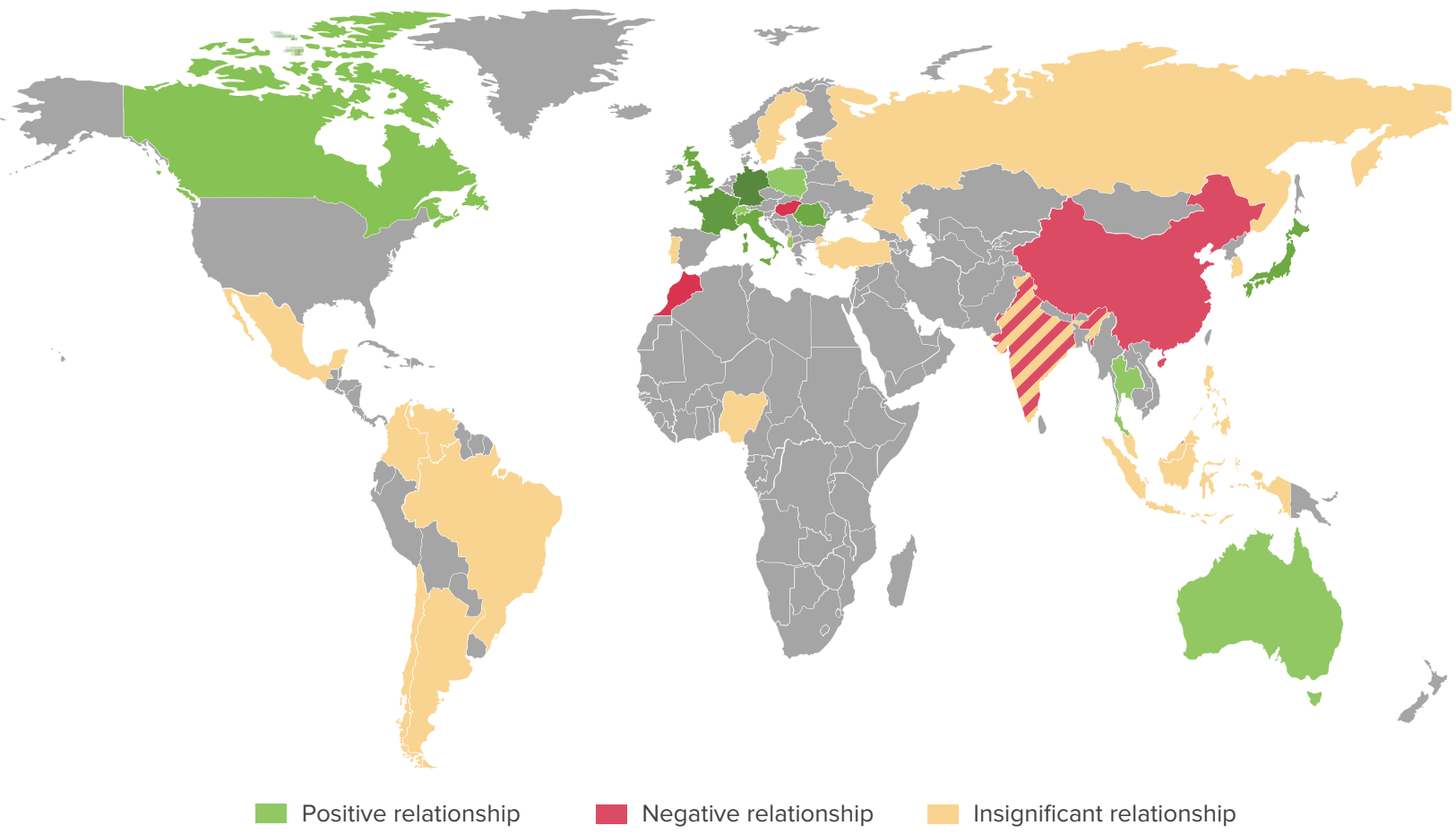

Figure 1. The Association Between the Interest Rate and the Exchange Rate by Country 
10 points and weighted average inflation of approximately $9 \%$. The methodology uses a convex functional form (the square root of the weighted average inflation rate for the most recent three years) to better separate countries with low inflation rates and provide much more gradation and accuracy for estimations.

\section{AGGREGATION OF PCC}

The calculated estimates of PCC vary in the range from -0.388 for Hungary, which is a weak negative correlation, to 0.955 for Germany, which represents a strong positive relationship. The resulting coefficients reflect the following tendency: the more developed country is, the higher positive relationship exists between the examined rates. On the other hand, for most developing economies, the effect of the interest rate on the exchange rate is found to be weak and even negative. In addition, the association between the interest rate and the exchange rate substantially varies for the length of the examined period. The association estimated for the lagged effect is weak in contrast to the instantaneous effect, for which positive moderate or strong correlation is found. The country composition of results is presented in Figure 1: the positive significant effect is marked with green, negative significant - with red and insignificant effect - with yellow.

Taking into account the wide range of PCC obtained, we used several estimation techniques. Since applying only a simple mean to reveal the true effect would be misleading due to the various limitations of this method, we conducted our analysis using three types of estimators: a simple average, a fixed-effect estimator, and a random-effect estimator. Moreover, to overcome a substantial heterogeneity among countries analyzed, we divided coefficients into the following groups: by period of the effect, by country income level, and by level of monetary freedom.

assumption of studied effects' homogeneity, it does not account for between-study heterogeneity. Therefore, we consider this estimator less precise than the random effects estimator. Allowing variation in effects to be normally distributed between studies, this method helps to account

Table 1. Mean Levels of PCC by Category and Overall for heterogeneity between them. The random-effects estimate for the size of the effect of the current interest rate on the exchange rate is $18.5 \%$, which is quite close to the simple average of partial correlation coefficients, while the effect of a lagged interest rate on the exchange rate remains economically insignificant and equal to $0.3 \%$.

The obtained values are also aggregated by the income status of the country and by the level of monetary freedom measured by the Heritage Foundation Index of Monetary Freedom. Estimates reveal that for countries with a higher degree of monetary freedom $>70$ during the analyzed period), the response of the interest rate change on the exchange rate is higher compared to countries with a lower level of monetary freedom. We also find that for highincome countries, the level of response of the exchange rate on the interest rate change is higher than for the lowincome countries. These results are robust to the choice of aggregation method.

To evaluate the heterogeneity of effects in studies, we made use of I-squared. The estimated value of $95.6 \%$ reveals that studies of the relationship of interest rate changes on the exchange rate exhibit a substantial heterogeneity, which influences the variation of partial correlation coefficients much more than a simple random error. It is not possible to confidently outline the reasons for such high heterogeneity as I-squared remains at a substantial magnitude even within the studies that we have analyzed.

\section{PUBLICATION BIAS}

Another objective of this research was to investigate the existence of publication bias, resulting from the tendency of academic journals to mostly publish papers with final results either coinciding with theoretical literature or containing statistically significant estimates. The theory suggests the positive interconnection between the interest rate and exchange rate. So taking into account that $40 \%$ of studies in the collected sample report a positive and significant relationship, there might be publication selection concerns related to this literature.

\begin{tabular}{l|c|c|c}
\hline Factors & $\begin{array}{c}\text { Simple } \\
\text { average }\end{array}$ & Fixed effects average PCC & Random effects average PCC \\
\hline Total & 0.141 & $0.182(0.163 ; 0.202)$ & $0.142(0.045 ; 0.239)$ \\
\hline \multicolumn{3}{|c|}{ Estimated PCCs for current and lagged interest rate } \\
\hline Current & 0.187 & $0.202(0.182 ; 0.222)$ & $0.185(0.069 ; 0.300)$ \\
Lagged & -0.001 & $0.003(-0.059 ; 0.065)$ & $0.003(-0.059 ; 0.065)$ \\
\hline
\end{tabular}

Estimated PCCs for countries varying at the level of monetary freedom

\begin{tabular}{l|c|c|c}
\hline High & 0.159 & $0.217(0.196 ; 0.238)$ & $0.198(0.078 ; 0.318)$ \\
Low & 0.112 & $-0.041(-0.093 ; 0.012)$ & $-0.048(-0.161 ; 0.066)$ \\
\hline
\end{tabular}

Estimated PCCs for countries varying at the income level

\begin{tabular}{l|c|c|c}
\hline $\begin{array}{l}\text { High and upper-middle- } \\
\text { income countries }\end{array}$ & 0.199 & $0.217(0.196 ; 0.238)$ & $0.198(0.078 ; 0.318)$ \\
$\begin{array}{l}\text { Low and lower-middle } \\
\text { income countries }\end{array}$ & -0.044 & $-0.041(-0.093 ; 0.012)$ & $-0.048(-0.161 ; 0.066)$ \\
\hline
\end{tabular}


As in Stanley \& Doucouliagos (2010), testing the existence of publication bias was implemented using a funnel plot, with partial correlation coefficients on the horizontal axis, and estimates of coefficients' precision - measured as the inverse of their standard errors - on the vertical axis. Typically, if there is no publication bias, the funnel plot tends to be symmetric (thus, its appearance tends to be similar to an inverted funnel) and there is no clear tendency for the effects to follow any direction (Doucouliagos et al., 2005). The estimates for both the short-term and the long-term impact are plotted on figures 1 and 2 respectively.

Figure 1 shows that the funnel plot is skewed to the right with the majority of observations scattered in the middle. These results indicate that the authors in this field tended to publish studies with large samples and mostly positive and significant regression coefficients, which might reach the conclusion of evidence of publication bias. Figure 2 indicates that the lagged effect reported is primarily positive, although it is difficult to conclude a publication bias due to the relatively low number of estimates and the economic insignificance of reported effects. To avoid making sound judgments based solely on the subjective representation of plots, we support our findings with funnel asymmetry tests.

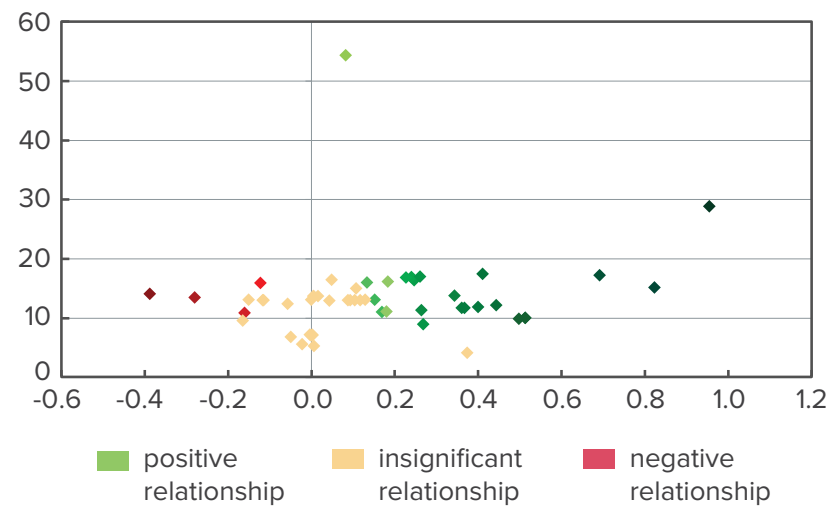

Figure 2. A Funnel Plot of the Instantaneous Effect of Interest Rate on Exchange Rate, 1/S.e.(PCC)

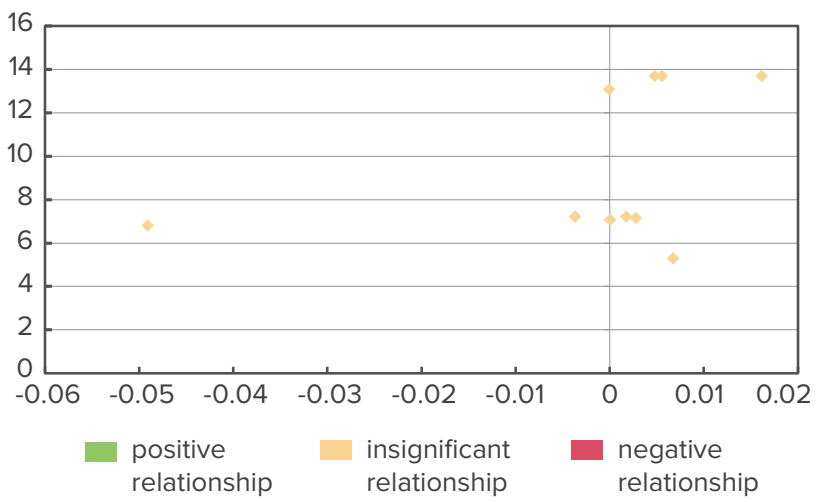

Figure 3. A Funnel Plot of the Lagged Effect of Interest Rate on Exchange Rate, $1 /$ S.e.(PCC)

The formal testing of both the short-term and the longterm impact is provided with the use of a funnel asymmetry regression test. To check for the inherent heteroskedasticity, the weighted least squares regression of the following form is utilized:

$$
\frac{P C C_{i j}}{\operatorname{SEpCC}_{i j}}=t_{i j}=\beta_{1}+\beta_{0}\left(\frac{1}{\operatorname{SEpcC}_{i j}}\right)+v_{i j}
$$

where SEpccij is the standard error of the partial correlation coefficient PCCij.

The results of the tests for the publication bias for both the short- and the long-term impact are provided in Table 1. In the absence of publication bias, there is no statistically significant relationship between the magnitude of the effect and its standard error, according to Doucouliagos et al. (2005). Therefore, if there is no publication bias, the intercept of the funnel asymmetry regression -weighted by standard errors - should not be statistically significant. According to Table 1, the intercepts of funnel asymmetry regressions for both the short-term and the long-term impact are not statistically significant. Therefore, the formal tests do not reveal any statistically significant evidence for the presence of publication bias in studies on the relationship between the interest rate and the exchange rate and these results are robust for the timing of effect.

Table 2. Test of the True Effect and Type I Publication Bias

\begin{tabular}{l|c|c}
\hline & Short-term & Long-term \\
\hline $1 /$ S.e.(PCC) & $0.228^{*}(0.121)$ & $0.020(0.012)$ \\
Constant & $-0.519(2.109)$ & $-0.183(0.113)$ \\
Number of observations & 31 & 10 \\
Number of studies & 5 & 3 \\
\hline
\end{tabular}

In addition to testing the tendency of published results to match theory, the prevalence of significant estimates among studies investigated should be also reviewed. The main threat of Type II publication bias is the selective reporting of studies with significant results. Consequently, studies reporting the absence of the effect could be overlooked, which in turn could mislead both researchers and policymakers on the presence of an effect that does not exist. To test Type II publication bias, the following methodology is used:

$$
\left|t_{i j}\right|=\beta_{1}+\beta_{0}\left(\frac{1}{\operatorname{SEpcc}_{i j}}\right)+v_{i j}
$$

where SEpccij is the standard error of the partial correlation coefficient PCCij.

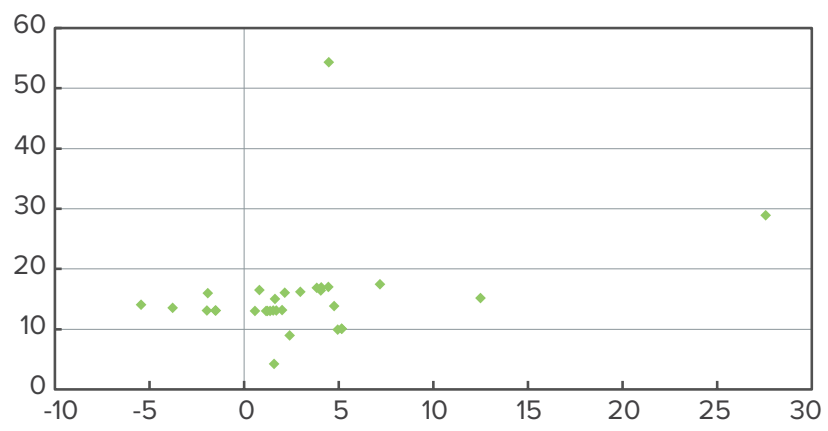

Figure 4. A Funnel Plot of the Effect of Interest Rates on Exchange Rate, $t$-value, $1 /$ S.e.(PCC) 
We didn't reject the null hypothesis that $\beta_{0}$ is equal to 0 , which proves the absence of a connection between the significance of estimates and their precision as reflected by $\frac{1}{S_{E P C c_{i j}}}$ both in the short- and in the long-term.

Table 3. Test of the Type II Publication Bias

\begin{tabular}{l|c|c}
\hline & Short-term & Long-term \\
\hline $1 /$ SEpcc & $0.204(0.106)$ & $0.003(0.011)$ \\
Constant & $0.905(1.841)$ & $0.050(0.111)$ \\
Number of observations & 31 & 10 \\
Number of studies & 5 & 3 \\
\hline
\end{tabular}

\section{MULTIVARIATE META-REGRESSION}

Although the methodology of meta-analysis is helpful in netting out the effect of interest rates on the exchange rate from other factors under interest, differences in research designs - as well as country-specific and timespecific factors - can also affect resulting estimates. To verify whether the above-mentioned heterogeneity has any effect on our results, we used a multivariate meta-regression methodology, specified in Havranek \& Irsova (2011) by the following equation:

$$
\begin{gathered}
t_{i j}=\beta_{1}+\beta_{0}\left(\frac{1}{\operatorname{SEpcC}_{i j}}\right)+ \\
+\sum_{k=1}^{K} \frac{\gamma_{k} Z_{i j k}}{S E p c c_{i j}}+\epsilon_{i j}, k=1, \ldots, K
\end{gathered}
$$

Here, $i$ is the index for a particular study, $j$ is the index of observation within the $i$ study, $Z_{i j k}$ comes as a set of variables that might affect the partial correlation coefficients, and $\epsilon_{i j}$ is the study-specific error term. The set of variables is weighted by the inverse of the standard error of the partial correlation coefficient for avoiding the inherent heteroskedasticity.

The obtained results are summarized in the table 4.

According to our forecast, the turnaround is expected to take place slowly. The reason is the above-mentioned inertia in the trend, which implies that even if the gap is negative, the decreasing trend of the previous years may partly or fully offset the mean-reverting forces. Therefore, our estimates predict a slight increase in credit-to-GDP for the following couple of years.

The results of meta-regression show that the heterogeneity in studies has a statistically significant effect on estimated partial correlation coefficients. The main reasons for these differences are the empirical methods and time units used for research. The income status of countries and the usage of a fixed exchange rate regime during the estimation period do not affect the values of partial correlation coefficients as much as the level of monetary freedom. According to the estimates in Table 1, in countries where the values of the Index of Monetary Freedom were higher than 70 during the estimation period, the response of interest rate change on the exchange rate was lower than for countries at the lower levels of the index. It can be observed that the studies that analyzed the period after 1990 reported significantly higher values of partial correlation coefficients. This finding can be explained by the composition of countries: only a few developing countries were present in the pre-1990 sample, while the proportion of developing countries was much higher in the post-1990 sample.

Table 4. Meta-Rregression Results

\begin{tabular}{l|l|c}
\hline Variable & Description & Coefficient \\
\hline$\frac{1}{S E p c c_{i j}}$ & Measure of precision for partial correlation coefficient & 0.23 \\
Current interest rate & $1-$ if the explanatory variable is the current level of interest rate & -1.25 \\
After 1990 & $1-$ if the study used observations only starting in 1990 & $10.36^{* * *}$ \\
\hline
\end{tabular}

\section{Country-specific effects}

High income

Monetary free

Fixed exchange rate

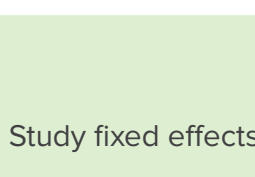

Study fixed effects
1 - if the analyzed country under study was in a high or high-middle income category during the study, $\mathrm{O}$ - if the country under study was in a low $-0.04$ or low-middle income category

1 - if the analyzed country had the value of the Heritage Foundation Index of Monetary Freedom over 70 during estimation, 0 - if less

1 - if the country used the fixed exchange rate regime during at least one year during the estimation period

Aggarwal(2013)

Sarmidi \& Salleh(2011)

$p$-values ${ }^{*} p<0.1 ;{ }^{* *} p<0.05 ;{ }^{* * *} p<0.01$ 


\section{CONCLUSION}

After conducting a meta-analysis of eight studies covering 30 countries, we conclude that there is a genuinely positive and statistically significant short-term effect of increases in interest rates on the exchange rate. Although being both economically and statistically significant in the short term, the effect is rather ambiguous in the long term, having a mostly insignificant interconnection with interest rates. The aggregation of coefficients - conditional on the country's level of monetary freedom and income status - revealed that in countries with higher levels of income and monetary freedom. the interconnection is stronger than in developing countries. The overall effect is estimated at the level of $14 \%$, while for high-income countries this effect remains higher by $4 \%$. These results are robust to the choice of the aggregation procedure and account for substantial heterogeneity in studies on this topic, resulting in an I-squared of $95.6 \%$.

To check if the results are valid and unbiased, we tested the results on publication selection. We tested for both
Type-1 and Type-2 publication biases, assessing both the extent of selecting only statistically significant estimates for publishing and the extent of selecting the estimates, which are consistent with economic theory. The results of the implemented tests have demonstrated that there is no statistically significant evidence of both types of publication biases in the estimates. The results of meta-regression have shown that the interconnection between interest rates and exchange rates is highly sensitive to a range of macroeconomic factors, especially when we are talking about the level of monetary freedom. Also, the effect was stronger for studies undertaken on post-1990 data.

Although due to data limitations, the inference about the possible effect of interest rate on exchange rate is made based on cross-country evidence rather than on the analysis of Ukrainian data, there is still a high probability that the same kind of relationship might be observed in Ukraine. Although there is no point in discussing the direct estimation of such a monetary policy instrument as the key policy rate on the national currency, the National Bank of Ukraine should take into account such an indirect inference while making its decisions regarding the key policy rate. 


\section{REFERENCES}

Baxter, M. (1994). Real exchange rates and real interest differentials. Journal of Monetary Economics, 33(1), 5-137. https://doi.org/10.1016/0304-3932(94)90012-4

Blinder, A. S. (2006). Monetary policy today: Sixteen questions and about twelve answers. CEPS Working Paper, 129. Princeton, NJ: Princeton University. Retrieved from https://www.princeton.edu/ ${ }^{\sim}$ ceps/workingpapers/129blinder. pdf

Coe, D. T., Golub, S. S. (1986). Exchange rates and real long-term interest-rate differentials: Evidence for eighteen OECD Countries. OECD Economics Department Working Papers, 28. Paris: OECD Publishing. https://doi. org/10.1787/18151973

Dornbusch, R. (1976). Expectations and exchange rate dynamics. Journal of Political Economy, 84(6), 1161-1176. https://doi.org/10.1086/260506

Doucouliagos, H., Laroche, P., Stanley, T. (2005). Publication bias in union-productivity research? Relations Industrielles, 60(2), 320-347. https://doi.org/10.7202/011724ar

Edison, H. J., Melick, W. R. (1999). Alternative approaches to real exchange rates and real interest rates: three up and three down. International Journal of Finance \& Economics, 4(2), 93-111. https://doi.org/10.1002/(sici)10991158(199904)4:2<93::aid-ijfe93>3.0.co;2-r

Edison, H. J., Pauls, D. B. (1993). A re-assessment of the relationship between real exchange rates and real interest rates: 1974-1990. Journal of Monetary Economics, 31(2), 165187. https://doi.org/10.1016/0304-3932(93)90043-f

Eichenbaum, M., Evans, C. L. (1995). Some empirical evidence on the effects of shocks to monetary policy on exchange rates. The Quarterly Journal of Economics, 110(4), 975-1009. https://doi.org/10.2307/2946646

Engel, C. (2015). Exchange rates, Interest rates, and the risk premium. American Economic Review, 106(2), 436-474. https://doi.org/10.1257/aer.20121365
Gould, D., Kamin, S. B. (2000). The Impact of Monetary Policy on Exchange Rates During Financial Crises, International Finance Discussion Papers, 669. Retrieved from http://www.federalreserve.gov/pubs/ifdp/2000/669/ default.htm

Havranek, T., Irsova, Z. (2011). Estimating vertical spillovers from FDI: Why results vary and what the true effect is. Journal of International Economics, 85(2), 234-244. https://doi.org/10.1016/j.jinteco.2011.07.004

MacDonald, R. (1999). What determines real exchange rates? The long and the short of it. In: MacDonald R., Stein J.L. (eds) Equilibrium Exchange Rates. Recent Economic Thought Series, 69. Dordrecht: Springer. https://doi. org/10.1007/978-94-011-4411-7_9

Meese, R., Rogoff, K. (1988). Was It Real? The exchange rate-interest differential relation over the modern floatingrate period. The Journal of Finance, 43(4), 933-948. https:// doi.org/10.1111/j.1540-6261.1988.tb02613.x

Nagayasu, J., MacDonald, R. (1999). The long-run relationship between real exchange rates and real interest rate differentials: A panel study. IMF Working Papers, 99(37), 1-12. https://doi.org/10.5089/9781451845556.001

Obstfeld, M., Rogoff, K. (1995). The mirage of fixed exchange rates. Journal of Economic Perspectives, 9(4), 7396. https://doi.org/10.1257/jep.9.4.73

Taylor, J. B. (2001). The role of the exchange rate in monetary-policy rules. American Economic Review, 91(2), 263-267. https://doi.org/10.1257/aer.91.2.263

United Nations (2018). World Economic Situation and Prospects. Retrieved from https://www.un.org/development/ desa/publications/wesp-2018.html

Valickova, P., Havranek, T., Horvath, R. (2013). Financial development and economic growth: A meta-analysis. Journal of Economic Surveys, 29(3), 506-526. https://doi. org/10.1111/joes.12068 
APPENDIX A. TABLES

Table 5. Data Collected for the Meta-Regression

\begin{tabular}{|c|c|c|c|c|c|c|c|c|c|}
\hline Country & $\begin{array}{c}\text { Dependent } \\
\text { variable }\end{array}$ & $\begin{array}{c}\text { Independent } \\
\text { variable }\end{array}$ & Coefficient & S.e. & D.f. & PCC & $\begin{array}{l}\text { S.e. } \\
\text { (PCC) }\end{array}$ & $\begin{array}{c}Z \\
(P C C)\end{array}$ & $\begin{array}{l}\text { 1/S.e. } \\
\text { (PCC) }\end{array}$ \\
\hline Indonesia & $d(E R)$ & $d(r)(t-1)$ & -0.005 & 0.015 & 46 & -0.049 & 0.147 & -0.049 & 6.791 \\
\hline Korea & $d(E R)$ & $d(r)(t-1)$ & 0.004 & 0.316 & 52 & 0.002 & 0.139 & 0.002 & 7.211 \\
\hline Malaysia & $d(E R)$ & $d(r)(t-1)$ & -0.011 & 0.418 & 52 & -0.004 & 0.139 & -0.004 & 7.211 \\
\hline Mexico & $d(E R)$ & $d(r)(t-1)$ & 0.000 & 0.958 & 171 & 0.000 & 0.076 & 0.000 & 13.077 \\
\hline Philippines & $d(E R)$ & $d(r)(t-1)$ & 0.000 & 0.862 & 50 & 0.000 & 0.141 & 0.000 & 7.071 \\
\hline Thailand & $d(E R)$ & $d(r)(t-1)$ & 0.005 & 0.252 & 51 & 0.003 & 0.140 & 0.003 & 7.141 \\
\hline Brazil & $d(E R)$ & $d(r)$ & 0.070 & 0.061 & 168 & 0.088 & 0.077 & 0.088 & 13.012 \\
\hline Chile & $d(E R)$ & $d(r)$ & -0.259 & 0.170 & 168 & -0.117 & 0.077 & -0.117 & 13.051 \\
\hline Mexico & $d(E R)$ & $d(r)$ & 0.046 & 0.034 & 168 & 0.104 & 0.077 & 0.104 & 13.032 \\
\hline Venezuela & $d(E R)$ & $d(r)$ & 0.142 & 0.093 & 168 & 0.117 & 0.077 & 0.118 & 13.051 \\
\hline Indonesia & $d(E R)$ & $d(r)$ & -0.464 & 0.236 & 168 & -0.150 & 0.076 & -0.151 & 13.110 \\
\hline Philippines & $d(E R)$ & $d(r)$ & 0.109 & 0.194 & 168 & 0.043 & 0.077 & 0.043 & 12.974 \\
\hline Thailand & $d(E R)$ & $d(r)$ & -1.981 & 1.322 & 168 & -0.115 & 0.077 & -0.115 & 13.048 \\
\hline Morocco & $d(E R)$ & $d(r)$ & -0.367 & 0.097 & 168 & -0.280 & 0.074 & -0.288 & 13.502 \\
\hline Hungary & $d(E R)$ & $d(r)$ & -0.551 & 0.101 & 168 & -0.388 & 0.071 & -0.409 & 14.063 \\
\hline Poland & $d(E R)$ & $d(r)$ & 0.086 & 0.043 & 168 & 0.152 & 0.076 & 0.154 & 13.115 \\
\hline Portugal & $d(E R)$ & $d(r)$ & 0.233 & 0.138 & 168 & 0.129 & 0.077 & 0.130 & 13.071 \\
\hline Romania & $d(E R)$ & $d(r)$ & 0.090 & 0.019 & 168 & 0.343 & 0.072 & 0.358 & 13.800 \\
\hline Russia & $d(E R)$ & $d(r)$ & 0.046 & 0.038 & 168 & 0.093 & 0.077 & 0.093 & 13.018 \\
\hline China & $d(E R)$ & $d(r)$ & -0.001 & 0.001 & 250 & -0.122 & 0.063 & -0.122 & 15.930 \\
\hline Argentina & $d(E R)$ & $d(r)(t-1)$ & -0.710 & -9.331 & 187 & 0.006 & 0.073 & 0.006 & 13.675 \\
\hline Chile & $d(E R)$ & $d(r)(t-1)$ & 0.008 & 0.128 & 187 & 0.005 & 0.073 & 0.005 & 13.675 \\
\hline Colombia & $d(E R)$ & $d(r)(t-1)$ & -0.112 & -0.506 & 187 & 0.016 & 0.073 & 0.016 & 13.677 \\
\hline Canada & $\ln (E R)$ & $d(r)$ & 0.860 & 0.290 & 252 & 0.184 & 0.062 & 0.186 & 16.149 \\
\hline Germany & $\ln (E R)$ & $d(r)$ & 0.860 & 0.120 & 252 & 0.411 & 0.057 & 0.437 & 17.417 \\
\hline Japan & $\ln (E R)$ & $d(r)$ & 0.300 & 0.140 & 252 & 0.134 & 0.062 & 0.135 & 16.018 \\
\hline Great Britain & $\ln (E R)$ & $d(r)$ & 0.890 & 0.220 & 252 & 0.247 & 0.061 & 0.252 & 16.382 \\
\hline Australia & $\ln (E R)$ & $d(r)$ & 0.530 & 0.130 & 270 & 0.241 & 0.059 & 0.246 & 16.930 \\
\hline Sweden & $\ln (\mathrm{ER})$ & $d(r)$ & 0.290 & 0.360 & 270 & 0.049 & 0.061 & 0.049 & 16.451 \\
\hline Switzerland & $\ln (E R)$ & $d(r)$ & 0.400 & 0.090 & 270 & 0.261 & 0.059 & 0.267 & 17.022 \\
\hline Malaysia & $\ln (E R)$ & $d(r)$ & 0.210 & 0.130 & 222 & 0.108 & 0.067 & 0.108 & 14.987 \\
\hline Thailand & $\ln (\mathrm{ER})$ & $d(r)$ & 0.730 & 0.190 & 270 & 0.228 & 0.059 & 0.232 & 16.875 \\
\hline Taiwan & $\ln (E R)$ & $d(r)$ & 0.250 & 0.160 & 15 & 0.374 & 0.239 & 0.393 & 4.176 \\
\hline Canada & $d(E R)$ & $d(r)$ & 0.320 & 0.133 & 74 & 0.269 & 0.112 & 0.275 & 8.931 \\
\hline France & $d(E R)$ & $d(r)$ & 0.400 & 0.032 & 74 & 0.824 & 0.066 & 1.168 & 15.166 \\
\hline Germany & $d(E R)$ & $d(r)$ & 0.530 & 0.019 & 74 & 0.955 & 0.035 & 1.881 & 28.871 \\
\hline Italy & $d(E R)$ & $d(r)$ & 0.190 & 0.037 & 74 & 0.514 & 0.100 & 0.568 & 10.026 \\
\hline Japan & $d(E R)$ & $d(r)$ & 0.330 & 0.064 & 74 & 0.513 & 0.100 & 0.567 & 10.021 \\
\hline UK & $d(E R)$ & $d(r)$ & 0.300 & 0.061 & 74 & 0.498 & 0.101 & 0.547 & 9.920 \\
\hline Turkey & $d(E R)$ & $d(r)(t-1)$ & -0.059 & -1.638 & 28 & 0.007 & 0.189 & 0.007 & 5.292 \\
\hline Great Britain & $d(E R)$ & $d(r)$ & 0.340 & 0.076 & 2931 & 0.082 & 0.018 & 0.083 & 54.323 \\
\hline
\end{tabular}


Table 6. The Instantaneous Effect of Interest Rate on Exchange Rate (Fixed Effect estimates vs Random Effect estimates)

\begin{tabular}{|c|c|c|c|}
\hline \multirow{2}{*}{ Name of the study, Country } & \multirow{2}{*}{ ES $(95 \% \mathrm{Cl})$} & \multicolumn{2}{|c|}{$\%$ Weight } \\
\hline & & $\mathrm{FE}$ & RE \\
\hline Sarmidi, Salleh (2011), Hungary & $-0.39(-0.53,-0.25)$ & 1.90 & 2.52 \\
\hline Sarmidi, Salleh (2011), Morocco & $-0.28(-0.43,-0,14)$ & 1.75 & 2.51 \\
\hline Sarmidi, Salleh (2011), Indonesia & $-0.15(-0.30,-0.00)$ & 1.65 & 2.50 \\
\hline Sarmidi, Salleh (2011), Chile & $-0.12(-0.27,0.03)$ & 1.64 & 2.50 \\
\hline Zhonxia, Jin (2003), China & $-0.12(-0.24,0.00)$ & 2.44 & 2.55 \\
\hline Sarmidi, Salleh (2011), Thailand & $-0.11(-0.27,0.04)$ & 1.64 & 2.50 \\
\hline Sarmidi, Salleh (2011), Philippines & $0.04(-0.11,0.19)$ & 1.62 & 2.50 \\
\hline Mehl, Cappiello (2009), Sweden & $0.05(-0.07,0.17)$ & 2.60 & 2.56 \\
\hline Aggarwal (2013), Great Britain & $0.08(0.05,0.12)$ & 28.39 & 2.65 \\
\hline Sarmidi, Salleh (2011), Russia & $0.09(-0.06,0.24)$ & 1.63 & 2.50 \\
\hline Sarmidi, Salleh (2011), Brazil & $0.09(-0.06,0.24)$ & 1.63 & 2.50 \\
\hline Sarmidi, Salleh (2011), Mexico & $0.10(-0.05,0.25)$ & 1.63 & 2.50 \\
\hline Mehl, Cappiello (2009), Malaysia & $0.11(-0.02,0.24)$ & 2.16 & 2.54 \\
\hline Sarmidi, Salleh (2011), Venezuela & $0.12(-0.03,0.27)$ & 1.64 & 2.50 \\
\hline Sarmidi, Salleh (2011), Portugal & $0.13(-0.02,0.28)$ & 1.64 & 2.50 \\
\hline Mehl, Cappiello (2009), Japan & $0.13(0.01,0.26)$ & 2.47 & 2.55 \\
\hline Sarmidi, Salleh (2011), Poland & $0.15(0.00,0.30)$ & 1.65 & 2.50 \\
\hline Mehl, Cappiello (2009), Canada & $0.18(0.06,0.30)$ & 2.51 & 2.55 \\
\hline Mehl, Cappiello (2009), Thailand & $0.23(0.11,0.34)$ & 2.74 & 2.56 \\
\hline Mehl, Cappiello (2009), Australia & $0.24(0.13,0.36)$ & 2.76 & 2.56 \\
\hline Mehl, Cappiello (2009), Great Britain & $0.25(0.13,0.37)$ & 2.58 & 2.56 \\
\hline Mehl, Cappiello (2009), Switzerland & $0.26(0.15,0.38)$ & 2.79 & 2.56 \\
\hline Hoffmann, MacDonald (2009), Canada & $0.27(0.05,0.49)$ & 0.77 & 2.34 \\
\hline Sarmidi, Salleh (2011), Romania & $0.34(0.20,0.49)$ & 1.83 & 2.52 \\
\hline Mehl, Cappiello (2009), Taiwan & $0.37(-0.10,0.84)$ & 0.17 & 1.64 \\
\hline Mehl, Cappiello (2009), Germany & $0.41(0.30,0.52)$ & 2.92 & 2.57 \\
\hline Hoffmann, MacDonald (2009), United Kingdom & $0.50(0.30,0.70)$ & 0.95 & 2.40 \\
\hline Hoffmann, MacDonald (2009), Japan & $0.51(0.32,0.71)$ & 0.97 & 2.40 \\
\hline Hoffmann, MacDonald (2009), Italy & $0.51(0.32,0.71)$ & 0.97 & 2.40 \\
\hline Hoffmann, MacDonald (2009), France & $0.82(0.69,0.95)$ & 2.21 & 2.54 \\
\hline Hoffmann, MacDonald (2009), Germany & $0.95(0.89,1.02)$ & 8.02 & 2.63 \\
\hline Subtotal (I squared $=96.5 \%, p=0.000$ ) & $0.20(0.18,0.22)$ & 90.27 & 77.11 \\
\hline Heterogeneity between groups $p=0.000$ & $-0.39(-0.53,-0.25)$ & & \\
\hline Overall (I-squared=95.6\%, p=0.000) & $-0.28(-0.43,-0.14)$ & 100.00 & 100.00 \\
\hline
\end{tabular}


Table 7. The Lagged Effect of Interest Rate on Exchange Rate (Fixed Effect estimates vs Random Effect estimates)

\begin{tabular}{|c|c|c|c|}
\hline \multirow{2}{*}{ Name of the study, Country } & \multirow{2}{*}{$\mathrm{ES}(95 \% \mathrm{Cl})$} & \multicolumn{2}{|c|}{$\%$ Weight } \\
\hline & & $\mathrm{FE}$ & $\mathrm{RE}$ \\
\hline Gould, Kamin (2000), Indonesia & $-0.05(-0.34,0.24)$ & 0.44 & 2.15 \\
\hline Gould, Kamin (2000), Philippines & $0.00(-0.28,0.28)$ & 0.48 & 2.19 \\
\hline Gould, Kamin (2000), Malaysia & $-0.00(-0.28,0.27)$ & 0.50 & 2.20 \\
\hline Gould, Kamin (2000), Thailand & $0.00(-0.27,0.28)$ & 0.49 & 2.19 \\
\hline Gould, Kamin (2000), Korea & $0.00(-0.27,0.27)$ & 0.50 & 2.20 \\
\hline Gould, Kamin (2000), Mexico & $-0.00(-0.15,0.15)$ & 1.65 & 2.50 \\
\hline Luo (2013), Chile & $0.00(-0.14,0.15)$ & 1.80 & 2.51 \\
\hline Gusmus (2002), Turkey & $0.01(-0.36,0.38)$ & 0.27 & 1.92 \\
\hline Luo (2013), Argentina & $0.01(-0.14,0.15)$ & 1.80 & 2.51 \\
\hline Luo (2013), Colombia & $0.02(-0.13,0.16)$ & 1.80 & 2.51 \\
\hline Subtotal (I squared=0.0\%, p=1.000) & $0.00(-0.06,0.06)$ & 9.73 & 22.89 \\
\hline
\end{tabular}




\title{
THE MISSING "CYCLE" PART AND OTHER THOUGHTS ON THE GLOBAL FINANCIAL CYCLE
}

\section{OLGA BONDARENKO ${ }^{a}$}

\author{
${ }^{a}$ National Bank of Ukraine \\ E-mail: Olha_Bondarenko@bank.gov.ua
}

\begin{abstract}
The paper studies co-movement in capital flows, which gives rise to a phenomenon dubbed the global financial cycle. It first estimates a global common factor in capital flows using a factor model and draws inferences of its quantitative importance. Then the paper studies the cyclical properties of the extracted factor and concludes that, in general, its importance for capital flows is relatively limited. This may suggest that the Mundell-Fleming trilemma (as opposed to dilemma) still describes the trade-off faced by policymakers, and domestic policies play the primary role in maintaining macroeconomic stability.
\end{abstract}

JEL Codes F32, F36, F4, G15

Keywords global financial cycle, capital flows, factor model, turning points, concordance

\section{INTRODUCTION}

In recent decades, the global financial system has undergone a notable transformation. Gradual capital account liberalization since the 1970 s by advanced and emerging economies alike has led to an increase in capital flows in both size and volatility. By 2008 , global gross flows have surged from below 5 percent of world GDP during 1980-99 to almost 20 percent (IMF, 2012) while gross external liabilities more than quadrupled to $200 \%$ of GDP. Following the global financial crisis, total cross-border positions have virtually stopped growing due to the slowdown in capital flows between advanced economies, especially financial centers, but in general, the level of financial integration has remained high (Lane and Milesi-Ferretti, 2017).

Back in 1996, Calvo et al. stated, "Global factors affecting foreign investment tend to have an important cyclical component, which has given rise to repeated booms and busts in capital inflows". Yet the notion of a "global financial cycle" gained its popularity only at the outbreak of the 2008-09 crisis: during this period, the number of references in the media tripled compared to 2007. Since then, the concept has become an important aspect of monetary or macroprudential policy discussions (Borio, 2019).

Its most popular definition comes from an influential paper by Rey (2015), according to which "global financial cycles are associated with surges and retrenchments in capital flows, booms and busts in asset prices and crises [... and] characterized by large common movements in asset prices, gross flows, and leverage". Building upon this statement, in this paper the global financial cycle is defined as an unobservable common component that reflects alternating peaks and troughs in gross capital flows across a broad sample of countries. Given that the paper is in essence devoted to this single topic, the terms "global financial cycle", "global cycle", as well as "global factor" might be used interchangeably throughout the study.

The existence of a powerful common cycle in capital flows and financial market prices constitutes an issue for policymakers. The classic Mundell-Fleming trilemma states that a flexible exchange rate allows for monetary policy independence when a capital account is open. In the presence of the global financial cycle, however, this does not hold true. If capital flows to and from a particular small open economy are well synchronized with the cycle, domestic financial conditions become aligned with global ones. Therefore, the trilemma turns into a dilemma: either to liberalize the financial account or pursue an independent monetary policy. Meanwhile, the choice of an exchange rate regime becomes irrelevant (Rey, 2015).

On the contrary, if the global cycle fails to explain developments in capital flows, traditional approaches to maintaining macro-financial stability remain appropriate. Hence, from a policymaking perspective, the question is not only "if the global financial cycle exists," but also "to what extent capital flows in and out of the country are dancing to the tune of the global cycle."

While economic literature generally gives an affirmative answer to the first of the aforementioned questions, it has not yet reached a persuasive conclusion on the quantitative importance of the global financial cycle for capital flows. Using a factor model, Barrot and Serven (2018) estimate that the global factor accounts on average for almost $40 \%$ of the 
variance of capital inflows to developed countries and about $15 \%$ to emerging market countries. Borio (2019) provides similar, but slightly lower figures: $30 \%$ and $8 \%$, respectively. Instead, Cerutti, Claessens, and Rose (2017) find that, with some exceptions, the global factor explains up to $25 \%$ of volatility in capital flows, and on average - only $5 \%$.

Although differences in methodology, country sample, and period are obvious candidates for the source of discrepancy in estimates, this paper explicitly shows that results of factor models are significantly influenced by data frequency and level of aggregation. Using an identical model setup and panel data, it finds that, on average, the share of variance explained varies from $25 \%$ for the most aggregated data to $7 \%$ for the least aggregated data.

Moreover, it might be important to separate the notion of synchronization from the share of variance explained. The latter takes into account not only a direction, but also a magnitude of change in capital flows. If the magnitude varies from cycle to cycle, this variance explained may appear to be an imperfect measure of synchronization. To check whether this holds, this paper computes the concordance index - a non-parametric measure of alignment between cycles - and test its significance. As is shown further, some capital flows generally share expansion and contraction phases with the global factor, but it explains only a small portion of volatility in these flows. The paper also documents some basic properties of the observed cycles.

The paper is structured as follows. Section 2 provides a short review of buoyant literature on the global financial cycle. Section 3 describes a dataset. Section 4 shows the results of the "traditional" factor model. Section 5 presents an analysis of turning points. Section 6 concludes.

\section{LITERATURE REVIEW}

Earlier literature analyzes capital flows through the lens of "push" and "pull" factors, where the former refer to conditions in a source country while the latter - in a recipient country. Starting with the works by Fernandez-Arias (1996) and Calvo et al. (1993), this framework was mostly devoted to explaining the drivers of capital inflows into emerging markets. Researchers have been choosing a limited number of variables to explain developments in capital flows. The pool of "global factors" contains predominantly, but not exclusively, indicators of risk aversion (VIX) and interest rates in advanced economies (the U.S.). Summarizing an extensive review of 40 empirical studies on the topic, Koepke (2015) states that these factors have the largest impact on portfolio flows, and somewhat less - on banking (other) flows. Global risk aversion is also found to play an important role in extreme capital flow episodes, such as surges and stops (Forbes and Warnock, 2012; Ghosh et al., 2014).

On the contrary, recent literature concentrates on an "alternative" approach - to extract a single factor from capital flows and compare it to observable variables, e.g. the VIX. Given the availability of large panel datasets, factor models turned out to be an appealing and simple framework for the analysis. Starting with Rey (2015), researchers have pointed to a strong commonality in gross capital inflows and outflows, which is a precondition to fit a factor model.
Barrot and Serven (2018) estimate a two-level latent factor model on annual flows from three groups of countries - advanced, emerging, and developing. They find that the global factor explains about $38 \%$ and $47 \%$ of the variance of inflows and outflows in advanced economies, while in emerging markets - just $15 \%$ and 25\%, respectively. The authors also confirm that global factors are related to traditional "push" variables: $70-80 \%$ of volatility is due to the VIX, U.S. interest rates, the U.S. real exchange rate, U.S. real GDP growth, and world commodity prices.

In turn, Cerutti et al. (2017) estimate a bunch of factor models on quarterly data and apply a range of techniques to quantify the importance of the global cycle. Still, they wrap up the paper stating that $25 \%$ is an approximate upper bound on the estimates of a share of volatility explained by a single common factor.

Davis et al. (2019) consider an impact of global factors both on gross and net capital flows with a classical static setup and annual aggregate data. They identify two significant factors - the global financial cycle and the commodity price factor - which account for about $40 \%$ of the variance of gross and net capital flows. The authors also replicate their analysis using quarterly data and find that their results change quantitatively (on average, the share of volatility due to these factors reduces to $25 \%$ ), but not qualitatively.

This paper generally fits this strand of literature. It documents divergences in the standard measure of the quantitative importance of the global cycle for capital flows and points to the presence of qualitative divergences as well. Next, the paper departs somewhat from a traditional approach and attempts to elaborate upon the cyclical properties of the variable termed "cycle". To do this, it relies on an analysis of turning points. This method is rarely used in the global financial cycle literature (the only example found is Reinhart et al., 2017), but is rather common in the determining domestic financial cycles (e.g., Drehmann et al, 2012; Claessens et al. 2011, 2012; Schuler et al., 2015).

\section{DATA}

A dataset is constructed using the IMF's International Financial Statistics and World Economic Outlook databases. Capital flows vis-à-vis the rest of the world are subdivided first into two broad categories: a) inflows, i.e. purchases of domestic assets by foreign residents, and b) outflows, or purchases of foreign assets by domestic residents. In accounting terms, both inflows and outflows are presented on a net basis in the financial account (incurrence of liabilities and acquisition of financial assets) but are commonly referred to as "gross" in the literature and this paper. These gross flows are further split into direct investments, portfolio equity, portfolio debt, and other investments. All measures exclude exceptional financing and are normalized by the trend of the country's GDP (at a respective frequency). ${ }^{1}$

The dataset comprises four balanced panels of annual and quarterly flows spanning 20 years, from 1999 to 2019. It covers a broad range of countries - 17 advanced economies (AE) and 33 emerging markets (EM), as reported 
in Table 2 - but excludes financial centers, as defined in Lane and Milesi-Ferretti (2017).

Descriptive statistics are provided in Table 3. As data contains outliers, the reported values are medians of selected descriptive statistics. Compared to EM countries, advanced economies receive larger capital inflows of all types, except for direct investment, and post higher outflows. This tendency is evident from both annual and quarterly data, as measures of central tendency are generally equivalent in these two sets. On the contrary, the standard deviation is about twice higher in quarterly data so that flows appear more volatile. In line with previous findings by Broner et al. (2013), inflows and outflows are correlated; yet, in annual data, correlation is higher. Figures 1 and 2 illustrate some of the above-mentioned facts.

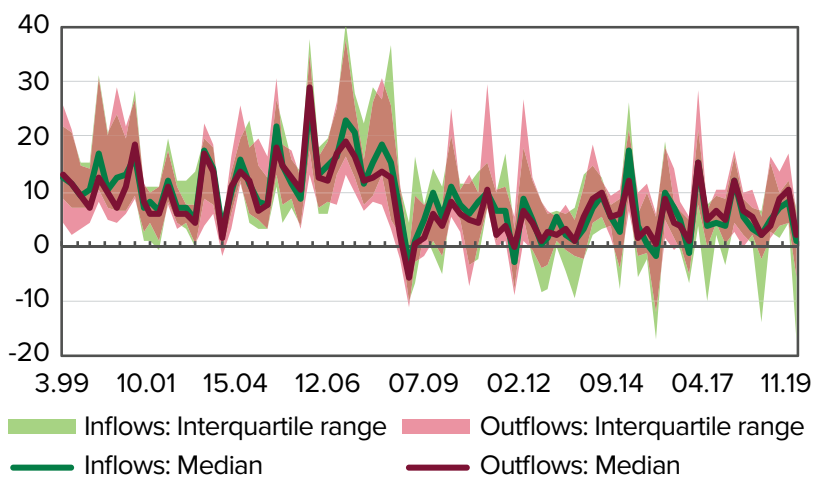

Figure 1. Aggregate Inflows and Outflows in AE Sources: own elaboration, based on IFS data.

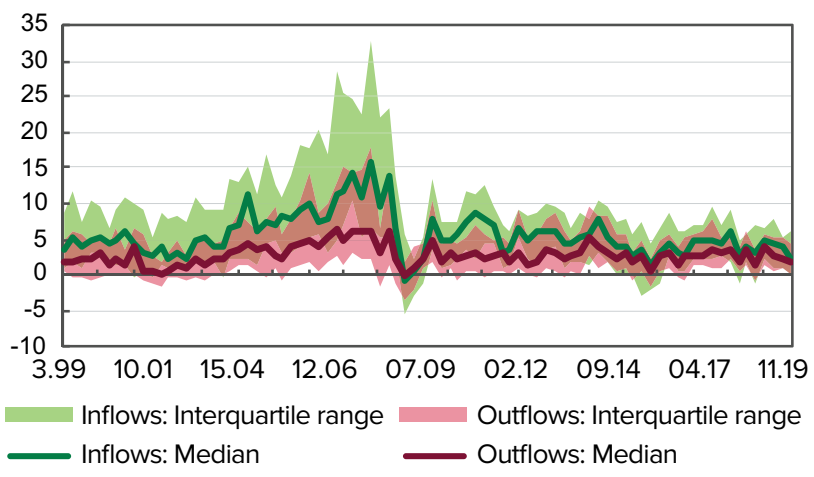

Figure 2. Aggregate Inflows and Outflows in EM Sources: own elaboration, based on IFS data.

To improve the comparability of data, the paper expresses quarterly flows as a four-quarter moving average. This transformation significantly reduces (but not eliminates) within-year volatility, as shown in Table 4, while the standard deviation becomes closer to the respective value in the annual data.

The final point touches upon the stationarity of data. The results of the Augmented Dickey-Fuller tests how that $60 \%$ of annual and $22 \%$ of quarterly (untransformed) capital flows are nonstationary. ${ }^{2}$

\section{FACTOR MODEL}

As was already mentioned, the estimation of a factor model is the most popular approach to extract the global cycle from either capital flows or asset prices. In essence, it attempts to explain co-movement in a vector $\mathbf{x}_{\mathbf{t}}$, containing a large number of variables, with a few common factors. For the sake of completeness, this paper includes some theoretical background of the factor models using large $N \rightarrow \infty$ data, the so-called approximate factor models. In its simplest form, it expresses any standardized capital flow $x_{i, t}$ as.

$$
x_{i, t}=\lambda_{i} \mathbf{F}_{\mathrm{t}}+\varepsilon_{i, t},
$$

where $F_{t}$ is a vector of unobserved common factors, $\lambda_{i}$ contains respective factor loadings, and $\varepsilon_{i, t}$ is an idiosyncratic component, capturing flow-specific dynamics. The term $\lambda_{i} F_{t}$ represent a common component of the model.

The principal component analysis (PCA) is a traditional method to estimate an approximate factor model. It decomposes $N \times N$ covariance matrix $\Sigma_{X}$ of $\mathrm{x}_{\mathrm{t}}$ into.

$$
\Sigma_{X}=\Lambda \Sigma_{f} \Lambda^{\prime}+\Sigma_{\varepsilon}
$$

by minimizing the sum of variances of the idiosyncratic terms. Intuitively, the higher the correlation between the series along one particular dimension (or the less spread is the data around an eigenvector for a principal component, describing that dimension), the higher portion of variance will be explained by that component. ${ }^{3}$ The setup also allows for mild serial and cross-sectional correlation in $\Sigma_{\varepsilon}$, i.e. for nonzero non-diagonal elements, which is typically observed in macroeconomic data.

Note, that as both loadings and factors are unobservable and not separately identifiable, restrictions should be imposed on the matrix of loadings $\Lambda$ and factors $F$. The PCA method implies that factors are orthogonal and have unit variance, $\Sigma_{f}=I$, and $\Lambda^{\prime} \Lambda$ is diagonal with distinct, decreasing diagonal elements (Lutkepohl, 2014). It turns Equation 2 into

$$
\Sigma_{X}=\Lambda \Lambda^{\prime}+\Sigma_{\varepsilon}=\Sigma_{\lambda}+\Sigma_{\varepsilon}
$$

Since variables in $x_{t}$ are standardized to have zero mean and unit variance, the covariance matrix $\Sigma_{X}$ is in essence a correlation matrix. Table 1 reports average pairwise correlations and shares of significant correlations in capital inflows by type (Table 5 - for outflows). ${ }^{4}$ All values are positive, which is in line with previous findings and generally confirms the existence of a common component in capital flows. Nevertheless, the share of significant correlations rarely exceeds $25 \%$, possibly pointing to a quite heterogeneous data. In absolute terms, the correlation between aggregated flows is higher than between specific types of investments, and even more so if quarterly data is used.

\footnotetext{
${ }^{2}$ The number of lags was determined by AIC with a maximum of 4 for annual data and 24 for quarterly.

${ }^{3}$ For derivations the reader is referred to, for example, Barigozzi (2018).

${ }^{4}$ The t-statistic for the correlation coefficient is calculated as $t_{c o r r}=\frac{r \sqrt{n-2}}{\sqrt{1-r^{2}}}$, where $\mathrm{r}$ is a correlation coefficient, and $\mathrm{n}$ is a length of series.
} 
Table 1. Unweighted Averages of Bilateral Correlation Coefficients* of Capital Inflows and Percentages of Significant Correlations

\begin{tabular}{|c|c|c|c|c|c|c|c|c|c|c|}
\hline \multicolumn{11}{|c|}{ Annual } \\
\hline & \multicolumn{2}{|c|}{ Aggregate flows } & \multicolumn{2}{|c|}{ Direct investment } & \multicolumn{2}{|c|}{$\begin{array}{c}\text { Portfolio } \\
\text { investment: Equity }\end{array}$} & \multicolumn{2}{|c|}{$\begin{array}{c}\text { Portfolio } \\
\text { investment: Debt }\end{array}$} & \multicolumn{2}{|c|}{ Other investment } \\
\hline & Corr. & Sign. & Corr. & Sign. & Corr. & Sign. & Corr. & Sign. & Corr. & Sign. \\
\hline Full sample & 21.6 & $19 \%$ & 13.3 & $12 \%$ & 10.0 & $16 \%$ & 10.0 & $10 \%$ & 16.0 & $15 \%$ \\
\hline$A E$ & 21.1 & $17 \%$ & 9.1 & $11 \%$ & 9.8 & $18 \%$ & 8.7 & $15 \%$ & 15.7 & $20 \%$ \\
\hline EM & 23.5 & $21 \%$ & 16.6 & $13 \%$ & 9.6 & $17 \%$ & 13.1 & $11 \%$ & 18.7 & $15 \%$ \\
\hline \multicolumn{11}{|c|}{ Quarterly } \\
\hline & \multicolumn{2}{|c|}{ Aggregate flows } & \multicolumn{2}{|c|}{ Direct investment } & \multicolumn{2}{|c|}{$\begin{array}{c}\text { Portfolio } \\
\text { investment: Equity }\end{array}$} & \multicolumn{2}{|c|}{$\begin{array}{c}\text { Portfolio } \\
\text { investment: Debt }\end{array}$} & \multicolumn{2}{|c|}{ Other investment } \\
\hline & Corr. & Sign. & Corr. & Sign. & Corr. & Sign. & Corr. & Sign. & Corr. & Sign. \\
\hline Full sample & 14.3 & $32 \%$ & 4.2 & $12 \%$ & 5.4 & $19 \%$ & 6.5 & $18 \%$ & 9.3 & $20 \%$ \\
\hline$A E$ & 13.8 & $29 \%$ & 2.1 & $12 \%$ & 6.3 & $21 \%$ & 7.0 & $24 \%$ & 7.7 & $22 \%$ \\
\hline EM & 15.9 & $38 \%$ & 5.2 & $12 \%$ & 4.8 & $20 \%$ & 7.1 & $17 \%$ & 11.6 & $24 \%$ \\
\hline
\end{tabular}

*Scaled by 100 .

${ }^{* *}$ Corr. - correlation coefficient, Sign. - percentage of correlation coefficients that are significant; AE - advanced economies, EM - emerging markets.

Given that some variables are nonstationary, the paper uses first differences to calculate both correlations and factors. Bai and $\mathrm{Ng}$ (2008) show that factors and loadings are consistently estimated in first differences without prior knowledge of whether factors or idiosyncratic terms are $I(0)$ or $I(1)$. The factor is then obtained by cumulation. In addition, factors are generally estimated consistently using PCA with $N \rightarrow \infty$ under different misspecifications, including inappropriate specification of temporal evolution of the factors and time-varying factor loadings (Banerjee et al., 2008).

Although Bai and $\mathrm{Ng}$ (2002) information criteria suggest as much as 19 factors for the case of annual data and only one factor for quarterly, to conform with the general logic of experiment (global factor, annual vs. quarterly) a single factor with largest eigenvalue is used. It is common in the literature to associate the global cycle with the first factor, which, by construction, explains the largest portion of the overall variation in the data. At the same time, the $2^{\text {nd }}, 3^{\text {rd }}$ etc. factors, representing other forces - regional influences, commodity prices (as in Davis et al., 2019) - may also appear important from economic point of view. Bringing to the attention these forces is a relevant avenue for future research. ${ }^{5}$
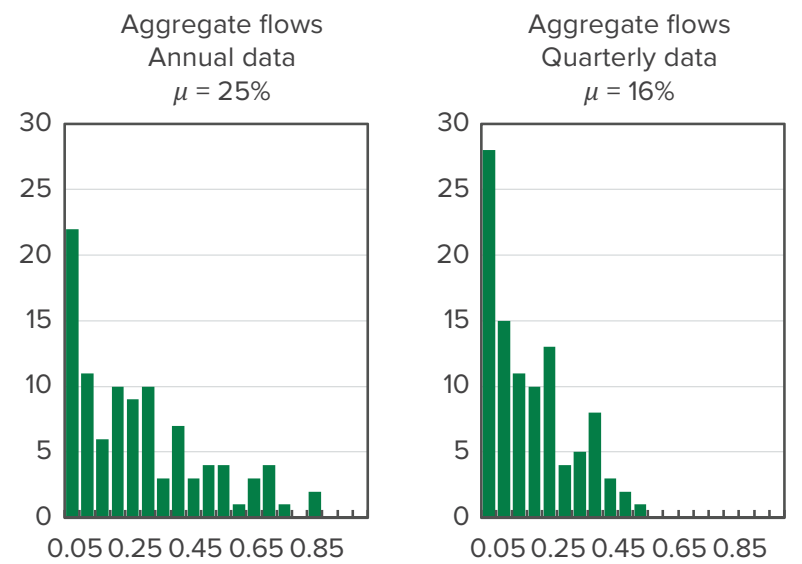

Figure 7 in the Appendix shows the extracted global factors from four panels of capital flows. Although annual and quarterly factors are generally comparable, except for magnitude, before the global financial crisis they show quite synchronous movement, while later local maxima and minima somewhat differ. For instance, the deepest point of the trough in disaggregated flows, caused by financial crisis, appears in 2008 in annual data but in 2009 in quarterly.

As data move from the most to the least aggregated state, the global factor tends to explain less and less volatility in capital flows. Although it might be reasonable to expect some proportional decline in the share of variance explained across all countries as one moves from annual to quarterly data, it is not supported by data. The interquartile range of ratio of annual to quarterly measure is wide, from 1.8 to 20.3 . Moreover, for $29 \%$ to $35 \%$ of flows the portion of volatility explained actually increase, on average, by 3.75 p.p. to 18.22 p.p. in disaggregated and aggregated data, respectively. The ranking of countries also changes: at different frequencies, top 10 flows in aggregated data are completely different, while in disaggregated data only two flows repeat. Hence, estimates of the significance of the global cycle, as it is commonly referred to, has some discrepancies of both quantitative and qualitative nature.
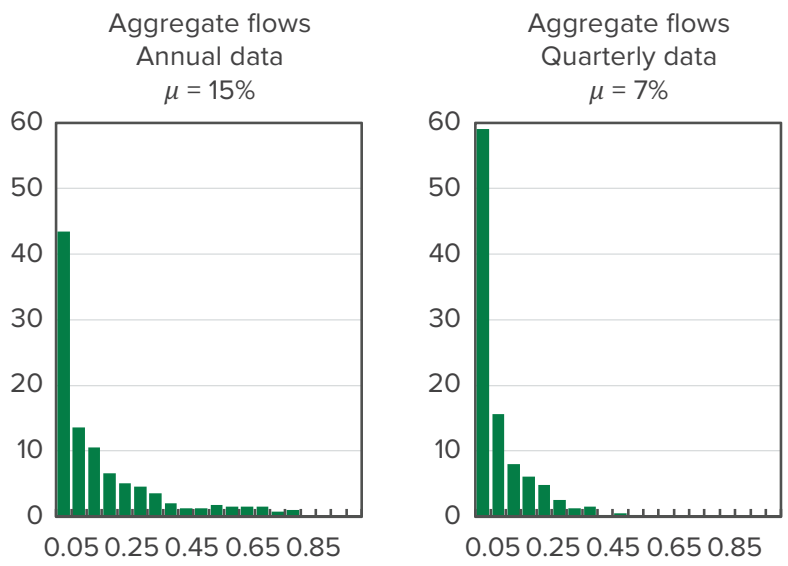

Figure 3. Cross-Country Differences in the Share of Variance Explained by Global Factor*, \% ${ }^{*} \mu$ indicates average. 
A decline in the share of variance explained matches the tendency in correlations, where less aggregated data had lower average pairwise correlation. Since loadings can be effectively interpreted as correlations between capital flows and the factor under the normalization $\Sigma_{f}=I$, the result is natural. To illustrate the point, Figure 8 in the Appendix shows a strong linear relationship between the number of significant pairwise correlations for a specific flow and the share of variance explained.

Thus, estimates of co-movement in capital flows vary, depending on data frequency and level of aggregation. The literature on temporal and cross-sectional aggregation confirms that these transformations can influence estimation results and model properties, such as dynamic patterns and Granger causality (Silvestrini and Veredas, 2008). Although to my knowledge, research on the topic in the context of factor models is limited, it is still possible to make inferences about potential issues, associated with aggregation, from the existing papers.

Granger (1987) shows that common factors are key to determine the dynamics of aggregates, though they might explain little at the micro level. Turning to capital flows, it is worth noting that - at least in the quarterly sample, where the time-series dimension $T$ is large - factors from crosssectionally aggregated and disaggregated flows exhibit quite similar behavior. At the same time, on average, the share of variance explained by the global factor is twice lower in the latter case, as Figure 3 demonstrates. Following Granger (1987), it is reasonable to conclude that the global cycle, having limited influence on specific FDI or portfolio flows at the micro level, should not be discarded entirely, as it can still play some role in macro level models.

Temporal aggregation smooths out high-frequency fluctuations and seasonal patterns in the data. However, Rossana and Seater (1995) argue that it systematically changes the time-series properties of the data. In particular, annual aggregates do not exhibit variation at business cycle frequencies (over 1 year), which is evident in monthly and quarterly data, and therefore, entail a significant loss of information about the actual data-generating process. In the PCA, which takes into account only contemporaneous observations, the cyclical pattern is still present, as shown in Figure 7 in the Appendix. How it compares to the cycle in the quarterly data is further explored in section 5 .

The observed quantitative importance of the global cycle as measured by the share of variance explained can be distorted not only by aggregation, but also by random events. Although being an extremely useful method to extract a global component, factor analysis per se does not guarantee that this component is a pure "cycle". In business cycle literature, a variable of interest $y_{t}$ is typically decomposed into trend and cycle as follows

$$
y_{t}=g_{t}+c_{t}+\varepsilon_{t}
$$

where $\varepsilon_{t}$ is a residual. After data is standardized as required by the PCA, both flows and the first factor are likely to be represented by a $c_{t}+\varepsilon_{t}$ rather than $c_{t}$ itself. Hence, at least one component, $\varepsilon_{t}$, might distort correlations (loadings) as a measure of synchronization between the global factor and capital flows. McDermott and Scott (2000) illustrate this case with an artificial example: two series were in the same phase of the cycle $50 \%$ of the time, and initially their correlation was small (0.12) and insignificant. The authors added a jump in both series at the same point in time, and the correlation grew to 0.6 while the phases of the cycles were left untouched. If, instead, the two series are correlated, and the jump is added to only one of them, the correlation is likely to fall while the correspondence in cycles - to be maintained. The next example from McDermott and Scott (2000) refers to the actual GDP data in the U.S. and Germany from the same paper. While the business cycle in both countries was largely synchronized, correlation turned out to be close to zero.

Accordingly, a deeper understanding of cyclical properties is required to judge to what extent the share of variance explained reflects the synchronization between the global cycle and capital flows.

\section{CONCORDANCE IN CAPITAL FLOWS}

One of the oldest strands of literature on cycles defines a cyclical component in an individual series by the existence of consecutive alternating turning points - peaks and troughs with periods in between being expansions and contractions. In this vein, two cycles are said to be synchronized if their corresponding turning points are so close to each other so that they share the same phase most of the time. The degree of synchronization is measured by the concordance index (Harding and Pagan, 2002), which is calculated as

$$
I=\frac{1}{T}\left(\sum_{t=1}^{T} S_{i, t} S_{j, t}+\sum_{t=1}^{T}\left(1-S_{i, t}\right)\left(1-S_{j, t}\right)\right),
$$

where $S_{i, t}$ indicates the state of capital flow $x_{i, t} ; S_{i, t}=1$ stands for expansion, and $S_{i, t}=0-$ for contraction. As inputs to the concordance index are binary, the results are not prone to changes in magnitudes either in specific periods or from cycle to cycle. Perfect positive synchronization occurs when $E(I)=1$, and perfect negative - if $E(I)=0$.

To construct binary indicators for each capital flow and estimated global factor, one needs to determine turning points in the series. In this paper, this task is accomplished, using the three-step procedure, outlined by Harding and Pagan (2002). First, a potential set of turning points is defined using rules for finding local minima and maxima, e.g. local maxima in series $x$ satisfies simultaneously the following conditions:

$$
\Delta_{2} x_{t}>0, \Delta x_{t}>0, \Delta x_{t+1}<0, \Delta_{2} x_{t+2}<0
$$

Second, one should ensure that peaks and troughs alternate. Third, additional rules apply to the resulting set, which specify minimum phase (contraction or expansion) and cycle duration. Harding and Pagan (2002) propose minimum phase duration of two quarters and minimum cycle duration of five quarters when applying the turning point detection algorithm to the business cycle. These values are typically used, but are not carved in stone, and in the same paper, the authors reduce the minimum cycle to four quarters for the UK, as an important recession episode is otherwise missing.

Thus, I generally follow the methodology by Harding and Pagan (2002) but somewhat adjust censoring rules on minimum phase and cycle duration. Borio (2019) states 
that the global cycle occurs at traditional business cycle frequencies, commonly referred to as two to eight years. Forbes and Warnock (2012), who study surges, stops, flights, and retrenchments in gross capital flows with a different methodology, find that on average each episode lasts about 3 to 5 quarters. Hence, the minimum phase is set to three quarters while the minimum cycle - to eight quarters. Since the turning points analysis does not require the underlying series to be stationary, a simple four-quarter moving average is used.

The cyclical properties of capital flows are outlined in Table 6. On average, expansion phases last somewhat longer than contractions, 9 and 7 quarters, respectively; the full cycle is thus about four years (or 16 quarters). Compared to inflows, outflows tend to be rather more stable, with the longest expansions recorded for EM countries in portfolio equity. This result, however, is likely to be distorted by the fact that in relation to GDP, portfolio equity flows are typically close to zero.

Coming back to the issue of temporal aggregation, turning point analysis highlights how differently one can define expansionary and contractionary years with annual and quarterly factors. For instance, the peak of the quarterly cycle occurs in Q2 2011 and only the two last quarters can be marked as contractionary while in the annual data, the peak is observed a year earlier, and 2011 is already believed to be contractionary. The reverse can be said about 2012 . Moreover, the quarterly factor tends to display less abrupt changes, especially during contractions, as shown in the lower panel of Figure 7 in the Appendix. Therefore, the loss of information entailed by temporal aggregation can result in an improper contemporaneous analysis and model specification (if used as an input).

Having defined the turning points for individual capital flows, the paper also extracts a common cycle using the non-parametric method as defined in Harding and Pagan (2006). This entails the determination of clusters of turning points in individual capital flows; for a detailed procedure, one is referred to the original paper. Figure 4 shows global cycles estimated from aggregate capital flows, from risky asset prices (Miranda-Agrippino and Rey, 2020; Habib and Venditti, 2019), and contraction phases obtained by the non-parametric algorithm. ${ }^{6}$ All cyclical representations generally co-move, and their turning points are clustered around the same dates. The only notable discrepancy occurs in 2002-03 with a trough in capital flows occurring earlier than in asset prices. Hence, all series are likely to represent the same underlying phenomena, named the "Global Financial Cycle".

Since in the present paper, the purpose of concordance analysis is to construct an alternative co-movement measure, with which the share of variance explained can be compared, global factors extracted by the PCA are used as benchmarks, with which country flows are assumed to be synchronous. Figure 10 in the Appendix shows the distributions of the degree of concordance between global factors and individual flows. On average, capital flows, reported by 50 countries, spend about $60-65 \%$ of the time in the same phase as the global cycle. Does this hint at a significant (in econometric terms) synchronization? As noted in Harding and Pagan (2006), $E(I)=0.5$ points to strong non-synchronization between two series only if both spend about $50 \%$ of time equally in expansion and contraction phases. Therefore, to test whether the two have a significant synchronization, it is required to mean correct it, i.e. estimate correlation $\rho_{S}$ between the binary series $S_{i}$ and $S_{j}$.

Harding and Pagan (2006) specify the following regression, from which $\rho_{S}$ can be inferred:

$$
\frac{S_{j, t}}{\hat{\sigma}_{S_{i}} \hat{\sigma}_{S_{j}}}=a_{1}+\rho_{S} \cdot \frac{S_{i, t}}{\hat{\sigma}_{S_{i}} \hat{\sigma}_{S_{j}}}+u_{t}
$$

where $\hat{\sigma}_{S i}$ is a standard deviation of $S_{i}, a_{1}$ is some constant, and $u_{t}$ is an error term. Since $S_{i}$ and $S_{j}$ typically exhibits serial correlation, neither is safe to assume $u_{t}$ is i.i.d., so the equation is estimated by the generalized method of moments.

Figures 5 and 6 plots the concordance index with the global factor versus the portion of volatility in capital flow explained by this factor. If the latter properly reflects the degree of synchronization with the cycle, one would expect a high and significant concordance index to correspond to

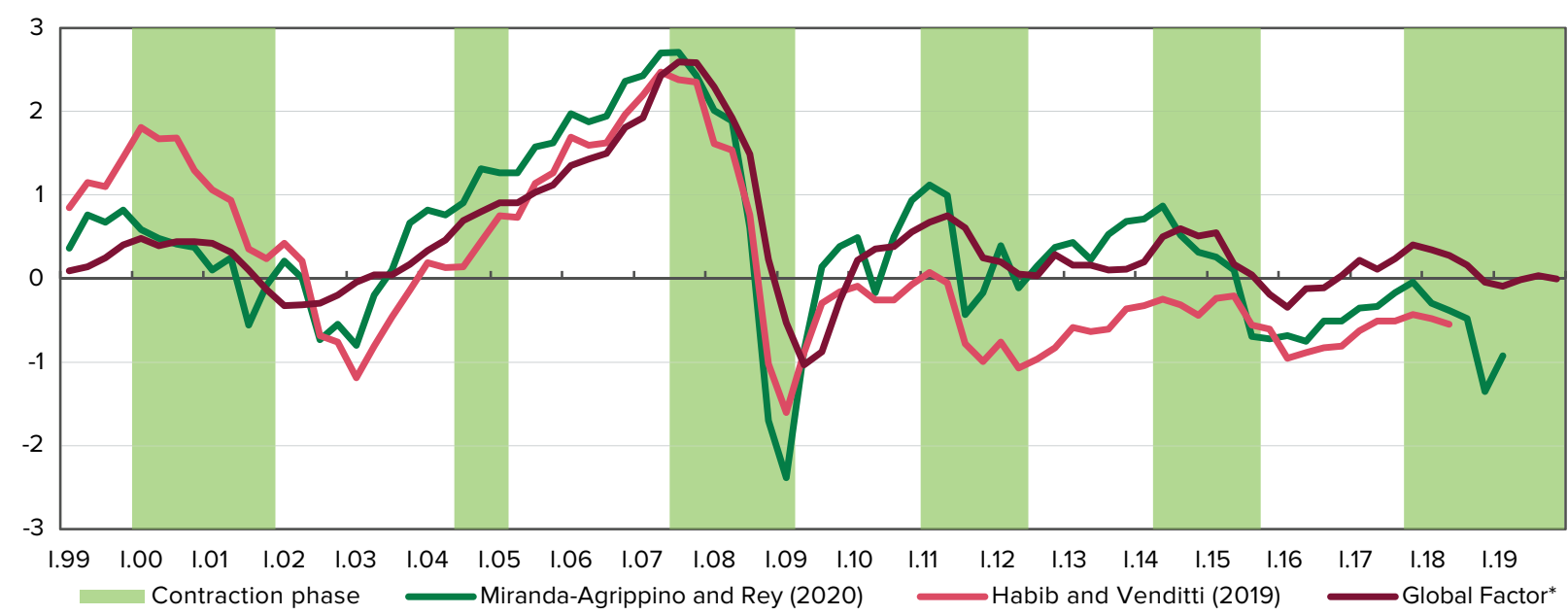

Figure 4. Estimates of the Global Financial Cycle

*The global factor from aggregated flows; scaled by 0.25 for visibility.

Source: own elaboration, personal web page of Miranda-Agrippino, and personal web page of Venditti. 
a high share of variance explained. The evidence generally supports this statement, although it is not one-to-one correspondence, and the high and significant degree of synchronization can occur even if the factor explains only a small part of the variance.

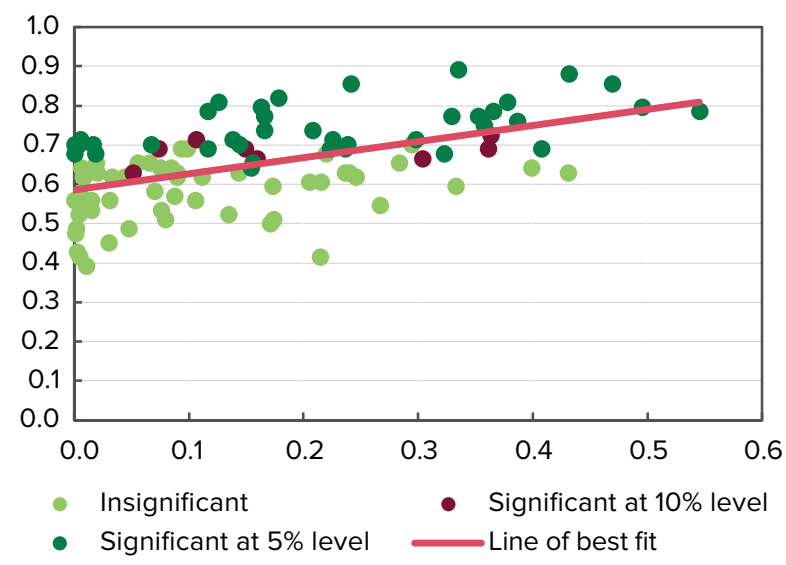

Figure 5. Share of Variance Explained and Concordance Index in Aggregate Capital Flows

Share of flows significant* at $5 \%$ is $38 \%$

Share of flows significant* at $10 \%$ is $46 \%$

*Significance refers to the concordance index. Dots represent capital flows, e.g. outflows from the U.S. or inflows into Ukraine.

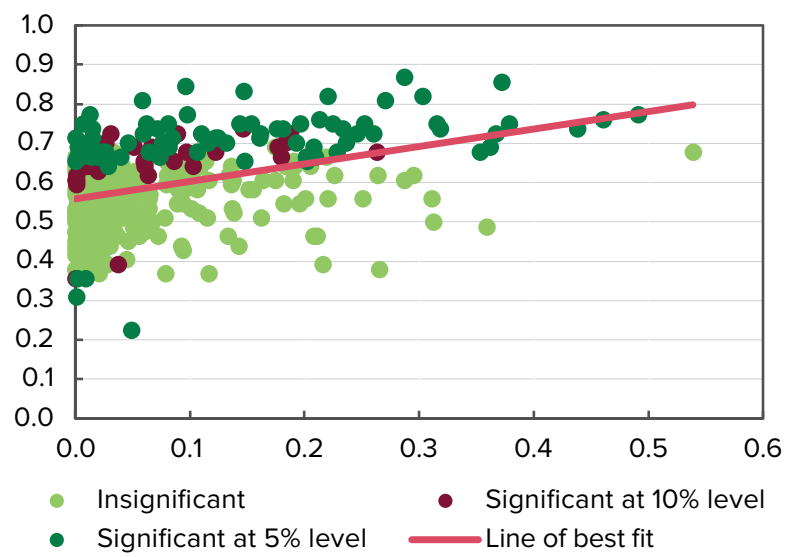

Figure 6. Share of Variance Explained and Concordance Index in Capital Flows (split by types)

Share of flows significant* at $5 \%$ is $19 \%$

Share of flows significant* at $10 \%$ is $28 \%$

*Significance refers to the concordance index. Dots represent capital flows, e.g. outflows from the U.S. or inflows into Ukraine.

Figure 11 in the Appendix illustrates what this implies in practice for the case of three aggregate flows, taken from the different parts of a spectrum. Capital outflows from Korea, characterized by both high share of variance explained and concordance, exhibit dynamics quite similar to that of the global factor. ${ }^{7}$ On the contrary, inflows to Hungary are more volatile and change their magnitude from phase to phase. Additionally, a spike in 2016, not matched by an equivalent event in the global factor, was likely to play a role in lowering the correlation between the series. At the same time, expansion and contraction periods, by and large, occur simultaneously. As a result, a very small part of the variance is explained by the global variable but the degree of synchronization is high. Inflows to Peru provide an example of a flow that is not well aligned with the cycle.

Generally, about half of aggregate flows in the sample have a statistically significant degree of concordance, both in advanced and emerging economies (Table 7). In the $A E$ group, out of 17 countries, six have inflows and outflows co-moving with the global cycle (including the U.S.), and in another five - one type of flow. Among EM, new Eurozone members and countries included in MSCI EM typically have at least one flow with significant concordance index. This might suggest the presence of a link between the level of financial development or the country's openness and adherence to the global cycle, a topic to be covered in further research.

It is interesting to note that, in line with the previous research, net flows exhibit limited concordance with the global factor - only 7 out of 50 countries have the index significant. ${ }^{8}$ In Turkey and Argentina, inflows dominate, and net flows co-move with the global cycle because inflows do so. In the U.S., Latvia, and Slovakia, inflows and outflows generally offset each other, but the resulting net flows are positively synchronized with the factor, while in Chile - negatively synchronized. In general, net flows are either rather stable with soft cycles or exhibit more short cycles, and spend less time in the same phase as the global factor - about $55 \%$ of the time.

As for the disaggregated data (Table 8), there are several things to mention here. First, 59\% of advanced economy and $23 \%$ of emerging market portfolio equity flows have a significant concordance. This is quite an intuitive result, given the high degree of similarity between the global factors estimated from capital flows and risky asset prices. Second, other investment flows are also synchronized with the global cycle: $38 \%$ and $23 \%$ of $A E$ and EM flows, respectively. Direct investment flows are the least numerous category, but for seven EM countries, inflows are significantly procyclical, while for Slovakia - significantly countercyclical.

The U.S. is an absolute leader in terms of the number of flows, co-moving with the global cycle. Yet there is limited room for the egg vs. chicken debate. Miranda-Agrippino and Rey (2020) show that U.S. monetary policy is an important driver of the global financial cycle, as measured by a global factor. Other advanced economies have on average about three synchronized flows, France and Germany - four. Countries from the EM group usually have two types of flows with significant concordance index, while nine countries, including Mexico and Ukraine - none.

As a final note, it is necessary to admit that the detection of turning points was done automatically via an algorithm without any judgmental input. Some disagreements between the results of an algorithm and one's perception may arise at the visual inspection since the data is volatile. If used for policymaking, the turning points and concordance index should be checked on a case-by-case basis.

\footnotetext{
${ }^{7}$ Remember, the factor model is estimated in first differences. Except for the "trending part" (constant in growth rate) after 2009, the dynamics are similar, as well as scale.

${ }^{8}$ See, for example, Rey (2015).
} 


\section{CONCLUSIONS}

The global financial cycle, as virtually any unobservable variable, has no unambiguous estimate. The literature on the topic is centered on the estimation of factor models, which offer useful insight into how the global cycle might look like. It is also quite common to infer its quantitative importance for individual capital flows from the share of variance explained by the factor. In the case of volatile data, however, it might appear misleading.

The paper studies four instances of factor analysis applied to datasets, differing in the level of temporal and cross-sectional aggregation. Although the cyclical patterns of factors extracted from annual and quarterly data are roughly similar, on average, the former points to its higher quantitative importance for capital flows than the latter. The ordering of flows from the most to the least synchronous (or the other way round) is also unstable. Still, if one continues to see the matter through the prism of the factor model, the share of variance explained by the factor is probably the only ready-made estimate of its significance.

Notwithstanding the fact that the setup of the factor model should be chosen, depending on the purpose of the exercise, it is reasonable to suggest the use of quarterly capital flows for estimation purposes. ${ }^{9}$ First, data at this frequency provide a consistent estimate of the factor for cross-sectionally aggregated and disaggregated data, or as $N \rightarrow \infty$. Second, according to the literature, it is likely to reflect cyclical properties and the data-generating process better if used in macro modeling. Third, transforming data in the temporal dimension occasionally changes the interpretation of a particular year from expansionary to contractionary, and vice versa.

Turning back to the share of variance explained, there is the additional (and more important) rationale behind questioning it as a measure of synchronization: the factor model does not guarantee that the extracted component is a pure "cycle". Thus, this paper changes the vantage point, moving from factor models to the traditional approach used in the business cycle and domestic financial cycle analysis. It involves the determination of turning points and expansion-contraction phases in capital flows. The degree of synchronization with the global factor is then measured by the concordance index.

The two alternatives are interrelated: in general, a high share of variance explained corresponds to a high and significant concordance index. However, this is not always the case: as correlations might be distorted by single events in series or varying magnitudes from phase to phase, so does the share of variance explained. At the same time, the co-movement of cyclical components in capital flows might be preserved.
As of now, the paper does not either compare the unobservable global cycle with cycles in potential observable counterparts, e.g. VIX, nor does it draw inferences on its source. It also omits the question of what country-specific characteristics - like capital account openness, flexible/fixed exchange rates, and level of financial developments - make country's flows more susceptible to the global cycle. Testing dilemma vs. trilemma theories, depending on the degree of co-movement between the global cycle and capital flows, is a promising direction for future research.

From a policymaking perspective, it is safe to assume that inflows and outflows scoring high on both measures of synchronization are dancing to the tune of the global cycle or are transmitting this cycle to the rest of the world (e.g., the U.S., although from the present analysis, it is impossible to distinguish between the two). In these instances, developments in individual flows - phases of the cycle and quarter-to-quarter changes - are coinciding with those in the global factor.

The number of such instances is limited, however. Although a case-by-case investigation is warranted, overall there is little evidence of an extensive and stable impact of the global financial cycle on capital flows. The use of the concordance index helps to broaden the subset of series to be watched more closely - now some of those with a low share of variance explained can be treated as synchronized with the global cycle. Still, in EM countries, on average, only two out of eight types of flows have a significant concordance index.

Although this paper does not provide any robust evidence on what level of co-movement hampers the ability of policymakers to conduct independent monetary policy, when the capital account is open, the results cast a shadow on a basic precondition for trilemma turning into dilemma. While additional research on the topic is warranted, it is still might be more relevant for policymakers to concentrate on fundamentals. This generally echoes a summary from pushpull literature by Koepke (2015), according to which the importance of cyclical factors may have been overstated at the expense of longer-term structural trends.

\footnotetext{
${ }^{9}$ Whenever only annual flows are available, the factor model should probably encompass more than 20 years of data to yield consistent results. This proposal, however, requires additional analysis.
} 


\section{REFERENCES}

Bai, J. Ng, S. (2002). Determining the number of factors in approximate factor models. Econometrica, 70 (1), 191-221. https://doi.org/10.1111/1468-0262.00273

Bai, J., Ng, S. (2008). Large dimensional factor analysis. Foundations and Trends $^{\circledR}$ in Econometrics, 3(2), 89-163. https://doi.org/10.1561/0800000002

Banerjee, A., Marcellino, M., Masten, I. (2008). Forecasting macroeconomic variables using diffusion indexes in short samples with structural change. CEPR Discussion Paper, 6706. Retrieved from https://cepr.org/active/publications/ discussion_papers/dp.php?dpno=6706

Barigozzi, M. (2018). Dynamic Factor Models. Lecture notes. Retrieved from http://www.barigozzi.eu/MB_DF_ lecture_notes.pdf

Barrot, L., Serven, L. (2018). Gross capital flows, common factors, and the global financial cycle. Policy Research Working Paper, 8354. http://hdl.handle.net/10986/29414

Borio, Claudio (2019). A tale of two financial cycles: domestic and global. Lecture at the University of Zürich Retrieved from https://www.bis.org/speeches/sp191119a.pdf

Boivin, J., Ng S. (2006). Are more data always better for factor analysis? Journal of Econometrics, 132(1), 169-194. https://doi.org/10.1016/j.jeconom.2005.01.027

Broner, F., Didier, T., Erce, A., Schmuker S. (2013). Gross capital flows: dynamics and crises. Journal of Monetary Economics, 60(1), 113-133. https://doi.org/10.1016/j. jmoneco.2012.12.004

Calvo, G. A., Leiderman, L., Reinhart, C. M. (1993). Capital inflows and real exchange rate appreciation in Latin America: the role of external factors. IMF Staff Papers, 40(1), 108-151. Retrieved from https://www.jstor.org/stable/3867379

Calvo, G. A., Leiderman, L., Reinhart, C. M. (1996). Inflows of capital to developing countries in the 1990s. Journal of Economic Perspectives, 10(2), 123-139. https://doi. org/10.1257/jep.10.2.123

Cerutti, E., Claessens, S., Rose A. K. (2017). How important is the global financial cycle? Evidence from capital flows. NBER Working Paper, 23699. Cambridge: National Bureau of Economic Research. https://doi.org/10.3386/w23699

Claessens, S., Kose, M. A., Terrones, M. E. (2011) Financial cycles: What? How? When? NBER International Seminar on Macroeconomics, 7(1), 303-344. https://doi. org/10.1086/658308

Claessens, S., Kose, M. A., Terrones, M. E. (2012). How do business and financial cycles interact? Journal of International Economics, 87(1), 178-190. https://doi. org/10.1016/j.jinteco.2011.11.008

Davis, J. S., Valente, G., van Wincoop, E. (2019). Global drivers of gross and net capital flows. Globalization Institute Working Paper, 357. https://doi.org/10.24149/gwp357
Drehmann, M., Borio, C., Tsatsaronis, K. (2012). Characterising the financial cycle: Don't lose sight of the medium term! BIS Working Paper, 380. Retrieved from http://www.bis.org/publ/work380.pdf

Fernandez-Arias, E. (1996). The new wave of private capital inflows: Push or pull? Journal of Development Economics, 48(2), 389-418. https://doi.org/10.1016/03043878(95)00041-0

Forbes, K. J., Warnock, F. E. (2012). Capital flow waves: Surges, stops, flight, and retrenchment. Journal of International Economics, 88(2), 235-251. https://doi. org/10.1016/j.jinteco.2012.03.006

Ghosh, A. R., Qureshi, M. S., Kim, J. I., Zalduendo, J. (2014). Surges. Journal of International Economics, 92(2), 266-285. https://doi.org/10.1016/j.jinteco.2013.12.007

Granger, C. W. J. (1987). Implications of aggregation with common factors. Econometric Theory, 3(2), 208-222. Retrieved from https://www.jstor.org/stable/3532462

Habib, M. M., Venditti, F. (2019).The global capital flows cycle: structural drivers and transmission channels. ECB Working Paper Series, 2280. Retrieved from https://www. ecb.europa.eu/pub/pdf/scpwps/ecb.wp2280 2e76974901. en.pdf

Harding, D., Pagan, A. (2002). Dissecting the cycle: a methodological investigation. Journal of Monetary Economics, 49(2), 365-381. https://doi.org/10.1016/S03043932(01)00108-8

Harding, D., Pagan, A. (2006). Synchronization of cycles. Journal of Econometrics, 132(1), 59-79. https://doi. org/10.1016/j.jeconom.2005.01.023

IMF (2012). The Liberalization and Management of Capital Flows: An Institutional View. Retrieved from https://www.imf.org/external/np/pp/eng/2012/111412.pdf

Koepke, R. (2015). What drives capital flows to emerging markets? A Survey of the Empirical Literature. MPRA Paper, 75887. Retrieved from https://mpra.ub.uni-muenchen. de/75887/

Lane, P. R., Milesi-Ferretti, G. M. (2017). International financial integration in the aftermath of the global financial crisis. IMF Working Paper, 17/115. Retrieved from https:// www.imf.org/en/Publications/WP/Issues/2017/05/10/ International-Financial-Integration-in-the-Aftermath-of-theGlobal-Financial-Crisis-44906

Lutkepohl, H. (2014). Structural vector autoregressive analysis in a data rich environment. DIW Discussion Paper, 1351. Retrieved from https://www.diw.de/documents/ publikationen/73/diw_01.c.434718.de/dp1351.pdf

McDermott, C. J., Scott, A. (2000). Concordance in business cycles. IMF Working Paper, 00/37. Retrieved from https://www.imf.org/en/Publications/WP/Issues/2016/12/30/ Concordance-in-Business-Cycles-3517 
Miranda-Agrippino, S., Rey, H. (2020). U.S. monetary policy and the global financial cycle. The Review of Economic Studies, 87(6), 2754-2776. https://doi.org/10.1093/restud/ rdaa019

Reinhart, C. M., Reinhart, V., Trebesch, C. (2016). Global cycles: Capital flows, commodities, and sovereign defaults, 1815-2015. American Economic Review, 106(5), 574-580. http://doi.org/10.1257/aer.p20161014

Rey, H. (2015). Dilemma not trilemma: The global financial cycle and monetary policy independence. NBER Working Paper, 21162. https://doi.org/10.3386/w21162
Rossana, R. J., Seater, J. J. (1995). Temporal aggregation and economic time series. Journal of Business \& Economic Statistics, 13(4), 441-451. Retrieved from https://doi. org/10.2307/1392389

Schuler, Y. S., Hiebert, P. P., Peltonen, T. A. (2015). Characterising the financial cycle: A multivariate and timevarying approach. ECB Working Paper, 1846. Retrieved from https://www.ecb.europa.eu/pub/pdf/scpwps/ecbwp1846. en.pdf

Silvestrini, A., Veredas, D. (2008). Temporal aggregation of univariate and multivariate time series models: A survey. Bank of Italy Working Paper, 685. Retrieved from https://www.bancaditalia.it/pubblicazioni/ temi-discussione/2008/2008-0685/en_tema_685.pdf 
APPENDIX A. TABLES

Table 2. Country Classification

\begin{tabular}{|c|c|c|}
\hline Advanced economies & Emerging markets & Financial centers ${ }^{10}$ \\
\hline Australia & Argentina & Belgium \\
\hline Austria & Brazil & Cyprus \\
\hline Canada & Bulgaria & Hong Kong S.A.R. of China \\
\hline Denmark & Chile & Ireland \\
\hline Finland & China & Luxembourg \\
\hline France & Colombia & Macao S.A.R. of China \\
\hline Germany & Costa Rica & Malta \\
\hline Greece & Croatia & Mauritius \\
\hline Israel & Czech Republic & Netherlands \\
\hline Italy & Estonia & Singapore \\
\hline Japan & Georgia & Switzerland \\
\hline New Zealand & Hungary & United Kingdom \\
\hline Norway & Iceland & \\
\hline Portugal & India & \\
\hline Spain & Indonesia & \\
\hline Sweden & Kazakhstan & \\
\hline \multirow[t]{17}{*}{ United States } & Korea & \\
\hline & Latvia & \\
\hline & Lithuania & \\
\hline & Malaysia & \\
\hline & Mexico & \\
\hline & Peru & \\
\hline & Philippines & \\
\hline & Poland & \\
\hline & Romania & \\
\hline & Russia & \\
\hline & Slovakia & \\
\hline & Slovenia & \\
\hline & South Africa & \\
\hline & Sri Lanka & \\
\hline & Thailand & \\
\hline & Turkey & \\
\hline & Ukraine & \\
\hline
\end{tabular}


Table 3. Descriptive Statistics

\begin{tabular}{|c|c|c|c|c|c|c|c|}
\hline & \multicolumn{3}{|c|}{ Inflows } & \multicolumn{3}{|c|}{ Outflows } & \multirow{2}{*}{$\begin{array}{l}\text { Correlation } \\
\text { in-outflows }\end{array}$} \\
\hline & Mean & Median & St. dev. & Mean & Median & St. dev. & \\
\hline \multicolumn{8}{|c|}{ Annual data } \\
\hline \multicolumn{8}{|c|}{ Aggregate flows } \\
\hline Full sample & 7.54 & 6.28 & 4.91 & 4.33 & 4.36 & 3.55 & 0.68 \\
\hline$A E$ & 9.44 & 9.51 & 8.09 & 7.89 & 7.56 & 6.82 & 0.90 \\
\hline EM & 6.15 & 5.76 & 4.53 & 2.90 & 2.89 & 2.65 & 0.63 \\
\hline \multicolumn{8}{|c|}{ Disaggregated flows } \\
\hline DI & 3.13 & 2.79 & 1.78 & 1.12 & 1.04 & 1.22 & 0.59 \\
\hline $\mathrm{DI}-\mathrm{AE}$ & 2.49 & 2.08 & 1.95 & 3.28 & 2.36 & 1.94 & 0.61 \\
\hline $\mathrm{DI}$ - EM & 3.33 & 3.12 & 1.61 & 0.90 & 0.83 & 0.88 & 0.51 \\
\hline PI D & 1.46 & 1.10 & 2.01 & 0.84 & 0.68 & 1.01 & 0.13 \\
\hline$P I D-A E$ & 3.32 & 3.19 & 3.52 & 2.26 & 2.13 & 2.35 & 0.38 \\
\hline PI D - EM & 1.05 & 0.80 & 1.68 & 0.40 & 0.35 & 0.72 & 0.04 \\
\hline PIE & 0.25 & 0.17 & 0.77 & 0.58 & 0.45 & 0.83 & 0.05 \\
\hline $\mathrm{PI} E-\mathrm{AE}$ & 0.70 & 0.70 & 1.28 & 1.40 & 1.38 & 1.27 & 0.22 \\
\hline $\mathrm{PI} E-\mathrm{EM}$ & 0.13 & 0.08 & 0.41 & 0.34 & 0.21 & 0.54 & 0.05 \\
\hline Ol & 2.03 & 1.28 & 3.23 & 1.24 & 1.35 & 2.31 & 0.39 \\
\hline $\mathrm{OI}-\mathrm{AE}$ & 2.13 & 2.01 & 5.06 & 1.75 & 1.64 & 4.04 & 0.66 \\
\hline $\mathrm{OI}$ - EM & 1.37 & 0.89 & 2.41 & 1.05 & 0.86 & 1.59 & 0.27 \\
\hline \multicolumn{8}{|c|}{ Quarterly data } \\
\hline \multicolumn{8}{|c|}{ Aggregate flows } \\
\hline Full sample & 7.66 & 6.38 & 7.90 & 4.17 & 4.26 & 6.05 & 0.62 \\
\hline$A E$ & 9.05 & 8.48 & 12.34 & 8.09 & 7.44 & 10.92 & 0.91 \\
\hline EM & 6.19 & 5.56 & 6.54 & 2.84 & 2.62 & 4.69 & 0.45 \\
\hline \multicolumn{8}{|c|}{ Disaggregated flows } \\
\hline DI & 3.11 & 2.93 & 2.68 & 1.13 & 0.87 & 1.77 & 0.41 \\
\hline $\mathrm{DI}-\mathrm{AE}$ & 2.53 & 2.11 & 3.83 & 3.32 & 2.81 & 3.47 & 0.49 \\
\hline DI - EM & 3.38 & 3.10 & 2.49 & 0.89 & 0.68 & 1.48 & 0.28 \\
\hline PI D & 1.47 & 0.95 & 3.65 & 0.84 & 0.69 & 1.77 & 0.11 \\
\hline PI D - AE & 3.35 & 2.91 & 6.58 & 2.27 & 1.67 & 3.58 & 0.28 \\
\hline PI D - EM & 1.06 & 0.36 & 2.72 & 0.40 & 0.32 & 1.36 & 0.06 \\
\hline PIE & 0.25 & 0.21 & 1.36 & 0.60 & 0.49 & 1.16 & 0.04 \\
\hline $\mathrm{PI} E-\mathrm{AE}$ & 0.71 & 0.65 & 2.33 & 1.49 & 1.35 & 2.06 & 0.10 \\
\hline PI E - EM & 0.14 & 0.06 & 0.76 & 0.33 & 0.17 & 0.77 & 0.04 \\
\hline OI & 1.96 & 1.38 & 4.99 & 1.26 & 1.09 & 4.60 & 0.35 \\
\hline $\mathrm{OI}-\mathrm{AE}$ & 2.25 & 1.82 & 9.30 & 1.83 & 1.77 & 8.72 & 0.65 \\
\hline OI - EM & 1.32 & 0.96 & 4.28 & 1.06 & 0.89 & 3.77 & 0.26 \\
\hline
\end{tabular}

*Values represent medians of means, medians, and standard deviations over individual countries.

${ }^{* *} \mathrm{AE}$ - advanced economies; EM - emerging markets; DI - direct investment; PI D - portfolio investment in debt; PI E - portfolio investment in equity; $\mathrm{Ol}$ - other investment. 
Table 4. Within-Year Variation in Quarterly Capital Flows

\begin{tabular}{l|c|c|c|c}
\hline & \multicolumn{2}{|c|}{ Inflows } & \multicolumn{2}{c}{ Outflows } \\
\hline & Raw data & Moving average & Raw data & Moving average \\
\hline Aggregate flows & 4.55 & 1.59 & 3.54 & 1.07 \\
Direct investment & 1.53 & 0.53 & 0.95 & 0.40 \\
Portfolio debt & 2.24 & 0.86 & 1.39 & 0.47 \\
Portfolio equity & 0.57 & 0.24 & 0.57 & 0.21 \\
\hline Other investment & 3.50 & 1.13 & 3.54 & 1.07 \\
\hline
\end{tabular}

*Values represent medians.

Table 5. Unweighted Aaverages of Bilateral Correlation Coefficients* of Capital Outflows and Percentages of Significant Correlations**

\begin{tabular}{|c|c|c|c|c|c|c|c|c|c|c|}
\hline \multicolumn{11}{|c|}{ Annual } \\
\hline & \multicolumn{2}{|c|}{ Aggregate flows } & \multicolumn{2}{|c|}{ Direct investment } & \multicolumn{2}{|c|}{$\begin{array}{c}\text { Portfolio } \\
\text { investment: Equity }\end{array}$} & \multicolumn{2}{|c|}{$\begin{array}{c}\text { Portfolio } \\
\text { investment: Debt }\end{array}$} & \multicolumn{2}{|c|}{ Other investment } \\
\hline & Corr. & Sign. & Corr. & Sign. & Corr. & Sign. & Corr. & Sign. & Corr. & Sign. \\
\hline Full sample & 15.0 & $18 \%$ & 8.9 & $11 \%$ & 19.8 & $23 \%$ & 6.6 & $12 \%$ & 8.4 & $15 \%$ \\
\hline$A E$ & 22.5 & $21 \%$ & 11.5 & $12 \%$ & 21.8 & $36 \%$ & 11.4 & $15 \%$ & 17.0 & $27 \%$ \\
\hline EM & 11.2 & $16 \%$ & 8.1 & $12 \%$ & 21.3 & $24 \%$ & 4.1 & $13 \%$ & 5.3 & $14 \%$ \\
\hline \multicolumn{11}{|c|}{ Quarterly } \\
\hline & \multicolumn{2}{|c|}{ Aggregate flows } & \multicolumn{2}{|c|}{ Direct investment } & \multicolumn{2}{|c|}{$\begin{array}{c}\text { Portfolio } \\
\text { investment: Equity }\end{array}$} & \multicolumn{2}{|c|}{$\begin{array}{c}\text { Portfolio } \\
\text { investment: Debt }\end{array}$} & \multicolumn{2}{|c|}{ Other investment } \\
\hline & Corr. & Sign. & Corr. & Sign. & Corr. & Sign. & Corr. & Sign. & Corr. & Sign. \\
\hline Full sample & 8.1 & $21 \%$ & 3.2 & $14 \%$ & 10.2 & $27 \%$ & 4.0 & $15 \%$ & 4.4 & $16 \%$ \\
\hline $\mathrm{AE}$ & 13.1 & $27 \%$ & 3.2 & $16 \%$ & 14.1 & $49 \%$ & 6.9 & $16 \%$ & 9.6 & $24 \%$ \\
\hline EM & 5.8 & $19 \%$ & 3.4 & $17 \%$ & 9.1 & $23 \%$ & 2.5 & $13 \%$ & 2.8 & $13 \%$ \\
\hline
\end{tabular}

*Scaled by 100 .

${ }^{* *}$ Corr. - correlation coefficient, Sign. - percentage of correlation coefficients that are significant; AE - advanced economies, EM - emerging markets.

Table 6. Cyclical Properties of Capital Flows*

\begin{tabular}{|c|c|c|c|c|c|c|c|c|c|c|}
\hline & \multicolumn{2}{|c|}{ Aggregate flows } & \multicolumn{2}{|c|}{ Direct investment } & \multicolumn{2}{|c|}{$\begin{array}{c}\text { Portfolio } \\
\text { investment: Equity }\end{array}$} & \multicolumn{2}{|c|}{$\begin{array}{c}\text { Portfolio } \\
\text { investment: Debt }\end{array}$} & \multicolumn{2}{|c|}{ Other investmen } \\
\hline & In. & Out. & In. & Out. & In. & Out. & In. & Out. & In. & Out. \\
\hline Expansion & 8.7 & 8.5 & 7.6 & 8.7 & 7.9 & 9.6 & 8.4 & 8.9 & 9.2 & 8.2 \\
\hline$A E$ & 7.8 & 7.9 & 7.5 & 8.6 & 7.1 & 8.8 & 8.7 & 7.7 & 8.9 & 7.9 \\
\hline EM & 9.2 & 8.8 & 7.7 & 8.8 & 8.4 & 10.1 & 8.1 & 9.5 & 9.3 & 8.4 \\
\hline Contraction & 6.9 & 6.7 & 7.8 & 7.4 & 8.1 & 7.1 & 6.7 & 7.6 & 6.8 & 6.8 \\
\hline$A E$ & 6.4 & 6.5 & 7.9 & 8.2 & 6.9 & 7.1 & 7.2 & 7.0 & 6.6 & 7.0 \\
\hline EM & 7.1 & 6.8 & 7.8 & 7.1 & 8.8 & 7.0 & 6.4 & 7.9 & 7.0 & 6.7 \\
\hline
\end{tabular}

${ }^{*} \mathrm{AE}$ - expansion/contraction of capital flows to/from advanced economies; EM - expansion/contraction of capital flows to/from emerging markets; In. - inflows, Out. - outflows. 
Table 7. Capital Flows with a Significant Degree of Concordance*

\begin{tabular}{|c|c|c|c|c|c|}
\hline \multicolumn{6}{|c|}{ Aggregate flows } \\
\hline & $\begin{array}{c}\% \text { of variance } \\
\text { explained }\end{array}$ & $\begin{array}{c}\text { Concordance } \\
\text { index }\end{array}$ & & $\begin{array}{c}\% \text { of variance } \\
\text { explained }\end{array}$ & $\begin{array}{c}\text { Concordance } \\
\text { index }\end{array}$ \\
\hline MY: outflow & $33 \%$ & 0.89 & TR: inflow & $22 \%$ & 0.71 \\
\hline US: outflow & $43 \%$ & 0.88 & BR: outflow & $11 \%$ & 0.71 \\
\hline US: inflow & $47 \%$ & 0.86 & AT: inflow & $14 \%$ & 0.70 \\
\hline IL: outflow & $24 \%$ & 0.86 & DK: inflow & $7 \%$ & 0.70 \\
\hline SE: outflow & $18 \%$ & 0.82 & HU: inflow & $0 \%$ & 0.70 \\
\hline AU: inflow & $13 \%$ & 0.81 & BG: outflow & $2 \%$ & 0.70 \\
\hline SI: outflow & $38 \%$ & 0.81 & CL: outflow & $24 \%$ & 0.70 \\
\hline IN: inflow & $50 \%$ & 0.80 & HR: outflow & $0 \%$ & 0.70 \\
\hline LV: outflow & $16 \%$ & 0.80 & KR: inflow & $41 \%$ & 0.69 \\
\hline IL: inflow & $12 \%$ & 0.79 & IT: outflow & $22 \%$ & 0.69 \\
\hline MY: inflow & $37 \%$ & 0.79 & CN: outflow & $12 \%$ & 0.69 \\
\hline KR: outflow & $55 \%$ & 0.79 & IS: outflow & $24 \%$ & 0.69 \\
\hline FR: inflow & $33 \%$ & 0.77 & PT: inflow & $7 \%$ & 0.69 \\
\hline SI: inflow & $35 \%$ & 0.77 & BR: inflow & $36 \%$ & 0.69 \\
\hline TH: outflow & $17 \%$ & 0.77 & GE: inflow & $15 \%$ & 0.69 \\
\hline LV: inflow & $39 \%$ & 0.76 & FI: inflow & $2 \%$ & 0.68 \\
\hline CN: inflow & $36 \%$ & 0.75 & CO: outflow & $0 \%$ & 0.68 \\
\hline SE: inflow & $17 \%$ & 0.74 & PL: outflow & $32 \%$ & 0.68 \\
\hline AR: inflow & $21 \%$ & 0.74 & NZ: inflow & $30 \%$ & 0.67 \\
\hline FR: outflow & $36 \%$ & 0.73 & AT: outflow & $16 \%$ & 0.67 \\
\hline EE: inflow & $30 \%$ & 0.71 & IT: inflow & $16 \%$ & 0.65 \\
\hline LK: inflow & $1 \%$ & 0.71 & MX: inflow & $15 \%$ & 0.64 \\
\hline RO: inflow & $14 \%$ & 0.71 & ZA: outflow & $5 \%$ & 0.63 \\
\hline
\end{tabular}

*First two letters indicate country using ISO 3166-1 alpha-2 code. 
Table 8. Capital Flows with a Significant Degree of Concordance*

\begin{tabular}{|c|c|c|c|c|c|}
\hline \multicolumn{6}{|c|}{ Quarterly flows } \\
\hline & $\begin{array}{c}\% \text { of variance } \\
\text { explained }\end{array}$ & $\begin{array}{c}\text { Concordance } \\
\text { index }\end{array}$ & & $\begin{array}{c}\% \text { of variance } \\
\text { explained }\end{array}$ & $\begin{array}{c}\text { Concordance } \\
\text { index }\end{array}$ \\
\hline NO: PI E inflow & $29 \%$ & 0.87 & US: PI D outflow & $36 \%$ & 0.69 \\
\hline IL: OI outflow & $37 \%$ & 0.86 & AT: PI E inflow & $21 \%$ & 0.69 \\
\hline US: PI E outflow & $10 \%$ & 0.85 & CR: DI inflow & $0 \%$ & 0.69 \\
\hline HU: PI D inflow & $15 \%$ & 0.83 & CR: PI D outflow & $5 \%$ & 0.69 \\
\hline DE: PI D outflow & $30 \%$ & 0.82 & BG: Ol outflow & $0 \%$ & 0.69 \\
\hline DE: PI E outflow & $22 \%$ & 0.82 & BR: Ol outflow & $7 \%$ & 0.69 \\
\hline KZ: PI D inflow & $6 \%$ & 0.81 & TH: Ol outflow & $8 \%$ & 0.69 \\
\hline CL: OI outflow & $27 \%$ & 0.81 & ES: DI outflow & $2 \%$ & 0.68 \\
\hline HU: PI D outflow & $1 \%$ & 0.77 & AT: PI D inflow & $0 \%$ & 0.68 \\
\hline BR: PI E inflow & $49 \%$ & 0.77 & AU: PI D inflow & $35 \%$ & 0.68 \\
\hline CZ: PI E outflow & $10 \%$ & 0.77 & FI: PI E inflow & $2 \%$ & 0.68 \\
\hline IN: PI inflow & $46 \%$ & 0.76 & GR: PI E inflow & $10 \%$ & 0.68 \\
\hline CN: Ol inflow & $21 \%$ & 0.76 & FR: PI E outflow & $11 \%$ & 0.68 \\
\hline DE: DI outflow & $8 \%$ & 0.75 & NO: OI inflow & $1 \%$ & 0.68 \\
\hline US: DI outflow & $14 \%$ & 0.75 & MY: DI inflow & $6 \%$ & 0.68 \\
\hline IT: PI E inflow & $6 \%$ & 0.75 & SI: PI D inflow & $26 \%$ & 0.68 \\
\hline DK: PI E outflow & $22 \%$ & 0.75 & EE: PI E outflow & $12 \%$ & 0.68 \\
\hline FI: PI E outflow & $38 \%$ & 0.75 & MY: PI E outflow & $3 \%$ & 0.68 \\
\hline IT: PI E outflow & $32 \%$ & 0.75 & KR: Ol inflow & $23 \%$ & 0.68 \\
\hline IL: OI inflow & $15 \%$ & 0.75 & KR: OI outflow & $2 \%$ & 0.68 \\
\hline US: OI inflow & $25 \%$ & 0.75 & AU: PI D inflow & $21 \%$ & 0.67 \\
\hline EE: DI outflow & $20 \%$ & 0.75 & CA: Ol inflow & $1 \%$ & 0.67 \\
\hline TR: DI outflow & $1 \%$ & 0.75 & AT: OI outflow & $2 \%$ & 0.67 \\
\hline NZ: PI D inflow & $32 \%$ & 0.74 & SE: Ol outflow & $0 \%$ & 0.67 \\
\hline US: PI E inflow & $18 \%$ & 0.74 & BR: DI inflow & $0 \%$ & 0.67 \\
\hline AT: PI E outflow & $18 \%$ & 0.74 & SI: PI D inflow & $4 \%$ & 0.67 \\
\hline AU: PI E outflow & $44 \%$ & 0.74 & BG: PI D outflow & $1 \%$ & 0.67 \\
\hline CA: PI E outflow & $7 \%$ & 0.74 & CN: PI D outflow & $2 \%$ & 0.67 \\
\hline AU: Ol outflow & $1 \%$ & 0.74 & AR: PI E outflow & $18 \%$ & 0.67 \\
\hline LV: DI inflow & $23 \%$ & 0.74 & HU: PI E outflow & $7 \%$ & 0.67 \\
\hline HR: PI E outflow & $15 \%$ & 0.74 & MY: Ol outflow & $20 \%$ & 0.67 \\
\hline US: PI D inflow & $19 \%$ & 0.73 & IL: DI outflow & $0 \%$ & 0.65 \\
\hline SE: PI D outflow & $37 \%$ & 0.73 & JP: PI E inflow & $20 \%$ & 0.65 \\
\hline FR: OI inflow & $25 \%$ & 0.73 & BR: PI D inflow & $15 \%$ & 0.65 \\
\hline US: OI outflow & $26 \%$ & 0.73 & LT: PI D inflow & 6 & 0.65 \\
\hline PL: DI inflow & $17 \%$ & 0.73 & TR: OI inflow & $9 \%$ & 0.65 \\
\hline TR: PI D inflow & $9 \%$ & 0.73 & FI: PI D outflow & $6 \%$ & 0.64 \\
\hline CN: PI E inflow & $3 \%$ & 0.73 & DE: PI E inflow & $3 \%$ & 0.64 \\
\hline IN: Ol inflow & $11 \%$ & 0.73 & SE: PI E outflow & $2 \%$ & 0.64 \\
\hline LK: OI inflow & $6 \%$ & 0.73 & NZ: OI outflow & $1 \%$ & 0.64 \\
\hline SE: DI inflow & $0 \%$ & 0.71 & PL: PI E inflow & $10 \%$ & 0.64 \\
\hline FR: OI outflow & $16 \%$ & 0.71 & BR: PI E outflow & $1 \%$ & 0.64 \\
\hline BR: DI outflow & $1 \%$ & 0.71 & HR: OI outflow & $1 \%$ & 0.64 \\
\hline CO: PI D outflow & $8 \%$ & 0.71 & ES: PI E inflow & $2 \%$ & 0.63 \\
\hline KZ: PI E outflow & $12 \%$ & 0.71 & IT: PI D inflow & $6 \%$ & 0.62 \\
\hline LV: PI E outflow & $12 \%$ & 0.71 & KR: DI inflow & $0 \%$ & 0.62 \\
\hline FR: PI E inflow & $5 \%$ & 0.70 & DK: DI inflow & $0 \%$ & 0.61 \\
\hline JP: OI outflow & $19 \%$ & 0.70 & SK: PI D outflow & $0 \%$ & 0.61 \\
\hline EE: DI inflow & $12 \%$ & 0.70 & PT: DI inflow & $0 \%$ & 0.60 \\
\hline LV: DI outflow & $13 \%$ & 0.70 & GR: OI outflow & $4 \%$ & 0.39 \\
\hline SI: PI E inflow & $3 \%$ & 0.70 & FI: PI D inflow & $0 \%$ & 0.36 \\
\hline LT: PI E outflow & $18 \%$ & 0.70 & NZ: PI E inflow & $1 \%$ & 0.36 \\
\hline CZ: Ol inflow & $1 \%$ & 0.70 & ID: OI outflow & $0 \%$ & 0.36 \\
\hline EE: OI inflow & $24 \%$ & 0.70 & AR: OI outflow & $0 \%$ & 0.31 \\
\hline SI: OI outflow & $8 \%$ & 0.70 & SK: DI inflow & $5 \%$ & 0.23 \\
\hline ES: PI D inflow & $18 \%$ & 0.69 & & & \\
\hline
\end{tabular}

*First two letters indicate country using ISO 3166-1 alpha-2 code.

** DI - direct investment; PI D - portfolio investment in debt; PI E - portfolio investment in equity; OI - other investment. 


\section{APPENDIX B. FIGURES}

(a) Global Factors in Annual Data

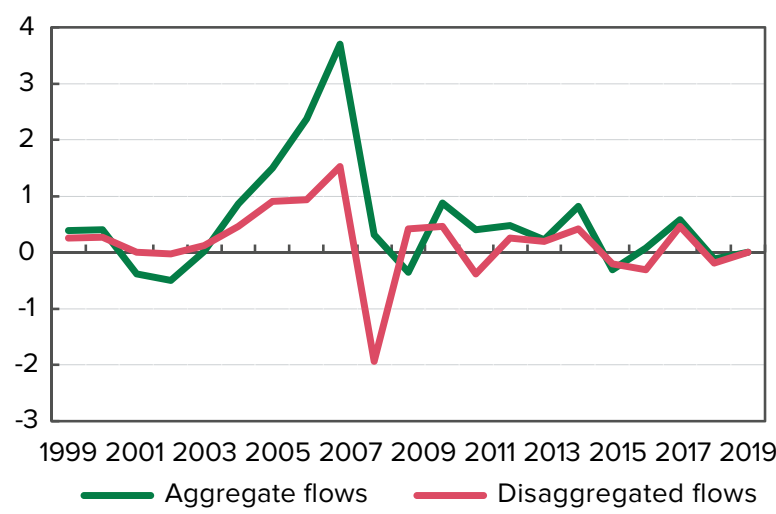

(c) Global Factors in Aggregate Flows

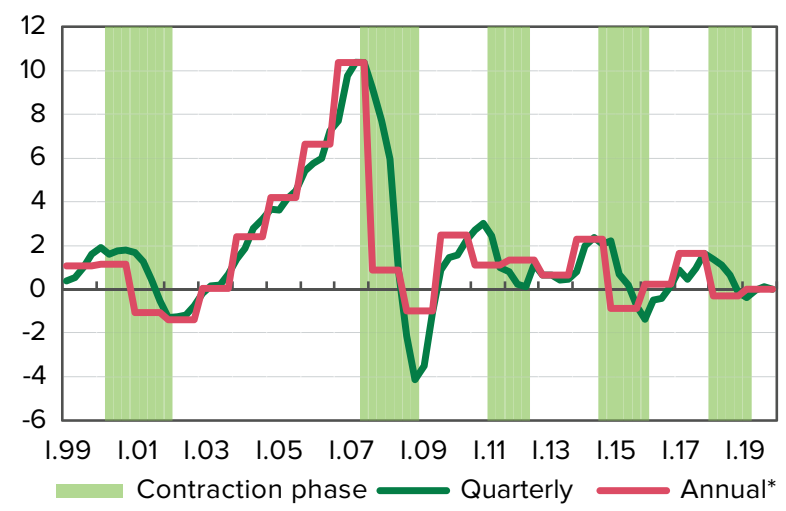

Figure 7. Global Factors in Data

*Scaled by 2.8 and 4.3 , respectively, for visibility.

(a) Annual Aggregated Flows

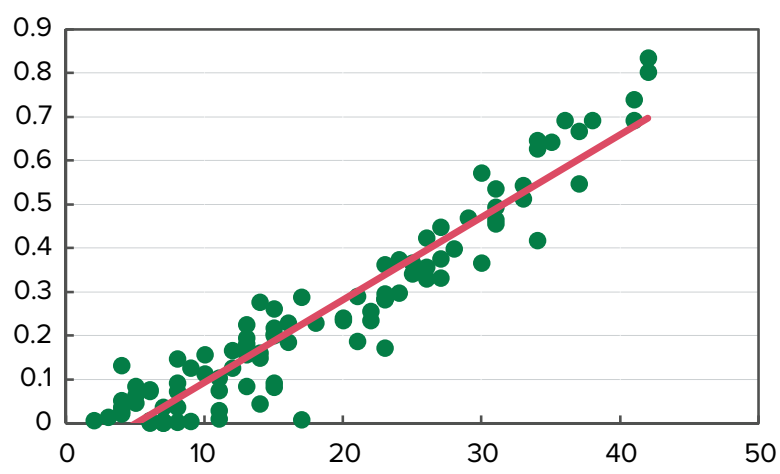

(c) Quarterly Aggregated Flows

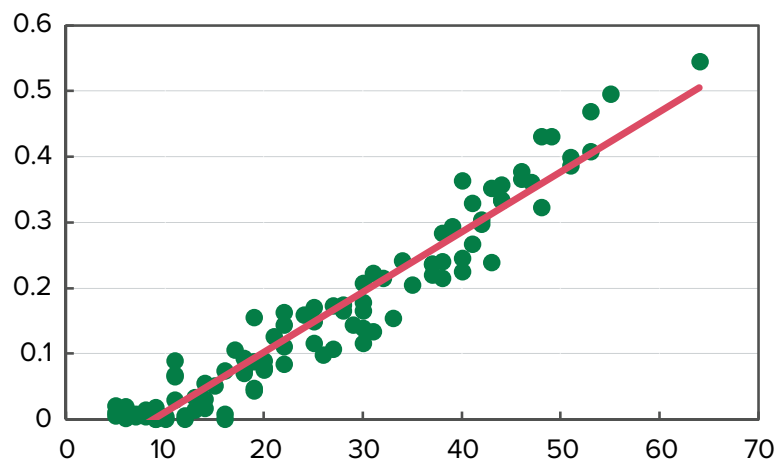

(b) Global Factors in Quarterly Data

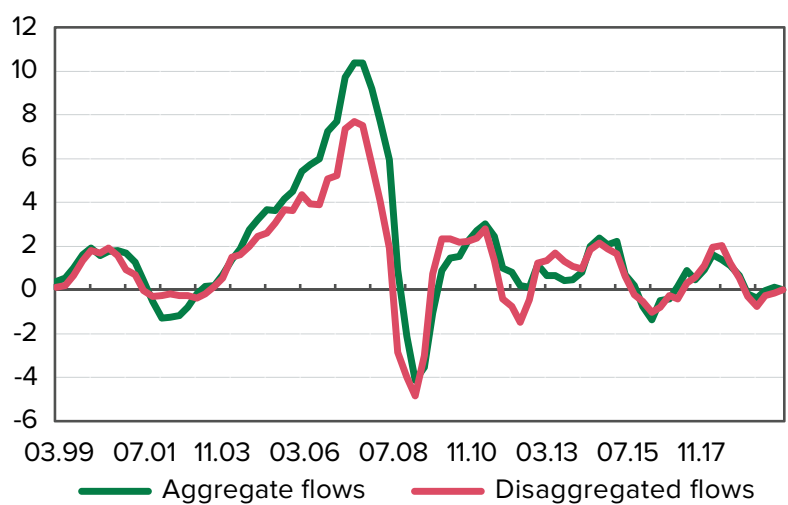

(d) Global Factors in Disaggregated Flows

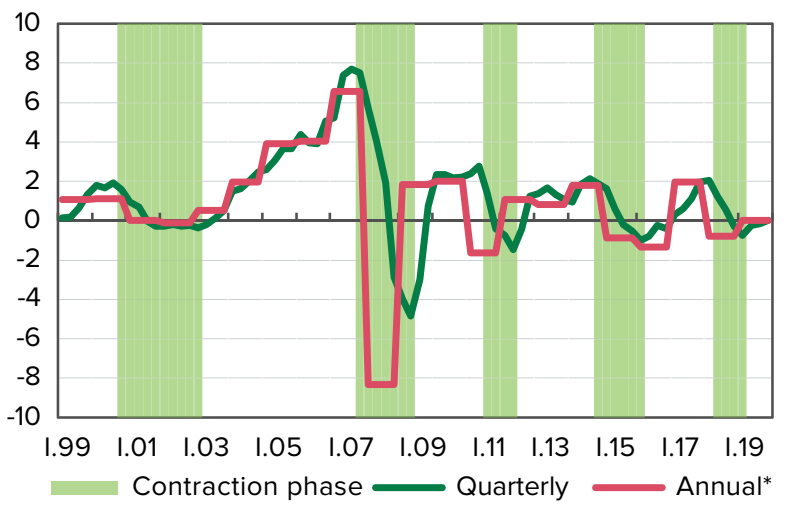

(b) Annual Disaggregated Flows

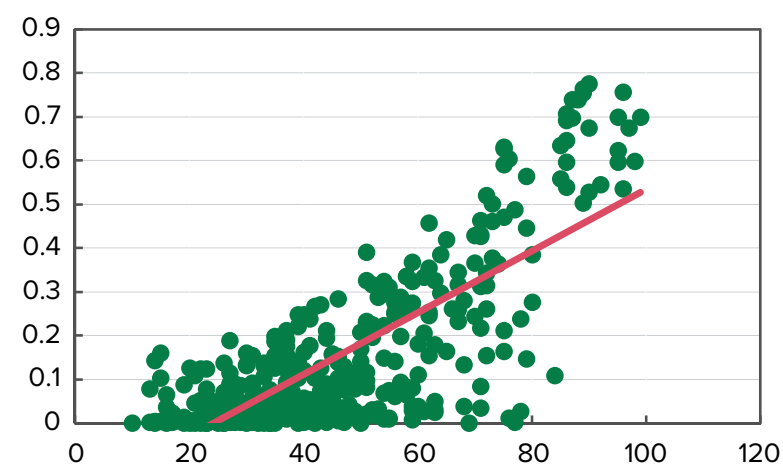

(d) Quarterly Disaggregated Flows

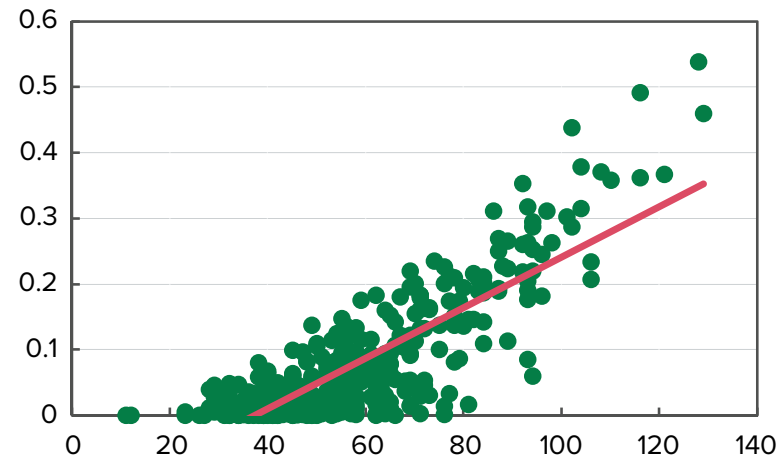

Figure 8. Linear Relationship Between the Share of Variance Explained and Number of Significant Pairwise Correlations*

*Dots represent capital flows, each particular flow can have 99 pairwise correlations in aggregated data and 395 pairwise correlations in disaggregated data. 


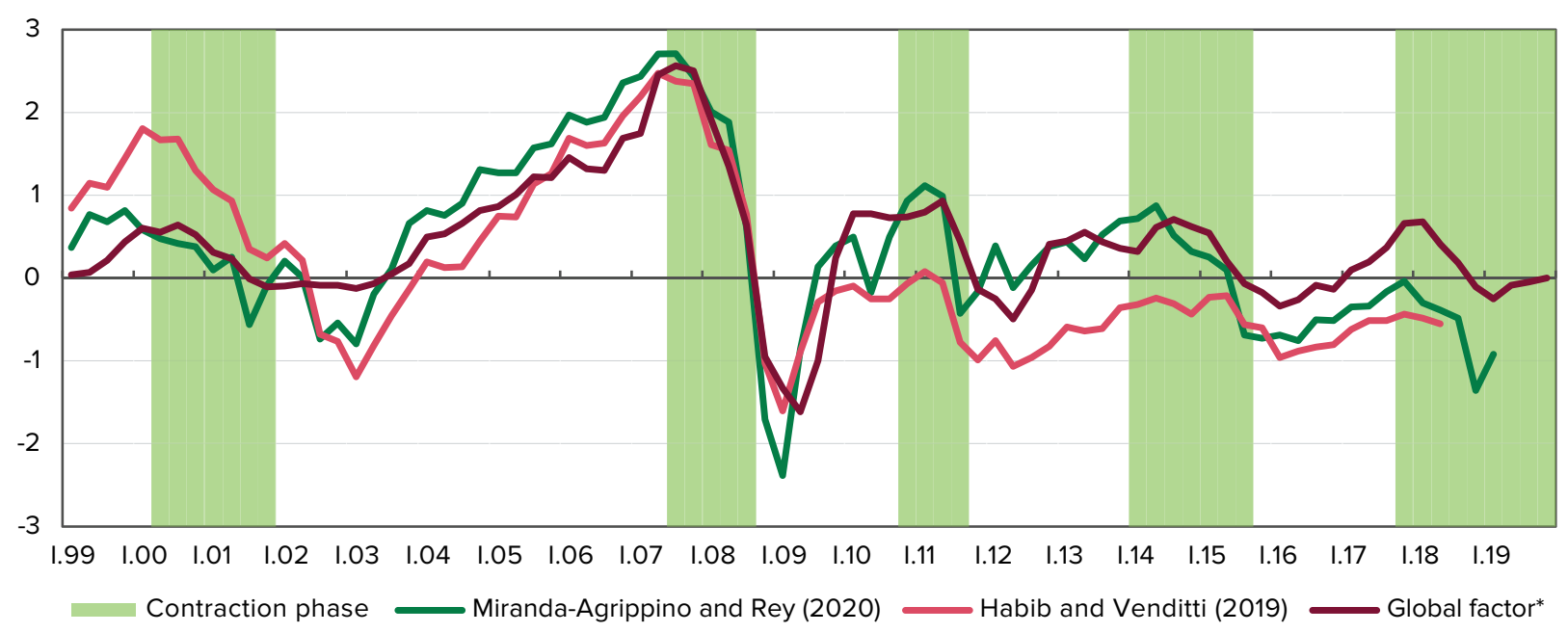

Figure 9. Estimates of the Global Financial Cycle

* The global factor from disaggregated flows; scaled by $1 / 3$ for visibility.

(a) Concordance Indices for Aggregate Flows

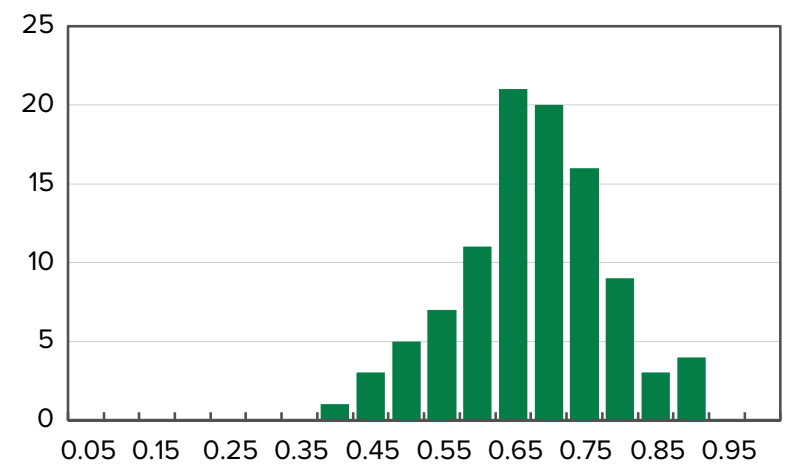

(b) Concordance Indices for Disaggregated Flows

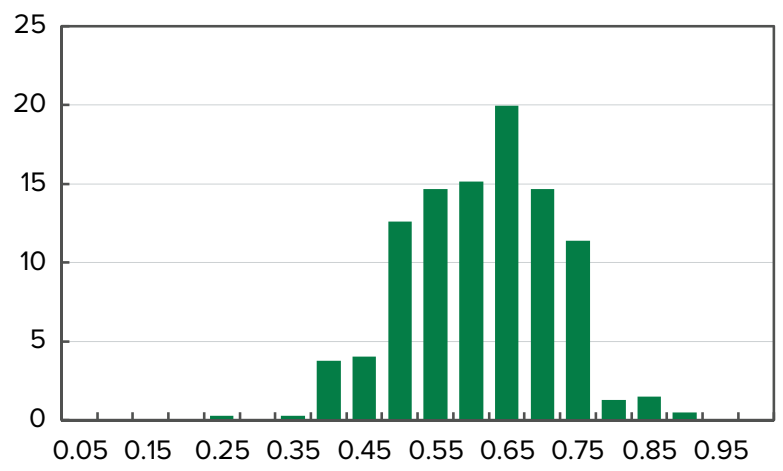

Figure 10. Distributions of Concordance Indices, Calculated using Aggregate Capital Flows (left) and Capital Flows, Disaggregated by Type (right) 
(a) Global Factor

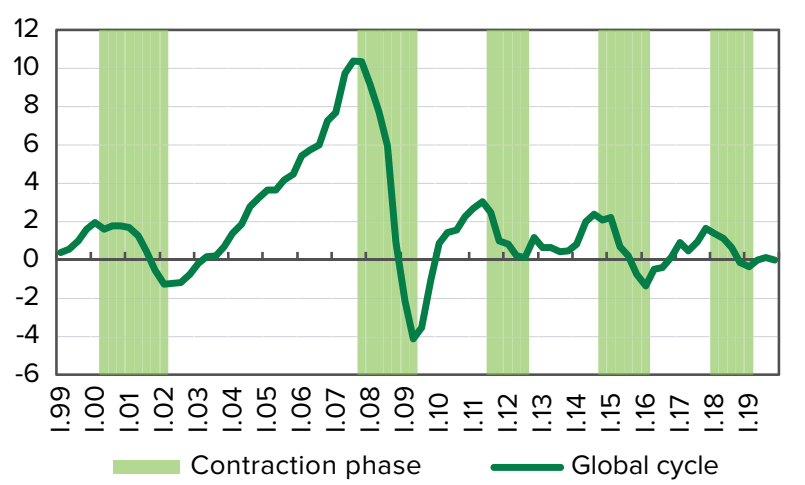

(c) Capital Inflows in Hungary

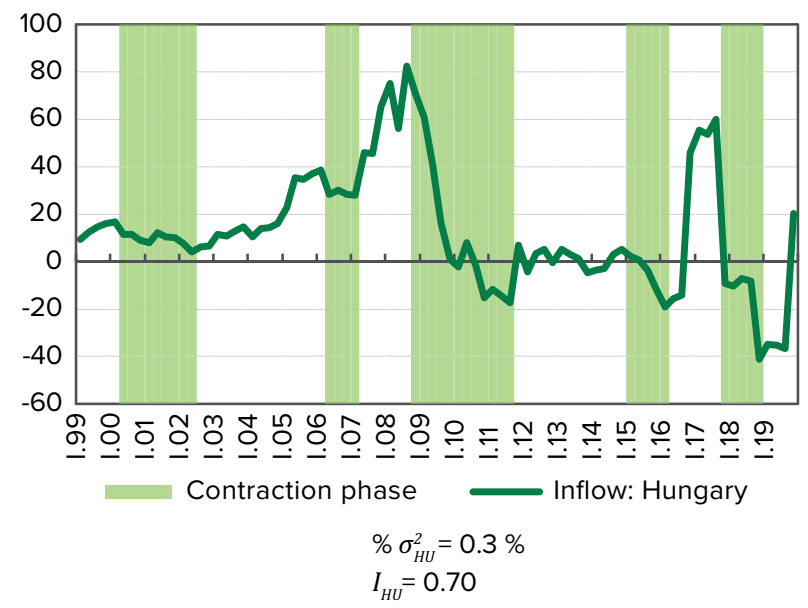

(b) Capital Outflows from Republic of Korea

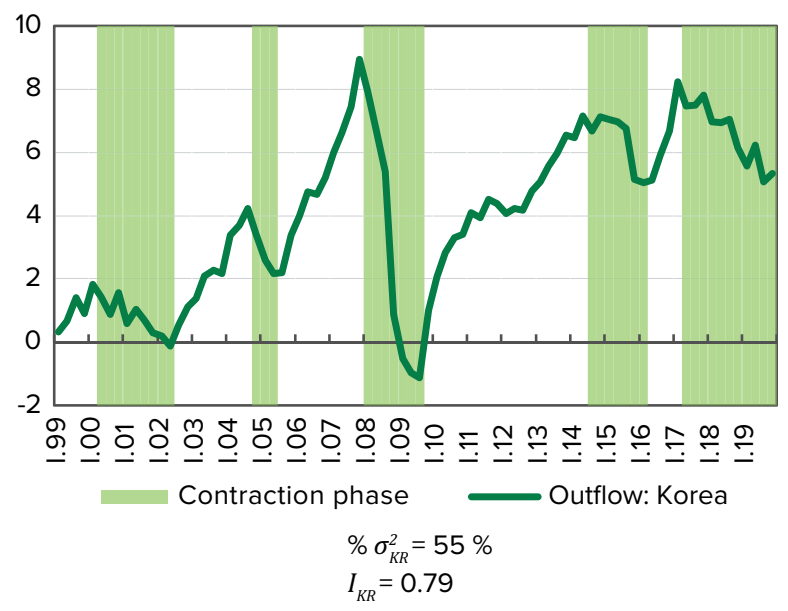

(d) Capital Inflows in Peru

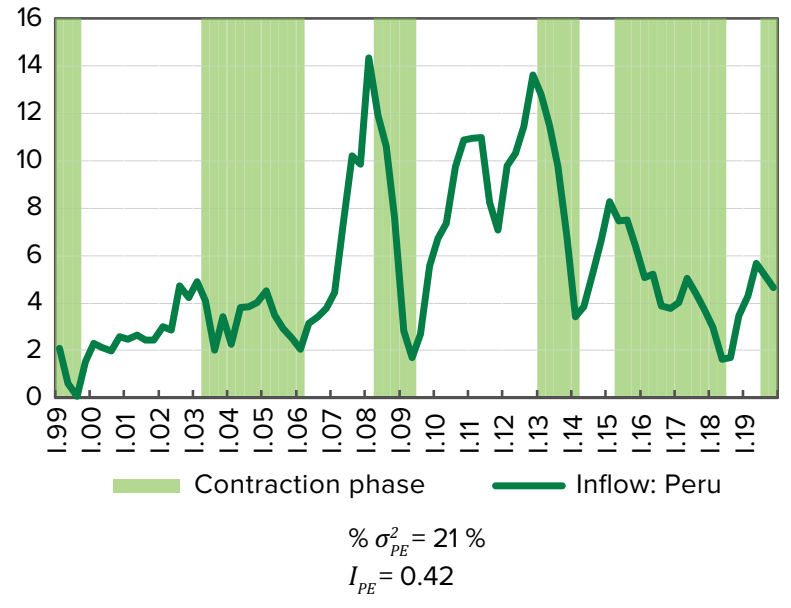

Figure 11. Cyclical Pattern is Global Factor and Selected Capital Flows* $* \% \sigma_{i}^{2}$-share of variance explained; $I_{i}-$ concordance index. 


\title{
PREDICTING BANK \\ DEFAULTS IN UKRAINE: A MACRO-MICRO PERSPECTIVE
}

\author{
${ }^{a}$ National Bank of Ukraine \\ E-mail: anatolii.hlazunov@bank.gov.ua \\ ${ }^{b}$ Kyiv School of Economics \\ E-mail: verchenko@kse.org.ua
}

ANATOLII HLAZUNOV ${ }^{a}$, OLESIA VERCHENKO ${ }^{b}$

\begin{abstract}
This paper develops an early warning model (EWM) for a micro-macro analysis of individual and aggregated bank vulnerabilities in Ukraine. We applied a stepwise logit for predicting defaults at Ukrainian banks based on a panel bank and macro-level data from Q1 2009 to Q3 2019. Next, we aggregated individual bank default probabilities to provide policymakers with information about the general state of the financial system with a particular focus on generating a signal for countercyclical capital buffer (CCB) activation. Our key findings suggest that the probability of default exceeding $11 \%$ could signal about a vulnerable state in a bank and, in the aggregated model, in a financial system in general. The aggregated model successfully issues an out-of-sample signal of a systemic crisis four periods ahead of the start of the 2014-2015 turmoil.
\end{abstract}

JEL Codes E44, E58, G01

Keywords early warning models, bank default probability, countercyclical capital buffer

\section{INTRODUCTION}

In 2015-2017, Ukraine went through a period of a largescale banking system "cleaning", the outcome of which was a decrease in the number of commercial banks from 163 at the beginning of 2015 to 82 at the end of 2017. As a result, the Ukrainian banking system emerged much more resilient to external and internal shocks, the evidence of which is in its remarkable stability during the current turmoil of the COVID-19 crisis.

The scale of bank closures over such a short period was probably unprecedented in recent economic history. There were also remarkable differences in their causes. Some banks were unwilling or unable to disclose their ownership structure in line with the new banking system transparency requirements. The National Bank of Ukraine (NBU) revoked the licenses of 24 such banks. Sixty-eight banks left the market due to an inability to comply with capital requirements and/or other regulated liquidity and financial stability ratios. Some banks experienced financial distress (having to restructure their NBU loans) but managed to stay in operation.

From an academic standpoint, this data provide very rich grounds for empirical analyses of individual bank responses to the new environment and their aggregate effect on the banking system. This is in contrast to numerous existing studies for other countries, which almost uniformly point out that bank distress events are quite rare (e.g., Betz et al, 2014, for the European Union, Rosa and Gartner, 2018, for Brazil, etc.).
While bank closures related to noncompliance with transparency (financial monitoring) requirements deserve a separate in-depth analysis, the focus of this paper is on distress events related to capital and other financial requirements. Though the period of 2015-2017 provides a particularly interesting case study on banking system reform, to make our conclusions more general, we decided to look beyond this period and considered all available data on bank distress events in Ukraine starting from Q1 2009. This also gained us additional degrees of freedom to produce forecasts and test their accuracy.

More specifically, the goal of this study is to conduct a micro-macro analysis of individual and aggregated bank vulnerabilities in Ukraine. For this, we first estimate a banklevel early warning model containing both bank-specific and macroeconomic factors. Early warning models for bank distress events are an important tool for the banking supervision framework as defined by Pillar 2 of the Basel recommendations developed by the Basel Committee on Banking Supervision (2010) to strengthen the regulation, supervision and risk management of banks.

While such models can be used to derive probabilities of individual banks being in vulnerable states, they can also be used to provide policymakers with information on the general state of the financial system, and to signal for a call to action. This is the second step of our analysis: to aggregate bank-level results with the purpose of detecting a buildup of systemic imbalances and possibly intervening with additional macroprudential measures. In this regard, we attempt to apply an aggregation methodology to our baseline 
bank-level model as a framework for operationalizing the countercyclical capital buffer (CCB) in Ukraine.

The CCB is a part of Basel III - a new iteration of the Basel framework in response to the financial crisis of 2007-09. In 2015, the NBU started implementing Basel III recommendations in Ukraine: it performed extensive stress testing and then gradually introduced new requirements to capital, liquidity and other ratios (National Bank of Ukraine, 2015). It also announced its intent to launch several new capital buffers: a CCB, a capital buffer for systemically important banks, a systemic risk buffer and a concentration buffer.

The CCB is an additional capital requirement called to counteract the procyclical behavior of the banking system, which tends to exhibit excessive credit growth during the expansionary phase of business cycles and disproportionate credit contractions during recessions. A gradually increasing CCB requirement during business cycle expansion is expected to discourage banks from issuing too many new loans, and a declining CCB requirement during recessions is expected to stimulate banks to transform their now excessive reserves into new loans, which is exactly what an economy needs to dampen the cycle. Excessive credit growth is only one of many possible reasons for a buildup of systemic imbalances in the banking system, and the CCB buffer's role is to counteract all such buildups, as well as to provide an additional layer of protection against them. The BCBS recommends accumulating an additional cushion of risk-weighted assets in a range of $0 \%$ to $2.5 \%$ of capital adequacy ratio as a CCB. The key question for policymakers is to identify the right moment to activate ("turn on") and deactivate ("turn off") the CCB requirement so that its effect is indeed stabilizing. In addition, banks should get sufficient advance notice about CCB activation for it not to be overly disruptive to their operations. Early warning models can potentially serve this purpose as they could help to build a system of indicators to signal the accumulation of such systemic risk.

To summarize, the main research questions of this paper are:

1) What bank-specific and macro-related variables can predict bank distress events in Ukraine?

2) What is the explanatory power of such early warning models for individual bank performance and on the aggregate level (in sample)?

3) What is the forecasting power of such early warning models for individual bank performance and on the aggregate level (out of sample)?

To answer these questions, we used an unbalanced panel of quarterly bank-level data for the period Q1 2009-Q3 2019 to estimate a logit model for the probability of an individual bank being in a vulnerable state in the future, using a set of bank-specific and macroeconomic variables. As a robustness check, we did all estimations both with and without "distorting" banks (banks that exited the market due to non-compliance with reporting requirements, rather than capital adequacy issues).

For meaningful comparisons of model predictions with actual data, we then needed to set a value for the threshold parameter $(\theta)$, such that if the model-based probability of a bank going into a vulnerable state exceeds $\theta$, the model is said to produce a (positive) signal, which can then be easily compared to the actual state of things ( 1 for crisis, 0 for no crisis). Following the literature, we set this parameter in such a way that the in-sample "relative usefulness" of the model is maximized. The relative usefulness measure can be used to evaluate both the in-sample and the out-of-sample performance of our model. A set of out-of-sample forecasts of future vulnerabilities was generated by the model on an expanding-window basis.

\section{Our main results were the following.}

1. The best model produces a signal (of 1 or 0 ), whose precision is $62.6 \%$ higher than a no signal case (always either 1 or 0 ), as measured by the relative usefulness indicator. This is comparable to the findings of other authors for other countries. Therefore, we used this model for aggregation, and an algorithm based on mean probabilities of individual bank defaults can indeed predict a banking crisis four periods ahead of the start of a crisis in real-time.

2. The relative usefulness of our preferred model in out-of-sample predictions is quite low, which is consistent with other studies. In particular, the model tends to produce distress signals during tranquil periods, which is consistent with the typical for this literature assumption that a central bank is much more tolerant to false positive bank default signals than to false negative ones.

3. Our analysis suggests that the CCB should be activated when the mean probability of bank default exceeds $11 \%$. However, this figure needs extra validation since the data period -for which model-produced forecasts are available does not contain any crises.

\section{LITERATURE REVIEW}

Early warning models became the main tool for the analysis of financial distress in the late 1970s. Martin (1977) was among the first to use a logistic modelling approach in this context. His model included such explanatory variables as financial ratios for asset quality, capital adequacy, and earnings. Barth et al. (1985) complemented this model with liquidity ratios, and Thomson (1992) added management quality as one more predictive factor. Not incidentally, these five variables are constituents of the CAMEL (Capital adequacy, Asset quality, Management, Earning and Liquidity) classification system introduced by banking regulators in the U.S. in 1979 as a tool for evaluating the strength of financial institutions. ${ }^{1}$ Numerous other authors (e.g., Sinkey, 1975; Altman, 1977; Arena, 2008; Cole \& White, 2012) have also used these variables in their studies, though some additional variables have also been suggested in the literature, e.g., market prices of financial instruments (Flannery, 1998; Bongini et al., 2002) and deposit rates (Kraft \& Galac, 2007).

Most of these studies focused on U.S. bank closures, though other countries have received some attention as well. For example, Poghosyan and Čihák (2009), Cipollini and Fiordelisi (2012), and Betz et al. (2013) considered bank defaults in the European Union; Bongini et al. (2001) and Arena (2008) looked at Easter-Asian banks, and González \& Hermosillo (1999) and Rosa and Gartner (2018) analyzed Latin America. Among the recent international studies are 
Altman et al. (2014), who used a sample of banks from 15 European countries and the U.S. during the period of 2007-2012.

In an earlier paper, Pazarbasioglu and Hardy (1998) built a multinominal logit model, which links the likelihood of bank distress events to country-specific and regional peculiarities. They analyzed the banking crises in 38 countries during the period of 1980-1997 and found that bank distress was associated with fall in real GDP growth, high inflation, declining capital-output ratio, and adverse trade shock, as well as decreases in FDI inflows and international reserves, high growth of domestic credit, increases in interest rates rise and an overvalued real exchange rate. Most importantly, the authors suggested that severe banking difficulties were mainly domestic in origin and effect.

Demirgüç-Kunt and Detragiache (1999) also built an EWM as a multinominal logit model using the data on 65 countries during the 1980-1995 period. They analyzed the probability of type I and type II model errors, the unconditional probability of a banking crisis, and the decision maker's preferences parameter for a preventive action in response to the anticipated crisis. They also performed the in-sample and out-sample analysis estimating the predictive power of the model. As a result, two monitoring tools were developed: a particular threshold of the probability indicator and a bank rating system. At the same time, the authors cautioned that aggregated variables convey information about general economic conditions, while the individual bank or specific segment data might point out weaknesses that could lead to contagion, but be invisible in the aggregated data.

Behn et al. (2013) focused on forecasting financial crises based on credit and other macro-financial variables in a sample of 23 EU countries during the period from Q2 1982 to Q3 2012. For validation purposes, they did an out-of-sample prediction of vulnerable states in Finland and Sweden in the early 1990s, and Italy and the U.K. in the mid-1990s preceding the financial crisis in those countries. They found that the loans-to-GDP gap is the best domestic indicator among other credit-related indicators. Moreover, the results showed that more global indicators, i.e. aggregated on a regional level, are outperforming domestic indicators, i.e. aggregated on the local level. However, they also pointed out to the caveat that the evaluation period included the global financial crises, but not the episodes of countryspecific crises.

One of the most important papers for our study is by Lang et al. (2018). These authors provided a detailed framework on building an EWM as either an explanatory or a predictive tool. The model that they suggested was aimed at predicting potential future crises at the micro (using aggregation method) and macro level using a large dataset of EU banks. The model exhibited quite satisfactory out-ofsample and in-sample signaling ability with 11 risk drivers and lead time of 1-8 quarters. For evaluation purposes, they used the loss function approach and cross-validation to find a model specification with optimal for the policymaker, realtime, out-of-sample forecasting power. The authors also illustrated how the model's output could assist policymakers by providing EWM visualization.
Our paper contributes to the existing literature by developing an EWM based on the Ukrainian quarterly banklevel data - over the period that includes several domestic crises - and by identifying variables and instruments that will help policymakers understand whether vulnerabilities are accumulating or not.

\section{DATA AND METHODOLOGY}

\subsection{Premodeling}

In general, early warning models are used for identifying vulnerable conditions before distress events. As a result, we can view our problem as a two-class identification process, in particular, whether an object is in a vulnerable state or not. According Lang et al. (2018), EWM modeling includes three stages: pre-modeling (purpose, forecast horizon and event indicators), modeling (evaluation criterion, modeling technique, model selection, and evaluation exercise) and post-modeling (policy-relevant dimensions, visualization).

Following Lang et al. (2018), we consider three types of events as bank distress events: bank bankruptcy, default, and NBU refinance. ${ }^{2}$ There are 86 such distress events in our sample, with most of them happening in small private banks. ${ }^{3}$ Banks that exited the market during the sample period because of the war, occupation of territory, merger or self-liquidation were not included in this count.

As Figure 1 demonstrates, the peak in the number of bank distress events in Ukraine was in Q4 2014. Interestingly, this indicator is highly correlated with a financial stress index (FSI) developed by Filatov (2020) for Ukraine, using 20 indicators containing information about the level of financial stress in the system. As Figure 1 shows, the FSI jumped in Q1 2014, signaling the start of the 2014-2015 crisis. We can also observe a sharp increase in the number of defaulted banks at the same time. Our goal is to produce a model that can signal a potential crisis at least one year in advance to leave banks with a sufficiently long window to accumulate a buffer once a policymaker "turns on" the CCB requirement. The crisis of 2014-2015 will serve as the main testing grounds for our model performance both in sample and out of sample.

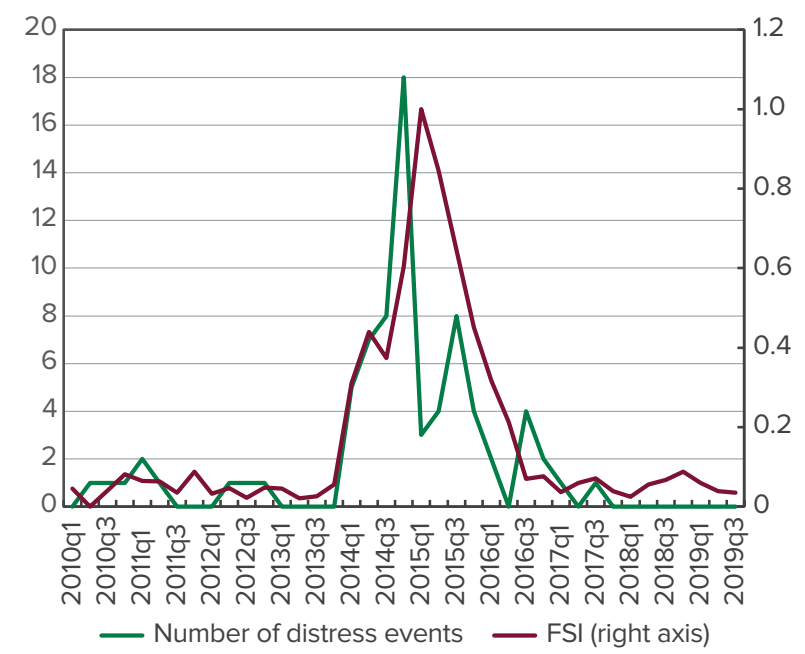

Figure 1. Total Number of Distress Events

\footnotetext{
2 During the sample period, the NBU shut down 24 banks due to non-compliance with financial monitoring requirements or an unclear stakeholder structure. These banks are excluded from the main sample as "distorting" banks since these events are not directly related to financial distress events, but are kept in robustness check regressions.

${ }^{3}$ Eight banks had a NBU loan refinance and all of them stayed in the market; 78 banks defaulted or declared bankruptcy and 68 of them left the market.
} 
The goal of an EWM is to generate a signal about a potential distress event in the future, which is typically defined not as one particular quarter $\mathrm{N}$ periods from now, but as any time between the next quarter and a quarter $\mathrm{N}$ periods from now. The more forward-looking the model is, the more time policymakers and banks have to introduce preventive measures. On the other hand, longer horizons mean lower degrees of freedom for estimations (which is particularly important given our relatively short sample) and, if financial vulnerabilities are building up quite quickly, become redundant after some point. As Lang et al. (2018) point out, there is no consensus about the time horizons in the literature, and this is an empirical question. In particular, we experimented with five different future time horizons $(\mathrm{TH})$ ranging from five to nine quarters.

Following Bussiere and Fratzscher (2006) and numerous other authors, we processed the data in the following way: first, we assigned the value of " 1 " to each period during the chosen time horizon before the distress event (corresponding to vulnerable states), and the value of " 0 " to all other (tranquil) periods for each bank. Then, the data points containing distress events and four subsequent periods were excluded from the sample due to the noise in the data caused by a crisis. We added up all signals across banks for each period and for different time horizons and received aggregated signals for various horizons (Figure 2). The optimal horizon will be chosen based on model's relative usefulness criterion explained in the next section.
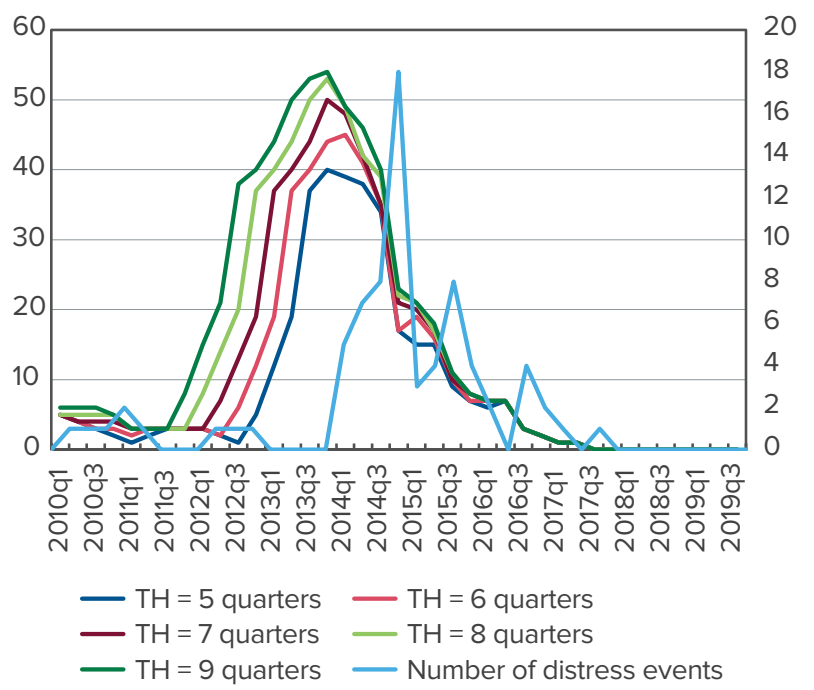

Figure 2. Aggregated Signaling Horizons

\subsection{Modeling}

The next step is to set up the modeling and evaluation approach. This involves stipulating the evaluation criterion, modeling technique, optimal model complexity, specification, and setting up evaluation procedure.

A bank distress event can be described as a binary variable $\mathrm{I}_{\mathrm{i}, \mathrm{i}} \hat{\imath}\{0,1\}$ which at time $t$ signals the state of bank $i$. If $\mathrm{I}_{\mathrm{i}, \mathrm{t}}=0$, then it is a tranquil period, and if $\mathrm{I}_{\mathrm{i}, \mathrm{t}}=1$, then the bank is in $a$ vulnerable state and could potentially have a distress event in five to nine periods depending on the selected time horizon. To estimate the probability that a bank will enter a vulnerable state, we suggest using the following logit model ${ }^{4}$ :

$$
\mathrm{p}\left(\mathrm{I}_{\mathrm{i}, \mathrm{t}}=1 \mid \mathrm{X}_{\mathrm{i}, \mathrm{t}}=\mathrm{x}_{\mathrm{i}, \mathrm{t}}\right)=\frac{\exp \left(\beta^{\prime} x_{i, t}\right)}{1+\exp \left(\beta^{\prime} x_{i, t}\right)},
$$

where, $\mathrm{p}(\mathrm{Yi}, \mathrm{t}=1 \mid \mathrm{Xi}, \mathrm{t}=\mathrm{xi}, \mathrm{t})$ denotes the probability that in period $t$ bank $i$ is in a vulnerable state. As independent variables, the vector $x_{i, t}$ includes credit, macro-financial, and balance sheet variables (Table 3). Betz et al. (2014) state that the frequency of banking crises corresponds to a fat-tailed error distribution, which makes a logit model more appropriate than a probit model.

The real-economy variables and credit-related variables are used as independent variables by Drehmann et al (2011), Detken, et al. (2014) and Behn, et al. (2013) and other authors. Lang et al. (2018) supplemented this explanatory variable by bank balance sheet data. In particular, these authors start with more than 100 balance-sheet variables and apply a selection operator (a recursive LASSO regression) to reduce the number of variables in the final model.

Our model also includes a wide range of balance sheet variables (according to the CAMEL methodology). In particular, we have 15 variables + four lags for each bank balance sheet variable ( 36 variables in total). We added lags to control for delays in the financial reporting. We applied the same stepwise selection operator to decide on the set of variables to be included in the final model specification.

Once the model is estimated, we can use the fitted values of $\mathrm{p}_{\mathrm{i}, \mathrm{t}}$ to construct a binary variable $\mathrm{P}_{\mathrm{i}, \mathrm{t}}$ that mimics the behavior of $\mathrm{I}_{\mathrm{i}, \mathrm{t}}$. In particular, when $\mathrm{p}_{\mathrm{i}, \mathrm{t}}$ exceeds a certain threshold $\theta \in[0,1]$, then $\mathrm{P}_{\mathrm{i}, \mathrm{t}}=1$ or $\mathrm{P}_{\mathrm{i}, \mathrm{t}}=0$ otherwise. Table 1 describes the relationship between $\mathrm{P}_{\mathrm{i}, \mathrm{t}}$, and $\mathrm{I}_{\mathrm{i}, \mathrm{t}}$ as a contingency matrix, and classifies the outcomes in terms of their signaling quality.

As in many other econometric applications, here we face a trade-off between Type I error (false negative) and Type

Table 1. Contingency Matrix

\begin{tabular}{l|c|c|c|}
\hline \multicolumn{2}{c|}{} & \multicolumn{2}{c|}{ Actual class $\mathrm{I}_{\mathrm{i}, \mathrm{t}}$} \\
\cline { 3 - 4 } \multicolumn{2}{c|}{} & Crisis & No crisis \\
\hline \multirow{3}{*}{$\begin{array}{l}\text { Predicted } \\
\text { Class } \mathrm{P}_{\mathrm{i}, \mathrm{t}}\end{array}$} & Signal & $\begin{array}{c}\text { A } \\
\text { True positive }\end{array}$ & $\begin{array}{c}\text { B } \\
\text { False positive }\end{array}$ \\
\cline { 2 - 4 } & No signal & C & D \\
& & False negative & True negative \\
\hline
\end{tabular}

II error (false positive). Starting from simple univariate early warning models by Drehmann et al. (2011), the area under the receiver operator curve (AUROC) is used as a standard instrument to measure the performance of such models. The receiver operator curve plots $A /(A+C)$, or the model's sensitivity, against $B /(B+D)$, or the false positive rate for a chosen threshold parameter $\theta .^{5}$ The area under the curve is the measurement of the model's performance, as this

\footnotetext{
${ }^{4}$ We also suggested conditional (fixed-effect) logistic regression. However, more than half of the sample was dropped due to the specific sample selection as the fixed effects logit model used only within variation while ignoring between variation. Moreover, standard errors became significantly larger due to the smaller sample, resulting in inadequate thresholds since most of the fitted values were concentrated near 0 or 1.

${ }^{5}$ Sensitivity is as same as true positive rate and is equal to $A /(A+C)$ from Table 1 . Specificity is the same as true negative rate and is equal to $D /(B+D)$ from the same table. In some literature, sensitivity is called a signal ratio and (1-specificity) is referred to as a noise ratio.
} 
measurement is independent of its objective: explanatory or predictory (Sarlin 2013).

An AUROC based on the whole sample can sometimes be overoptimistic, and the way to correct for this is to use a $\mathrm{K}$-fold cross-validation AUROC. It is a validation technique for assessing how the estimated model will generalize to an independent data set. Its logic is to split data into k folds, build a model on $\mathrm{k}-1$ folds (training sample), test its classification performance by using AUROC on the last $k_{\text {th }}$ fold (test sample) that is independent of the training sample and repeat these steps for each fold. Afterwards, we averaged the AUROCs corresponding to each fold and applied the bootstrap procedure to the cross-validated AUROC to obtain statistical inference and 95\% bias corrected confidence intervals $(\mathrm{Cl})^{6}$

Betz et al. (2014) and Lang et al. (2018) applied recursive methods for optimizing their models and thresholds. Recursive methods help researchers to compute the floating threshold (a threshold that differs across periods). A recursive approach uses an in-sample period, i.e. data available at the beginning (before $t=1,2 \ldots T$ ), for training the model and computing the optimal threshold (the one at which the model exhibits maximum usefulness, or, equivalently, minimum loss for the policymaker). The next step is to make predictions during the out-of-sample period, i.e. the next quarter ( $t)$, with the in-sample threshold and collect the results. The final step is to recursively re-estimate the model at $\mathrm{t}=\mathrm{t}+1$ and repeat all the previous steps till $\mathrm{t} \leq \mathrm{T}$. As a result, we have more precise estimates of the model's usefulness and thresholds.

The concept of model usefulness, which is a standard performance evaluation criterion in this strand of literature, is closely linked to the concept of the policymaker's (in our case, the central bank's) loss function. Following Sarlin (2013), we assume that it is of the following form:

$$
\mathrm{L}(\mu)=\mu \mathrm{P}_{1} \mathrm{~T}_{1}+(1-\mu) \mathrm{P}_{2} \mathrm{~T}_{2},
$$

where $P_{1}=P\left(l_{i, t}=1\right)$ and $P_{2}=P\left(l_{i, t}=0\right)=1-P_{1}$ are the estimated frequencies of the classes (unconditional probabilities: $P_{1}=(A+C) /(A+B+C+D)$ and $P_{2}=(B+D) /(A+B+C+D), T_{1}=C /(A+C)$ is the false positive rate and $T_{2}=B /(B+D)$ is the false negative rate and $\mu$ is a preferences parameter. ${ }^{7}$ Both $T_{1}$ and $T_{2}$ are functions of the threshold parameter $\theta$ : a higher threshold reduces the false positive rate $T_{1}$ and at the same time increases the false negative rate $T_{2}$, and vice versa. The optimal value of the threshold parameter for each $\mu$ is the one that minimizes the policymaker's loss function.

Policymakers could get a loss $\mu \mathrm{P}_{1}$ when the model never signals a crisis or $(1-\mu) P_{2}$ when the model always issues a signal. Therefore, the loss is equal to $\min \left[\mu \mathrm{P},(1-\mu) \mathrm{P}_{2}\right]$ if a policymaker does not apply the early warning model (the CCB is always either on or off). We can then compute the absolute usefulness of the model, $\mathrm{Ua}$, by subtracting the loss associated with using the model from the loss incurred from ignoring it:

$$
\mathrm{U}_{\mathrm{a}}(\mu)=\min \left[\mu \mathrm{P}_{1},(1-\mu) \mathrm{P}_{2}\right]-\mathrm{L}(\mu),
$$

Along the same lines, the relative usefulness of the model, $U_{r}$, is the ratio of this "model-induced loss recovery" to the baseline "no-model" loss:

$$
\bigcup_{r}(\mu)=\frac{\mathrm{U}_{a}(\mu)}{\min \left[\mu \mathrm{P}_{1},(1-\mu) P_{2}\right]}=1-\frac{\mathrm{L}(\mu)}{\min \left[\mu \mathrm{P}_{1},(1-\mu) P_{2}\right]},
$$

Notice that if $L(\mu)=0$, then $U_{a}(\mu)=\min \left[\mu P_{1},(1-\mu) P_{2}\right]$ and $U_{r}(\mu)=1$ meaning that the model is working perfectly. The relative usefulness criterion is our main model performance criterion, in particular for identifying the optimal threshold $(\theta)$ and the optimal time horizon $(\mathrm{TH})$.

\subsection{Postmodeling}

Once the model is estimated, and all evaluation exercises are performed, it is important to decide how the model output could be analyzed and visualized. Taking into account that we have bank-level data, it is important to analyze the aggregate effect on the financial system. For this purpose, we experimented with two alternative aggregation approaches: we took either the mean or the median estimated default probabilities among all banks in each period. Then, we compared the aggregated results with FSI to identify which approach gives more precise results within the in-sample analysis.

Next, we conducted an out-of-sample analysis using the following algorithm. First, our preferred model is estimated based on shorter, ever-expanding sub-samples of the data. Then, the estimated model coefficients are used to forecast the probabilities of individual bank defaults over the future time horizon, along with the optimal threshold parameter. Finally, these projected individual bank default probabilities are aggregated using the preferred aggregation approach to produce a single system-wide signal on accumulated vulnerabilities.

\subsection{Data Description}

Our data set contains information on 209 banks in the period from Q1 2009 to Q3 2019 (5,632 observations in total). We identified 86 relevant distress events in our sample. ${ }^{8}$ The data was collected from the websites of State Statistics Service of Ukraine (SSSU) and the NBU. It is unbalanced panel bank-level quarterly data (Table 3). Some banks had reporting gaps during the sample period. Such banks were eliminated from the sample. A detailed data description could be found in Table 3. We did not exclude outliers as we believe they could contain important information on financial system vulnerabilities.

\section{ESTIMATION RESULTS}

Below we present the estimation results of models with different time horizons based on the entire sample. As described in the methodology section, we focus on the relative usefulness statistics $\left(U_{r}\right)$ as the main indicator of the model's explanatory power. Therefore, an early warning model with the optimal time horizon (TH) will have the highest relative usefulness $\left(U_{\mathrm{r}}\right)$. Table 2 reports the results of the estimated absolute and relative usefulness of our models for varying time horizons (TH) and different values of the preference paramerter $\mu$. The highest relative usefulness is for the models with six- and seven-quarter horizons and the preference parameter $\mu=0.9$. These results are quite

\footnotetext{
${ }^{6}$ Following Lang and Peltonen (2018), we use ten folds, which is also a standard in Stata.

${ }^{7}$ Following the literature, we experimented with several values of the preferences parameter $\mu$ between 0.6 and 0.9 , implying that it is relatively more costly for the central bank to miss a crisis than to issue a false signal.

${ }^{8}$ According to the NBU website, the number of banks in Ukraine dropped from 175 in 2008 to 77 in 2019.
} 
comparable to the findings of other authors, suggesting that this modeling approach is as valid for Ukrainian data as it is for other countries.

Though there is some variability in the results of the models with different time horizons, no rigorous tests are available to evaluate whether these differences are statistically significant, and the top model must be chosen on a mostly ad hoc basis. For the lack of more formal arguments, we decided to use the middle-horizon (seven quarter) model as the baseline since it has higher relative usefulness than the short-horizon (five quarter) model and either slightly underperforms or noticeably outperforms the long-horizon (nine quarter) one. Fortunately, the conclusions are robust to the choice of time horizon, including those concerning the optimal threshold parameter $\theta$, as Table 2 clearly demonstrates. expenses per liability increases this probability. As a result, the model shows the balance sheet's effective management is a key indicator of bank solvency.

Return on assets (ROA) is robust for the first and second lags, but the sign is positive, meaning that better return on assets increases the probability of the signal being issued. The most likely explanation for this is that higher returns on assets are also associated with their higher riskiness, which in turn makes banks more vulnerable.

The higher ratio of provisions to total assets reduces the probability of a signal being issued: more generous provisions against expected losses add to bank stability. The cumulative (over all lags) effect of the ratio of total equity to total assets is consistently negative for all model specifications, which is also in line with what the theory suggests.

Table 2. In-Sample Analysis of the Models Based on Five to Nine Quarter Time Horizons

\begin{tabular}{|c|c|c|c|c|c|}
\hline & 5 quarter & 6 quarter & 7 quarter & 8 quarter & 9 quarter \\
\hline$\mu$ & \multicolumn{5}{|c|}{ Absolute usefulness } \\
\hline 0.6 & 0.011 & 0.016 & 0.021 & 0.024 & 0.027 \\
\hline 0.7 & 0.018 & 0.025 & 0.030 & 0.034 & 0.039 \\
\hline 0.8 & 0.028 & 0.036 & 0.043 & 0.049 & 0.055 \\
\hline 0.9 & 0.041 & 0.051 & 0.056 & 0.052 & 0.048 \\
\hline$\mu$ & \multicolumn{5}{|c|}{ Relative usefulness } \\
\hline 0.6 & 0.243 & 0.296 & 0.328 & 0.330 & 0.335 \\
\hline 0.7 & 0.331 & 0.390 & 0.405 & 0.404 & 0.422 \\
\hline 0.8 & 0.455 & 0.494 & 0.510 & 0.520 & 0.518 \\
\hline 0.9 & 0.605 & 0.626 & 0.626 & 0.590 & 0.555 \\
\hline$\mu$ & \multicolumn{5}{|c|}{ Threshold } \\
\hline 0.6 & 0.422 & 0.397 & 0.401 & 0.432 & 0.410 \\
\hline 0.7 & 0.312 & 0.340 & 0.330 & 0.352 & 0.357 \\
\hline 0.8 & 0.242 & 0.225 & 0.252 & 0.246 & 0.248 \\
\hline \multirow[t]{2}{*}{0.9} & 0.132 & 0.123 & 0.107 & 0.131 & 0.137 \\
\hline & \multicolumn{5}{|c|}{ AUROC } \\
\hline cvMean AUC: & 0.876 & 0.881 & 0.881 & 0.881 & 0.872 \\
\hline $\begin{array}{l}\text { Bootstrap bias } \\
\text { corrected } 95 \%\end{array}$ & 0.850 & 0.861 & 0.852 & 0.857 & 0.855 \\
\hline $\begin{array}{l}\text { Confidence } \\
\text { intervals }\end{array}$ & 0.895 & 0.901 & 0.893 & 0.895 & 0.890 \\
\hline
\end{tabular}

By analyzing the results of the benchmark model, we can distinguish what bank-specific and macro-related variables can predict bank distress events in Ukraine (Table 4). We consider only those variables that are significant for the best model and compare them with other models for robustness check. If most of the models have significant results (with same signs), then we consider such results as robust. Therefore, we describe below only robust results.

Net interest income/total assets, net commission/ total assets, and interest expenses/total liabilities indicate the efficiency of the assets and liabilities respectively as these ratios show net commission and interest income per asset and expenses per liability. ${ }^{9}$ The rising income per asset reduces the probability of issuing a signal and rising
Among the macroeconomic variables, the consistently significant ones for all time horizons are the ratio of international reserves to GDP, the house price index and the ratio of state budget surplus to GDP. All these variables have expected signs and are very robust in terms of magnitudes across all specifications. Interestingly, the real GDP growth variable is insignificant in the preferred (midhorizon) specification, but is negative and significant for the five-quarter horizon, and positive and significant for the nine-quarter horizon. This might suggest that this variable contains some interesting cyclical features, and further analysis is required to properly map them into our variables of interest.

The next step is to go from bank-level results to systemlevel outcomes. To aggregate the estimated probabilities

${ }^{9}$ There is a negative sign, as the original data expenses also have a negative sign, meaning that rising expenses will increase the probability of signaling. 
of individual bank vulnerabilities into a single figure that reflects the state of the banking system as a whole, we experimented with two aggregation strategies: by taking either the mean or the median default probability across all banks for each period. From Figure 3, we can observe that before the 2014-2015 crisis, the mean default index gave an earlier and more pronounced signal about the accumulated vulnerabilities than the median indicator. However, after the peak of Q2 2014, aggregation by mean tends to drag on in terms of overly strong signals and becomes quite volatile. Still, since the mean approach produces an earlier signal than the median one, we chose it as our preferred approach for further analysis.
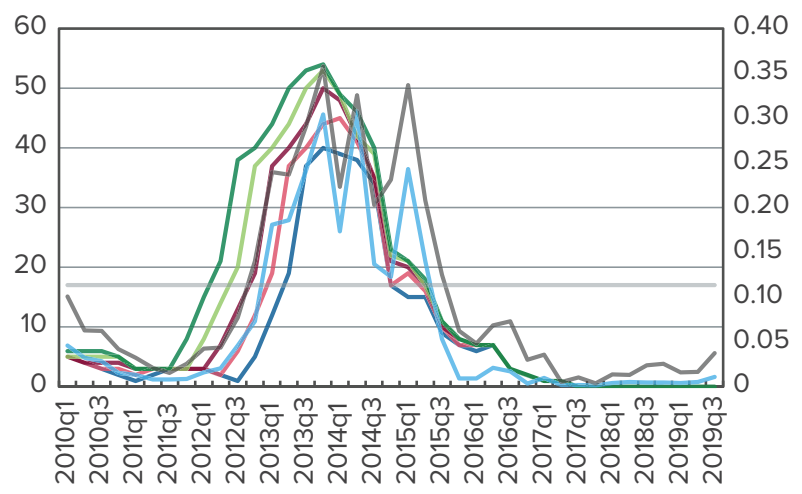

$$
\begin{aligned}
& -\mathrm{TH}=5 \text { quarters }-\mathrm{TH}=6 \text { quarters }-\mathrm{TH}=7 \text { quarters } \\
& -\mathrm{TH}=8 \text { quarters }-\mathrm{TH}=9 \text { quarters }- \text { median } \\
& \text { mean }
\end{aligned}
$$

Figure 3. Aggregated Probabilities of Bank Distress Events (in-sample analysis)

Note: Time horizons are aggregated signaling horizons from Figure 2.

Figure 4 depicts the mean-based aggregated probabilities of bank defaults and the FSI index for clearer comparisons. Here we can see that the mean algorithm gave a signal in Q4 2012, and the crisis started to unravel in Q1 2014, according to the FSI. That means the (sevenquarter horizon) model is issuing an accurate positive signal on the whole banking system crunch five periods ahead of the critical time. This result is very encouraging since a policymaker has five quarters to implement CCB before the start of a crisis, which should potentially help with reducing the negative costs associated with it or even preventing it entirely.

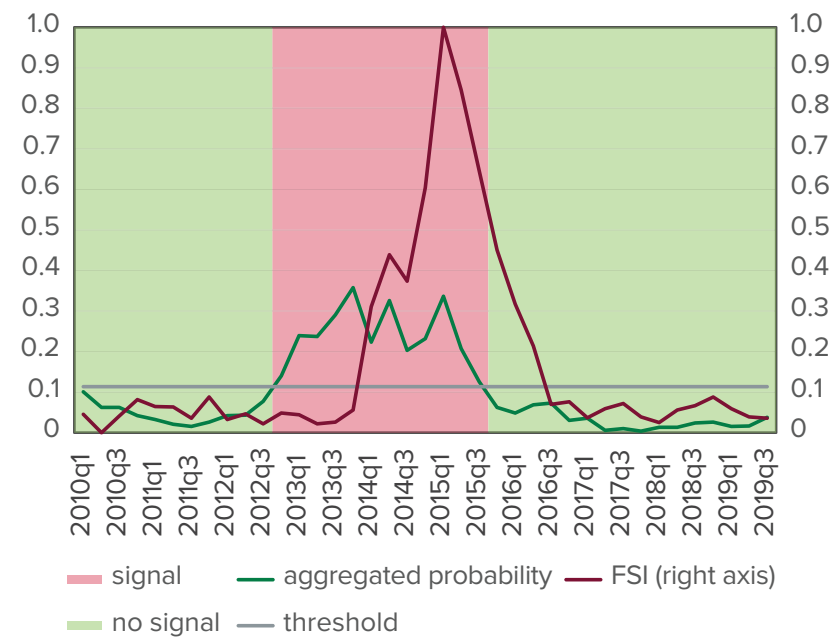

Figure 4. Comparison Combined Aggregated Results with FSI
Next, we do recursive model estimations based on shorter, ever-expanding sub-samples. For each of them, we estimate optimal thresholds (for the preference parameter $\mu=0.9$, which corresponds to the most apprehensive and vigilant central bank among all considered alternatives), generate predictions for each individual bank and then calculate a mean-based measure of aggregate probability of crisis. Quite expectedly, the out-of-sample relative usefulness of the model falls and now is only $37 \%$. Still, using the model is much better than not using any model at all.

Figure 5 summarizes other important out-of-sample results. Due to data restrictions, the first available prediction is for Q1 2013. The threshold parameter varies between 3\% and $22 \%$, and more or less stabilizes around $12 \%$ once the sub-sample length reaches 20 quarters. Most importantly, starting from Q1 2013, the model produces a positive out-ofsample signal that gives policymakers four quarters before the crisis starts in Q12014. At the same time, we observe that the out-of-sample aggregated signal is relatively unstable: it produces a false signal in Q3 2016. However, given that the thresholds are also estimated with errors, this signaling mistake could actually be quite within the threshold confidence bounds.

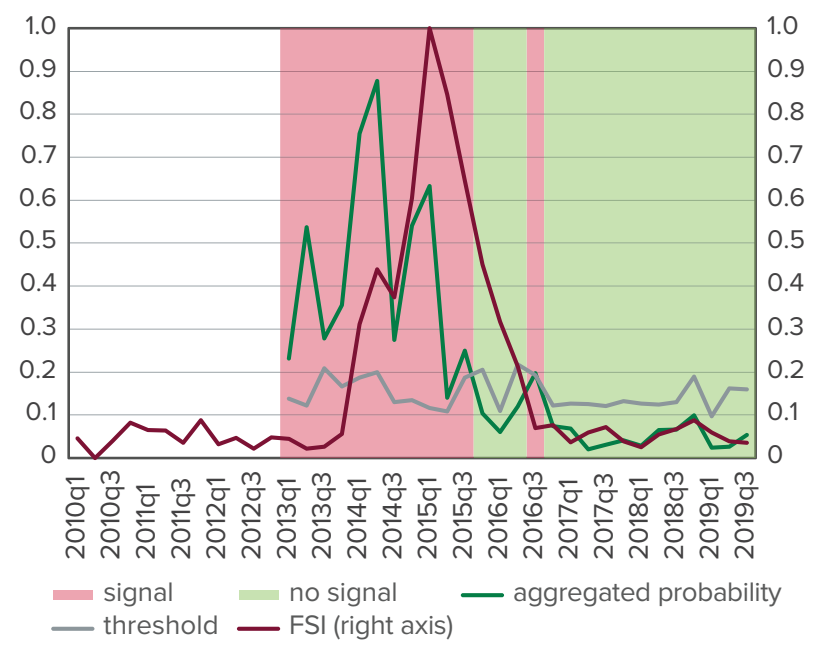

Figure 5. Recursive Estimation (out-of-sample analysis)

\section{CONCLUSIONS}

The main goal of setting a CCB is to protect the banking sector from the excessive aggregate credit growth associated with broad systemic risk. For this instrument to be effective, its timing (the "on" and "off" switch) must be as precise as possible. Numerous economists analyzed a wide range of indicators and thresholds that signaled when to activate CCB and concluded that the credit-to-GDP gap is one of the most accurate indicators for many countries. However, this was not the case for East European countries, including Ukraine, as they have structural changes and a relatively short observation period.

An alternative approach is to use bank-level data to identify individual bank vulnerabilities and then aggregate them into a system-wide risk measure. We use an earlywarning bank default model as a building block for this approach. The model contains both bank-specific and macro-level variables. To be consistent with the literature (e.g., Sarlin, 2013), we use a relative usefulness measure to evaluate its empirical performance both in sample and out of 
sample. We can conclude that the model based on a sevenquarter signaling period (benchmark model) and $\mu=0.9$ is the best one according to its relative usefulness $(62.5 \%$, which indicates that the explanatory power of the model is quite high). This model gives a signal when the probability of default exceeds the (optimal) threshold of $11 \%$.

To aggregate the individual bank data, we use the mean-based approach, in which the mean of the estimated

\section{REFERENCES}

Altman, E. I. (1977). Predicting performance in the savings and loan association industry. Journal of Monetary Economics, 3(4), 443-466. https://doi.org/10.1016/03043932(77)90015-0

Altman, E. I., Cizel, J., Rijken, H. A. (2014). Anatomy of bank distress: The information content of accounting fundamentals within and across countries. Retrieved from https://papers. ssrn.com/sol3/papers.cfm?abstract_id=2504926

Arena, M. (2008). Bank failures and bank fundamentals: A comparative analysis of Latin America and East Asia during the nineties using bank level data. Journal of Banking \& Finance 32(2), 299-310. https://doi.org/10.1016/j. jbankfin.2007.03.011

Barth, J. R., Brumbaugh, R. D., Sauerhaft, D., Wang, G. H. (1985). Thrift institution failures: Causes and policy issues. Proceedings of the 21st Annual Conference on Bank Structure and Competition, 184-216. Chicago: Federal Reserve Bank of Chicago. Retrieved from http://webhome. auburn.edu/ ${ }^{\sim}$ barthjr/publications/Thrift\%20Institution\%20 Failures\%20Causes\%20and\%20Policy\%20lssues.pdf

Basel Committee on Banking Supervision. (2010). Guidance for National Authorities Operating the Countercyclical Capital Buffer. Bank for International Settlements. Retrieved from https://www.bis.org/publ/ bcbs187.pdf

Behn, M., Detken., Peltonen, T. A., Schudel, W. (2013) Setting countercyclical capital buffers based on early warning models. Would it work? ECB Working Paper, 1604. Frankfurt am Main: Europen Central Bank. Retrieved from https://www.ecb.europa.eu/pub/pdf/scpwps/ecbwp1604.pdf

Betz, F., Oprica, S., Peltonen, T. A., Sarlin, P. (2014). Predicting distress in European banks. Journal of Banking \& Finance, 45, 225-241. https://doi.org/10.1016/j. jbankfin.2013.11.041

Bongini, P., Laeven, L., Majnoni, G. (2002). How good is the market at assessing bank fragility? A horse race between different indicators. Journal of Banking \& Finance, 26(5), 1011 - 1028. https://doi.org/10.1016/S0378-4266(01)00264-3

Bussiere, M., Fratzscher, M. (2006). Towards a new early warning system of financial crises. Journal of International Journal of International Money and Finance, 25(6), 953-973. https://doi.org/10.1016/j.jimonfin.2006.07.007

Cipollini, A., Fiordelisi, F. (2012). Economic value, competition and financial distress in the European banking system. Journal of Banking \& Finance, 36(11), 3101-3109. https://doi.org/10.1016/j.jbankfin.2012.07.014 individual-bank probabilities of default is the statistic to be compared to the threshold value. This approach produces a positive signal about the 2014-2015 crisis (and therefore the need to launch the CCB accumulation) five periods ahead of its start with in-sample estimations and 4 period ahead with out-of-sample estimations. We conclude that the model can potentially be used as a predictive instrument to help policymakers identify a build-up of system vulnerabilities and substantiate the need for policy intervention.

Cole, R. A., White, L. J. (2012). Déjà vu all over again: The causes of U.S. commercial bank failures this time around. Journal of Financial Services Research, 42(1-2), 5-29. https://doi.org/10.1007/s10693-011-0116-9

Demirgüç-Kunt, A., Detragiache, E. (1999). Monitoring banking sector fragility: A multivariate logit approach. IMF Working Paper, 99/147. International Monetary Fund. Retrieved from https://www.imf.org/external/pubs/ft/ wp/1999/wp99147.pdf

Detken, C., Weeken, O., Alessi, L., Bonfim, D., Boucinha, M. M., ... Welz, P. (2014). Operationalising the countercyclical capital buffer: indicator selection, threshold identification and calibration options. Occasional Paper Series, 5. European Systemic Risk Board. Retrieved from https://www.esrb. europa.eu//pub/pdf/occasional/20140630_occasional_ paper_5.pdf

Drehmann, M., Borio, C., Kostas, T. (2011). Anchoring countercyclical capital buffers: The role of credit aggregates. International Journal of Central Banking, 7(4), 189-240. Retrieved from https://www.ijcb.org/journal/ijcb11q4a8.pdf

Filatov, V. (2020). A new financial stress index for Ukraine. Working Papers, HEIDWP15-2020. Switzerland: Graduate Institute of International and Development Studies. Retrieved from http://repec.graduateinstitute.ch/ pdfs/Working_papers/HEIDWP15-2020.pdf

Flannery, M. J. (1998). Using market information in prudential bank supervision: A review of the U.S. empirical evidence. Journal of Money, Credit and Banking, 30(3), 273-305. https://doi.org/10.2307/2601102

Kraft, E., Galac, T. (2007). Deposit interest rates, asset risk and bank failure in Croatia. Journal of Financial Stability, 2(4), 312-336. https://doi.org/10.1016/j.jfs.2006.08.001

González-Hermosillo, B. (1999). Determinants of exante banking system distress: A macro-micro empirical exploration of some recent episodes. IMF Working Paper, 99/33. Retrieved from https://www.imf.org/en/Publications/ WP/Issues/2016/12/30/Determinants-of-Ex-Ante-BankingSystem-Distress-A-Macro-Micro-Empirical-Exploration-ofSome-2908

Lang, J. H., Peltonen, P., Sarlin, T. A. (2018). A framework for early-warning modeling with an application to banks. ECB Working Paper, 2182. Frankfurt am Main: European Central Bank. Retrieved from https://www.ecb.europa.eu/pub/pdf/ scpwps/ecb.wp2182.en.pdf

Martin, D. (1977). Early warning of bank failure: A logit regression approach. Journal of Banking \& Finance, 1(3), 249-276. https://doi.org/10.1016/0378-4266(77)90022-X 
Pazarbasioglu, C., Hardy, D. C. (1998). Leading indicators of banking crises: Was Asia different? IMF Working Paper, 98/91. International Monetary Fund. Retrieved from https://www.imf.org/external/pubs/ft/wp/wp9891.pdf

Poghosyan, T., Cihak, M. (2009). Distress in European banks: An analysis based on a new data set. IMF Working Paper, 09/9. International Monetary Fund. Retrieved from https://www.imf.org/en/Publications/WP/Issues/2016/12/31/ Distress-in-European-Banks-An-Analysis-Basedon-a-NewDataset-22547

Rosa, P. S., Gartner, I. R. (2018). Financial distress in Brazilian banks: an early warning model. Revista Contabilidade \& Finanças, 29(77), 312-331. https://doi. org/10.1590/1808-057×201803910
Sarlin, P. (2013). On policymakers' loss functions and the evaluation of early warning systems. ECB Working Paper, 1509. Frankfurt am Main: European Central Bank. Retrieved from https://www.ecb.europa.eu/pub/pdf/scpwps/ ecbwp1509.pdf

Sinkey, J. F. Jr. (1975). A multivariate statistical analysis of the characteristics of problem banks. Journal of Finance 30(1), 21-36. https://doi.org/10.1111/j.1540-6261.1975.tb03158.x

Thomson, J. B. (1992). Modeling the bank regulator's closure option: A two-step logit regression approach. Journal of Financial Services Research, 6, 5-23. https://doi. org/10.1007/BF01046114 
APPENDIX A. TABLES

Table 3. Descriptive Statistics

\begin{tabular}{|c|c|c|c|c|}
\hline & Mean & Standard deviation & Max & Min \\
\hline \multicolumn{5}{|c|}{ Bank balance sheet variables } \\
\hline Net Interest income per asset & 0.034 & 0.046 & 2.051 & -0.106 \\
\hline Net commission income per asset & 0.012 & 0.023 & 0.415 & -0.470 \\
\hline Net interest expenses per liability & -0.055 & 0.288 & 0.018 & -21.159 \\
\hline Provisions/total assets & -0.101 & 0.393 & 0.649 & -22.552 \\
\hline Total equity/total assets & 0.235 & 0.454 & 1.000 & -27.763 \\
\hline Common equity/total assets & 0.261 & 0.296 & 6.837 & 0.000 \\
\hline ROE & 0.177 & 9.708 & 537.000 & -47.824 \\
\hline ROA & -0.021 & 0.465 & 0.549 & -31.175 \\
\hline \multicolumn{5}{|c|}{ Credit-related variables } \\
\hline State budget surplus/deficit to GDP & -0.034 & 0.015 & 0.003 & -0.062 \\
\hline Money supply growth & 0.024 & 0.037 & 0.080 & -0.100 \\
\hline Central government debt service to GDP & 0.023 & 0.011 & 0.046 & 0.004 \\
\hline \multicolumn{5}{|c|}{ Real-economy variables } \\
\hline Real GDP growth & -0.017 & 0.083 & 0.067 & -0.249 \\
\hline Current account growth as \% of GDP & 0.052 & 0.039 & 0.206 & 0.001 \\
\hline House price index & 51.892 & 13.054 & 72.547 & 31.493 \\
\hline REER & 0.892 & 0.104 & 1.014 & 0.660 \\
\hline Reserves as \% of GDP & 0.684 & 0.202 & 1.174 & 0.394 \\
\hline Observations & 5,632 & & & \\
\hline
\end{tabular}


Table 4. All Results of the Models

\begin{tabular}{|c|c|c|c|c|c|}
\hline & $\mathrm{TH}=5$ quarters & $\mathrm{TH}=6$ quarters & $\mathrm{TH}=7$ quarters & $\mathrm{TH}=8$ quarters & $\mathrm{TH}=9$ quarters \\
\hline Net commission income per asset & & $\begin{array}{c}-14.4000^{*} \\
(7.262)\end{array}$ & $\begin{array}{c}-14.1300^{*} \\
(6.758)\end{array}$ & $\begin{array}{c}-13.0000^{*} \\
(6.351)\end{array}$ & $\begin{array}{c}-14.9700^{*} \\
(5.894)\end{array}$ \\
\hline Net commission income per asset(-1) & $\begin{array}{c}-12.8900 \\
(7.339)\end{array}$ & $\begin{array}{c}-14.2300 \\
(8.015)\end{array}$ & $\begin{array}{c}-15.4600^{*} \\
(7.132)\end{array}$ & $\begin{array}{c}-17.2800^{*} \\
(7.050)\end{array}$ & $\begin{array}{c}21.5700^{* * *} \\
(5.725)\end{array}$ \\
\hline Net commission income per asset(-2) & $\begin{array}{c}-13.9300^{*} \\
(6.281)\end{array}$ & $\begin{array}{c}-7.7940 \\
(5.158)\end{array}$ & $\begin{array}{l}-8.1320 \\
(5.007)\end{array}$ & $\begin{array}{l}-7.9300 \\
(5.255)\end{array}$ & \\
\hline Net commission income per asset(-4) & $\begin{array}{c}-9.5140 \\
(5.214)\end{array}$ & & & & \\
\hline Net Interest income per asset & $\begin{array}{c}-21.3000^{* * *} \\
(5.279)\end{array}$ & $\begin{array}{c}-21.1500^{* * *} \\
(5.188)\end{array}$ & $\begin{array}{c}-25.7800^{* * *} \\
(4.800)\end{array}$ & $\begin{array}{c}-27.9900^{* * *} \\
(5.431)\end{array}$ & $\begin{array}{c}-30.1600^{* * *} \\
(5.300)\end{array}$ \\
\hline Net Interest income per asset(-1) & $\begin{array}{c}-16.0200^{*} \\
(6.519)\end{array}$ & $\begin{array}{c}-23.2400^{* * *} \\
(6.160)\end{array}$ & $\begin{array}{c}-18.4400^{* * *} \\
(5.476)\end{array}$ & $\begin{array}{c}-21.0400^{* * *} \\
(5.202)\end{array}$ & $\begin{array}{c}-23.5600^{* * *} \\
(4.363)\end{array}$ \\
\hline Net Interest income per asset(-2) & $\begin{array}{c}-13.6900^{* *} \\
(5.165)\end{array}$ & $\begin{array}{c}-6.3380 \\
(4.538)\end{array}$ & $\begin{array}{l}-6.3120 \\
(4.283)\end{array}$ & $\begin{array}{c}-5.4620 \\
(4.058)\end{array}$ & \\
\hline Net Interest income per asset(-4) & & & & $\begin{array}{l}7.2360 \\
(3.888)\end{array}$ & $\begin{array}{c}8.9800 * \\
(3.756)\end{array}$ \\
\hline Corporate deposits growth & & & & & $\begin{array}{l}0.0122 \\
(0.009)\end{array}$ \\
\hline Corporate deposits growth(-1) & & & & $\begin{array}{c}0.0121 \\
(0.008)\end{array}$ & $\begin{array}{c}0.0117 \\
(0.008)\end{array}$ \\
\hline Net interest expenses per liability & $\begin{array}{c}-2.0740 \\
(1.147)\end{array}$ & $\begin{array}{c}-2.1780 \\
(1.141)\end{array}$ & $\begin{array}{c}-2.9980^{*} \\
(1.223)\end{array}$ & $\begin{array}{c}-3.4680^{* *} \\
(1.270)\end{array}$ & $\begin{array}{c}-4.0510^{* *} \\
(1.431)\end{array}$ \\
\hline Net interest expenses per liability(-1) & $\begin{array}{c}-22.7600^{* * *} \\
(2.933)\end{array}$ & $\begin{array}{c}-23.9700^{* * *} \\
(2.819)\end{array}$ & $\begin{array}{c}-24.1100^{* * *} \\
(2.723)\end{array}$ & $\begin{array}{c}-24.0900^{* * *} \\
(2.650)\end{array}$ & $\begin{array}{c}-24.6900^{* * *} \\
(2.278)\end{array}$ \\
\hline Net interest expenses per liability(-2) & $\begin{array}{c}-14.4200^{* * *} \\
(3.058)\end{array}$ & $\begin{array}{c}-13.6800^{* * *} \\
(2.884)\end{array}$ & $\begin{array}{c}-12.9200^{* * *} \\
(2.731)\end{array}$ & $\begin{array}{c}-11.8100^{* * *} \\
(2.621)\end{array}$ & $\begin{array}{c}-8.4370^{* * *} \\
(1.872)\end{array}$ \\
\hline Net interest expenses per liability(-3) & $\begin{array}{c}-6.0300^{* * *} \\
(1.363)\end{array}$ & $\begin{array}{c}-6.3320^{* * *} \\
(1.506)\end{array}$ & $\begin{array}{c}-4.1770^{* *} \\
(1.447)\end{array}$ & $\begin{array}{c}-3.0580^{*} \\
(1.283)\end{array}$ & $\begin{array}{c}-3.1630^{* *} \\
(1.183)\end{array}$ \\
\hline Provisions/total assets & & & & & $\begin{array}{c}2.0700^{*} \\
(0.883)\end{array}$ \\
\hline Provisions/total assets(-1) & $\begin{array}{c}-2.8920^{*} \\
(1.322)\end{array}$ & $\begin{array}{c}1.8390 \\
(1.013)\end{array}$ & $\begin{array}{c}-2.3170 * \\
(0.952)\end{array}$ & $\begin{array}{c}-1.9150 * \\
(0.938)\end{array}$ & \\
\hline Provisions/total assets(-2) & $\begin{array}{c}-2.5340 \\
(1.573)\end{array}$ & & & & \\
\hline Provisions/total assets(-4) & $\begin{array}{c}-1.5880 \\
(1.228)\end{array}$ & $\begin{array}{c}-2.9470 * * \\
(0.956)\end{array}$ & $\begin{array}{c}-3.3200^{* * *} \\
(0.874)\end{array}$ & $\begin{array}{c}-2.5510^{* *} \\
(0.879)\end{array}$ & $\begin{array}{c}-2.2570^{* *} \\
(0.803)\end{array}$ \\
\hline Total equity/total assets & $\begin{array}{l}2.7890 \\
(1.945)\end{array}$ & $\begin{array}{l}2.8770 \\
(1.854)\end{array}$ & & & \\
\hline Total equity/total assets(-1) & $\begin{array}{c}-6.2800^{*} \\
(2.663)\end{array}$ & $\begin{array}{c}-6.4910^{*} \\
(2.541)\end{array}$ & $\begin{array}{c}-4.7740^{* *} \\
(1.805)\end{array}$ & $\begin{array}{c}-5.2690^{* *} \\
(1.768)\end{array}$ & $\begin{array}{c}-5.1430^{* * *} \\
(1.392)\end{array}$ \\
\hline Total equity/total assets(-2) & $\begin{array}{c}-5.0380 * \\
(2.059)\end{array}$ & $\begin{array}{c}-5.4140 * \\
(2.562)\end{array}$ & $\begin{array}{c}-6.7210^{* *} \\
(2.158)\end{array}$ & $\begin{array}{c}-3.0700 \\
(1.778)\end{array}$ & \\
\hline Total equity/total assets(-3) & & $\begin{array}{l}-4.1040 \\
(2.627)\end{array}$ & & & $\begin{array}{c}-2.8480^{*} \\
(1.355)\end{array}$ \\
\hline Total equity/total assets(-4) & & $\begin{array}{c}4.6130^{* *} \\
(1.717)\end{array}$ & $\begin{array}{l}3.1120^{*} \\
(1.249)\end{array}$ & & \\
\hline
\end{tabular}


Table 4 (continued). All Results of the Models

\begin{tabular}{|c|c|c|c|c|c|}
\hline & $\mathrm{TH}=5$ quarters & $\mathrm{TH}=6$ quarters & $\mathrm{TH}=7$ quarters & $\mathrm{TH}=8$ quarters & $\mathrm{TH}=9$ quarters \\
\hline ROE & & $\begin{array}{l}0.0424 \\
(0.032)\end{array}$ & $\begin{array}{l}0.0460 \\
(0.027)\end{array}$ & $\begin{array}{l}0.0503 \\
(0.027)\end{array}$ & $\begin{array}{l}0.0591^{*} \\
(0.023)\end{array}$ \\
\hline $\mathrm{ROE}(-2)$ & $\begin{array}{c}-0.0567 \\
(0.043)\end{array}$ & & & & \\
\hline $\mathrm{ROE}(-4)$ & & & & & $\begin{array}{c}-0.0910^{*} \\
(0.042)\end{array}$ \\
\hline ROA & $\begin{array}{l}5.8510 \\
(3.626)\end{array}$ & $\begin{array}{l}5.1200 \\
(3.202)\end{array}$ & $\begin{array}{l}5.9420^{*} \\
(2.948)\end{array}$ & $\begin{array}{l}6.5840 * \\
(2.900)\end{array}$ & $\begin{array}{l}5.5820^{*} \\
(2.346)\end{array}$ \\
\hline $\operatorname{ROA}(-1)$ & $\begin{array}{c}11.3100^{* *} \\
(3.816)\end{array}$ & $\begin{array}{c}11.6500^{* *} \\
(3.738)\end{array}$ & $\begin{array}{c}11.2700^{* * *} \\
(3.257)\end{array}$ & $\begin{array}{c}10.5300^{* * *} \\
(3.134)\end{array}$ & $\begin{array}{c}9.9440^{* * *} \\
(2.641)\end{array}$ \\
\hline $\mathrm{ROA}(-2)$ & $\begin{array}{c}4.6730^{* *} \\
(1.527)\end{array}$ & $\begin{array}{c}4.1420^{* *} \\
(1.516)\end{array}$ & $\begin{array}{c}4.3850^{* *} \\
(1.439)\end{array}$ & $\begin{array}{c}3.4500^{*} \\
(1.491)\end{array}$ & $\begin{array}{c}2.5830^{*} \\
(1.300)\end{array}$ \\
\hline $\mathrm{ROA}(-3)$ & $\begin{array}{c}2.2630^{*} \\
(0.957)\end{array}$ & $\begin{array}{c}2.5050^{*} \\
(1.032)\end{array}$ & & & \\
\hline ROA(-4) & & & $\begin{array}{l}1.9940 \\
(1.215)\end{array}$ & $\begin{array}{l}2.6010 \\
(1.328)\end{array}$ & $\begin{array}{l}3.6610^{*} \\
(1.586)\end{array}$ \\
\hline Real GDP growth & $\begin{array}{c}6.0800^{* * *} \\
(1.834)\end{array}$ & $\begin{array}{c}2.8440 \\
(1.762)\end{array}$ & & $\begin{array}{l}-2.1480 \\
(1.568)\end{array}$ & $\begin{array}{c}-4.0690^{* *} \\
(1.546)\end{array}$ \\
\hline Money supply growth M3 & $\begin{array}{c}-7.1090 * * \\
(2.752)\end{array}$ & $(2.604)$ & $\begin{array}{l}-3.5060 \\
(2.342)\end{array}$ & -4.0410 & \\
\hline Reserves as \% of GDP & $\begin{array}{c}-7.0010^{* * *} \\
(0.654)\end{array}$ & $\begin{array}{c}-7.1400^{* * *} \\
(0.620)\end{array}$ & $\begin{array}{c}-6.9070^{* * *} \\
(0.536)\end{array}$ & $\begin{array}{c}-6.6130^{* * *} \\
(0.542)\end{array}$ & $\begin{array}{c}-6.5150^{* * *} \\
(0.523)\end{array}$ \\
\hline House price index & $\begin{array}{c}0.0589^{* *} \\
(0.019)\end{array}$ & $\begin{array}{c}0.0474^{* *} \\
(0.017)\end{array}$ & $\begin{array}{c}0.0562^{* * *} \\
(0.016)\end{array}$ & $\begin{array}{c}0.0740^{* * *} \\
(0.015)\end{array}$ & $\begin{array}{c}0.0624^{* *} \\
(0.021)\end{array}$ \\
\hline Central government debt service to GDP & & & & & $\begin{array}{c}-36.4700 \\
(19.036)\end{array}$ \\
\hline State budget surplus to GDP & $\begin{array}{c}-35.2300^{* * *} \\
(8.281)\end{array}$ & $\begin{array}{c}-35.6300^{* * *} \\
(7.660)\end{array}$ & $\begin{array}{c}-30.7500^{* * *} \\
(6.883)\end{array}$ & $\begin{array}{c}-15.4100^{*} \\
(5.984)\end{array}$ & \\
\hline REER & $-6.6740^{* * *}$ & $-3.7270^{*}$ & -2.4140 & -2.7100 & -2.2590 \\
\hline Constant & $3.8060^{* * *}$ & $1.9460^{*}$ & 0.7230 & 0.6260 & 2.3980 \\
\hline Observations & 4,107 & 4,107 & 4,107 & 4,107 & 4,107 \\
\hline Pseudo R-squared & 0.361 & 0.368 & 0.369 & 0.362 & 0.355 \\
\hline AIC & $1,519.692$ & $1,690.021$ & $1,852.620$ & $2,035.838$ & $2,198.058$ \\
\hline $\mathrm{BIC}$ & $1,702.985$ & $1,873.314$ & $2,023.273$ & $2,212.810$ & $2,375.030$ \\
\hline
\end{tabular}

$p$-values ${ }^{*} p<0.1 ;{ }^{* *} p<0.05 ;{ }^{* * *} p<0.01$

Standard errors are in parentheses. TH stands for time horizon. 